DANIEL SCODELER RAIMUNDO

NANOESTRUTURAS METÁLICAS E DE SILÍCIO PARA INTENSIFICAÇÃO DE CAMPO PRÓXIMO 
FICHA CATALOGRÁFICA

Raimundo, Daniel Scodeler

Nanoestruturas metálicas e de silício para intensificação de campo próximo / D.S. Raimundo. -- São Paulo, 2009. $102 \mathrm{p}$.

Tese (Doutorado) - Escola Politécnica da Universidade de São Paulo. Departamento de Engenharia de Sistemas Eletrônicos.

1. Materiais nanoestruturados 2. Silício 3. Nanotecnologia 4. Superfície física I. Universidade de São Paulo. Escola Politécnica. Departamento de Engenharia de Sistemas Eletrônicos II. t. 
DANIEL SCODELER RAIMUNDO

\section{NANOESTRUTURAS METÁLICAS E DE SILÍCIO PARA INTENSIFICAÇÃO DE CAMPO PRÓXIMO}

Tese apresentada à Escola Politécnica da Universidade de São Paulo para obtenção do título de Doutor em Engenharia 


\section{NANOESTRUTURAS METÁLICAS E DE SILÍCIO PARA INTENSIFICAÇÃO DE CAMPO PRÓXIMO}

Tese apresentada à Escola Politécnica da Universidade de São Paulo para obtenção do título de Doutor em Engenharia

Área de Concentração:

Engenharia Elétrica

Orientador: Prof. Livre-Docente Walter Jaimes Salcedo 
Dedico este trabalho à minha mãe, a mew pai (in memorian), à minha irmã, à minha sobrinha e a meu cunhado.

"A ciência nos traz conhecimento; a vida, sabedoria." 


\section{AGRADECIMENTOS}

Embora uma tese seja entendida como um trabalho individual, diversas pessoas foram fundamentais para que a presente tese se tornasse realidade, atuando tanto no âmbito profissional quanto no âmbito pessoal. A estrutura racional de um cientista não tem significado sem um apoio emocional rígido e consistente.

Agradeço imensamente à minha família, por sempre apoiar fortemente meus estudos. Em especial, aos meus pais Teolinda e Arlindo (in memorian), alicerces de toda a estrutura. Dedicação, presença e apoio são palavras que descrevem o que ambos entendem por "criar um filho". Agradeço a minha irmã Beatriz pelo companheirismo e apoio.

Agradeço ao amigo e orientador Prof. Livre-Docente Walter Jaimes Salcedo por toda a ajuda, apoio, confiança e paciência, e por sempre dividir comigo seus inumeráveis conhecimentos.

Aos colegas do grupo de pesquisas, pela paciência e companheirismo, em especial a Keth, Danilo, Mauro, Gustavo, Rodrigo e Aldo.

Agradeço aos colegas do Laboratório de Microeletrônica (LME) da EPUSP, em especial à Cristina, Rita, Tereza, Antônio Marco, João, Jairzão, Pedrinho, Enrique, Sr. Latife e Márcio, pelo apoio técnico e paciência.

Agradeço aos colegas do Laboratório de Sistemas Integráveis (LSI) da EPUSP, em especial ao Alexandre e Adir, pelas medidas de Microscopia Eletrônica.

Agradeço aos colegas do Laboratório de Espectroscopia Molecular (LEM) do IQUSP, em especial à Profa. Dra. Márcia Temperini, por autorizar a realização de medidas de espectroscopia.

Agradeço aos colegas do Laboratório de Caracterização Tecnológica (LTC) da EPUSP, em especial à Liz e Marianne, pelas medidas de Microscopia Eletrônica. 
Agradeço ao CNPq, em especial ao Programa Nacional de Microeletrônica (PNM), pelo apoio financeiro.

Agradeço aos amigos, por estarem sempre ao meu lado e me apoiando continuamente, em especial à Ana Carolina, Adriana, Priscila Calíope, Ana Paula, Patrícia Calvão, Patrícia Rocha, Priscila Sartorelli, Michel, Fernando Galante, Thatiana, Juliana, Kátia, Denise e Nair.

Agradeço ao corpo docente da EPUSP por sempre incentivar intensamente os estudos e as pesquisas científicas e tecnológicas.

Agradeço aos membros da banca de defesa da tese pela atenção, paciência e pelas contribuições.

Agradeço a todos aqueles que direta ou indiretamente contribuíram para o sucesso deste trabalho. 


\section{RESUMO}

Durante os últimos cinco anos, a nanotecnologia tem atingido avanços significativos em diversas áreas da ciência e tecnologia. Um dos assuntos que está sendo intensamente estudado pela comunidade científica é a intensificação de campo próximo (hot spot) que pode ser aplicada em dispositivos sensores com capacidade de detecção de apenas uma molécula e em nano-antenas ópticas aplicadas na fabricação de dispositivos plasmônicos. Neste sentido, as principais contribuições da presente tese são processos de fabricação de nanoestruturas metálicas e de silício e o estudo da intensificação de campo próximo denominada de pontos quentes (hot spots) nestas estruturas. As nanoestruturas metálicas de Au (ouro) foram obtidas a partir do processo de auto-organização de esferas de poliestireno. As esferas de poliestireno serviram como camada sacrificial (molde) para a obtenção de nanoestruturas metálicas organizadas. Sobre as estruturas de Au organizadas foram depositadas moléculas de cristal violeta para serem utilizadas como moléculas de prova (sondas) no monitoramento da existência dos pontos quentes com o auxílio do espalhamento Raman das moléculas. As nanoestruturas de Au possibilitaram uma intensificação do espalhamento Raman devido à intensificação do campo próximo na superfície metálica periódica de Au. As nanoestruturas e microestruturas de silício foram obtidas a partir da tecnologia de silício poroso. As propriedades do silício poroso foram moduladas através da implantação de íons de hidrogênio $\left(\mathrm{H}^{+}\right)$que possibilitou a formação de silício microporoso com forte emissão fotoluminescente $(P L)$ e intensificação do espalhamento Raman superficial devido ao fenômeno de Raman ressonante. Sobre as estruturas macroporosas de silício foram adsorvidas moléculas de azul de metileno para serem utilizadas como moléculas de prova para monitoramento da intensificação do campo próximo e do efeito SERS no silício. A obtenção da intensificação de campo próximo em silício é uma contribuição completamente inédita, pois este fenômeno devia-se, até o momento, somente a materiais metálicos (nanoestruturas metálicas), mostrando sua existência também no silício.

Palavras-chave: nanotecnologia, pontos quentes, espalhamento Raman, silício poroso, sistemas auto-organizados. 


\begin{abstract}
During the last five years, nanotechnology has achieved significant progress in several areas of science and technology. One of the issues that are being intensively studied by the scientific community is the intensification of near-field (hot spot) that can be applied to devices with sensors capable of detecting a single molecule and nano-optical antennas used in the fabrication of plasmonic devices. In this sense, the main contributions of this thesis are processes for manufacture of metal and silicon nanostructures and the study of near-field intensification called hot spots in these structures. The metal nanostructures of $\mathrm{Au}$ (gold) were obtained from the process of self-assembling of polystyrene beads. The polystyrene beads were used as sacrificial layer (mold) for obtaining organized metallic nanostructures. On the structures of organized Au were deposited molecules of violet crystal to be used as proof of molecules (probes) to monitor the existence of hot spots with the help of Raman scattering of molecules. The Au nanostructures allowed an intensification of the Raman scattering due to the intensification of the near-field in the periodic $\mathrm{Au}$ surface. The microstructures and nanostructures of silicon were obtained using the porous silicon technology. The properties of porous silicon were modulated by the implantation of hydrogen ions $\left(\mathrm{H}^{+}\right)$that allowed the formation of microporous silicon which showed high photoluminescence emission (PL) and Raman scattering intensification of the surface due to the phenomenon of resonant Raman. Methylene blue molecules were adsorbed on the macroporous silicon structures to be used as probe molecule for the monitoring of near-field intensification and the SERS effect in silicon. The obtaining of near-field intensification in silicon is an entirely unprecedented contribution, because this phenomenon had been observed, so far, only on the metallic materials (metal nanostructures), showing its existence in the silicon too.
\end{abstract}

Keywords: nanotechnology, hot spots, Raman scattering, porous silicon, selfassemble systems. 
LISTA DE FIGURAS

LISTA DE TABELAS

LISTA DE ABREVIATURAS E SIGLAS

LISTA DE SÍMBOLOS

CAPÍTULO I

1. CONSIDERAÇÕES INICIAIS

CAPÍTULO II

2. REVISÃO BIBLIOGRÁFICA E FUNDAMENTAÇÃO TEÓRICA 3

2.1 A espectroscopia Raman, o efeito SERS ("Surface-Enhanced Raman Spectroscopy") e o Espalhamento Mie 5

2.2 Os sistemas auto-organizados $\quad 22$

2.2.1 As esferas de poliestireno e sua auto-organização 24

2.2.2 O silício poroso 26

2.3 O silício, o silício poroso e suas diversas possibilidades de $\begin{array}{ll}\text { aplicações } & 27\end{array}$

2.3.1 O silício e os efeitos Raman Espontâneo e Raman Estimulado 28 CAPÍTULO III 38

3. OBJETIVOS 38

CAPÍTULO IV $\quad 40$

4. JUSTIFICATIVAS $\quad 40$

CAPÍTULO V $\quad 42$

5. PROCEDIMENTOS EXPERIMENTAIS

5.1 Obtenção de estruturas de silício poroso (PS) 42

5.2 Obtenção de estruturas metálicas organizadas (EMO) a partir de monocamadas de esferas de poliestireno $\quad 44$

5.3 Adsorção de moléculas sobre as estruturas de silício poroso (PS) e sobre as estruturas metálicas organizadas (EMO) 46

5.4. Caracterização das estruturas $\quad 47$

CAPÍTULO VI $\quad 48$

6. RESULTADOS E DISCUSSÃO 
6.1 Nanoestruturas metálicas periódicas de Au para intensificação de campo próximo

6.1.1 Formação de estruturas auto-organizadas de microesferas de poliestireno

6.1.2. Formação das estruturas metálicas periódicas de $\mathrm{Au}$

6.1.3 Estudo da intensificação do campo próximo nas estruturas metálicas de $\mathrm{Au}$ por monitoramento do espalhamento Raman da molécula de cristal violeta (CV)

6.2 Estruturas de silício para intensificação de campo próximo

6.3 Intensificação do espalhamento Raman do fônon óptico do cristal de silício para aplicação em um dispositivo de emissão laser de silício

6.3.1 Introdução

6.3.2 Implantação de hidrogênio e recozimento térmico rápido em lâminas de silício

6.3.3 Formação de silício poroso

6.3.4 Caracterização dos filmes de PS modulados por implantação de $\mathrm{H}^{+}$

6.3.5 Resultados Preliminares e Discussão

7. CONCLUSÕES E PERSPECTIVAS FUTURAS 


\section{LISTA DE FIGURAS}

Fig. 2.1 Transferência de energia entre fóton e molécula. (a) Processo Stokes e (b) Processo anti-Stokes.

Fig. 2.2 Transferência de energia entre fóton e molécula. Processo de espalhamento Raman estimulado.

Fig. 2.3 Capacidades de diferentes materiais para gerar Efeito Raman.

Fig. 2.4 Geração de Raman estimulada (SRS).

Fig. 2.5 Geração de raio laser por SRS.

Fig. 2.6 Curva que mostra o Limite imposto pelo fenômeno "absorção de dois fótons".

Fig. 2.7 Processo de remoção de elétrons livres.

Fig. 5.1 Esquema da célula eletrolítica utilizada para a formação do PS a partir do processo de anodização eletroquímica das lâminas de silício.

Fig. 5.2 Esquema do processo de obtenção das máscaras metálicas $(\mathrm{Au})$. Está representado: o substrato de silício (em cinza), o $\mathrm{SiO}_{2}$ (em verde), as esferas de poliestireno (em azul) e o Au (em amarelo). (a) indica a etapa de oxidação, (b) a etapa de deposição das esferas, (c) a etapa de deposição de metal e (d) a remoção das esferas.

Fig. 6.1 Imagens SEM das estruturas de esferas de poliestireno obtidas sobre substratos de vidro, a $50^{\circ} \mathrm{C}$, utilizando-se monodispersões de concentração $2.13 w t \%$, com umidades relativas de (a) $50 \%$, (b) $60 \%$, (c) $70 \%$, (d) $80 \%$ e (e) $90 \%$. A barra de escala apresenta comprimento de $10 \mu \mathrm{m}$ para todas as imagens, e todas as imagens apresentam aumento de 2500X.

Fig. 6.2 Imagens SEM de uma máscara de Au obtida sobre substrato de silício oxidado utilizando-se as esferas de poliestireno de 660nm de diâmetro. A imagem (a) mostra a vista a 600 e a imagem (b) mostra a vista a $0^{\circ}$. A imagem (a) apresenta aumento de 6200X e barra de escala que representa um comprimento de $10 \mu \mathrm{m}$. A imagem (b) apresenta aumento de 10000X e barra de escala 
que representa um comprimento de $1 \mu \mathrm{m}$.

Fig. 6.3 Imagens SEM das amostras após deposição de Au, recozimento térmico e dissolução das esferas de poliestireno com clorofórmio e ultra-som. (a) Amostra I recozida a $150^{\circ} \mathrm{C}$, (b) Amostra II recozida a $250{ }^{\circ} \mathrm{C}$, (c) Amostra III recozida a $300{ }^{\circ} \mathrm{C}$, (d) Amostra IV recozida a $400{ }^{\circ} \mathrm{C}$, (e) Amostra $\mathrm{V}$ recozida a $500{ }^{\circ} \mathrm{C}$ and (f) Amostra VI recozida a $750{ }^{\circ} \mathrm{C}$ (veja texto para detalhes).

Fig. 6.4 Espectros Raman de moléculas de cristal violeta adsorvidas na superfície das amostras I, II, III, IV, V e VI respectivamente. As amostras foram excitadas com uma radiação laser de 632,8 nm.

Fig. 6.5 Imagens SEM das estruturas obtidas com soluções de DMF com (a) $8 \%$ de HF e com (b) $16 \%$ de HF.

Fig. 6.6 Imagem SEM da estrutura macroporosa de Si obtida por anodização em DMF+HF com $12 \%$ de HF em 30 s seguida de Voltametria Cíclica em solução de MB para recobrir a superfície, a $\mathrm{V}=20 \mathrm{mV} / \mathrm{s}$ e $-0.4 \mathrm{~V}<\mathrm{V}<0.6 \mathrm{~V}$ com $\mathrm{V}_{0}=0$ em 5 ciclos.

Fig. 6.7 Imagem SEM da estrutura macroporosa de $\mathrm{Si}$ obtida por anodização em DMF+HF com $12 \%$ de HF por 10 minutos, seguida de oxidação térmica.

Fig. 6.8 Espectros Raman do silício monocristalino (c-Si) (x2,c-Si) e do silício macroporoso (Macro-porous sample) obtido a partir de uma solução de DMF com $12 \%$ de ácido fluorídrico (HF). Os espectros foram obtidos a partir da excitação das amostras com um laser de $\lambda=632.8 \mathrm{~nm}$ e $\mathrm{P}=6 \mathrm{~mW}$.

Fig. 6.9 Espectros Raman de estruturas de silício do silício macroporoso obtido a partir de uma solução de DMF com (a) $8 \%$ de ácido fluorídrico (HF) e (b) $12 \%$ de HF, com moléculas de azul de metileno (MB) adsorvidas na superfície (em a e b). Os espectros foram obtidos a partir da excitação das amostras com um laser de $\lambda=632,8 \mathrm{~nm}$ e $P=6 \mathrm{~mW}$.

Fig. 6.10 Espectros PL das estruturas macropororosas de silício obtidas com (a) $8 \%$ de HF em DMF e (b) $12 \%$ de HF em DMF, após a adsorção de moléculas de azul de metileno a partir de uma 
solução de azul de metileno em etanol de $10^{-3} \mathrm{M}$.

Fig. 6.11 Imagem SEM da amostra R2 clivada

Fig. 6.12 Espectros Raman da amostra clivada R2 com o feixe de excitação focalizado na camada I (layer I), camada II (layer II) e substrato (substrate) respectivamente. Os espectros foram excitados com laser de 457,0 nm.

Fig. 6.13 Espectros de emissão PL na amostra R2 (clivada). O espectro de emissão PL foi excitado com laser de 457,0 nm.

Fig. 6.14 Espectros Raman das amostras (não clivadas) E, S, R1 e c-Si. Os espectros Raman foram excitados com laser de 632,8 nm.

Fig. 6.15 Espectros Raman de Segunda ordem das amostras (não clivadas) E, S, R1 e c-Si. Os espectros Raman foram excitados com laser de 632,8 nm.

Fig. 6.16 Espectros Raman das amostras (não clivadas) E, S, R1 e c-Si. Os espectros Raman foram excitados com laser de $514,5 \mathrm{~nm}$.

Fig. 6.17 Espectros Raman de segunda ordem das amostras (não clivadas) E, S, R1e c-Si. Os espectros Raman foram excitados com laser de $514,5 \mathrm{~nm}$.

Fig. 6.18 Espectros Raman das amostras (não clivadas) E, S, R1 e c-Si. Os espectros Raman foram excitados com laser de $457,0 \mathrm{~nm}$ e potência de $8 \mathrm{~mW}$.

Fig. 6.19 Espectros Raman das amostras (não clivadas) E, S, R1, R2 e cSi. Os espectros Raman foram excitados com laser de $457,0 \mathrm{~nm}$ e potência de $4 \mathrm{~mW}$.

Fig. 6.20 Intensidades relativas das bandas de espalhamento de primeira ordem relativa ao do c-Si com superfície polida.

Fig. 6.21 Espectros Raman de uma amostra de c-Si corroída, implantada com $\mathrm{H}^{+}$e submetida a processo de RTA. Para comparação é mostrada a banda de espalhamento Raman do c-Si de superfície polida e sem implantação de $\mathrm{H}^{+}$.

Fig. 6.22 Espectros de espalhamento Raman numa microestrutura de PS. $O$ interior da Figura mostra a seção transversal da microestrutura com o filme fino (thin film) de $1 \mu \mathrm{m}$ de espessura 
na parte superficial da estrutura de PS. O feixe foi focalizado na região de filme fino.

Fig. 6.23 Espectros de refletância especular das amostras E, S e R1. A referência foi o c-Si com superfície polida.

Fig. 6.24 Diagramas esquemáticos dos processos de espalhamento Raman ressonante de primeira (first order) e de segunda ordem (second order). 


\section{LISTA DE TABELAS}

Tabela I - Números de onda $\left(\mathrm{cm}^{-1}\right)$ de maior intensidade observados nos Espectros Raman da molécula de cristal violeta (CV) em estruturas de Au (figura 6.4), em pó e as atribuições tentativas dos modos vibracionais [100].

Tabela II - Freqüências vibracionais $\left(e m \mathrm{~cm}^{-1}\right)$ observadas nos espectros Raman (excitados em 514,5 nm) do $\mathrm{MB}^{+}$no estado sólido e em solução, com as respectivas atribuições tentativas [112].

Tabela III - Lâminas de silício implantadas com $\mathrm{H}^{+}$e submetidas a recozimento térmico rápido. 


\section{LISTA DE ABREVIATURAS E SIGLAS}

SERS Surface-Enhanced Raman Spectroscopy (Espectroscopia Raman de intensificação de superfície)

ULSI Ultra Large Systems Integration

SEM Scanning Electron Microscopy (Microscopia Eletrônica de Varredura)

TEM Microscopia Eletrônica de Transmissão

SNOM Microscopia óptica de campo próximo

RR Raman Ressonante

SERRS Surface-Enhanced Resonance Raman Spectroscopy

SEIRA Surface-Enhanced Infrared Absorption

EM Intensificação eletromagnética

PS Silício Poroso

EP Esferas de poliestireno auto-organizadas

EMO Estruturas metálicas organizadas

DMF Dimetilformamida

DI Deionizada

RTA Recozimento Térmico Rápido

MB Azul de metileno

CV Cristal violeta

LSI Laboratório de Sistemas Integráveis

LCT Laboratório de Caracterização Tecnológica

USP Universidade de São Paulo

LEM Laboratório de Espectroscopia Molecular

LME Laboratório de Microeletrônica

$\mathrm{PL} \quad$ Fotoluminescência

$\mathrm{RHs} \quad$ Umidades relativas

NF Campo próximo

SPP Modo polarizado do plasma de superfície radiativo

RCA limpeza inicial convencional da microeletrônica

LNLS Laboratório Nacional de Luz Sincrotron

SRS Espalhamento Raman Estimulado 


\section{LISTA DE SÍMBOLOS}

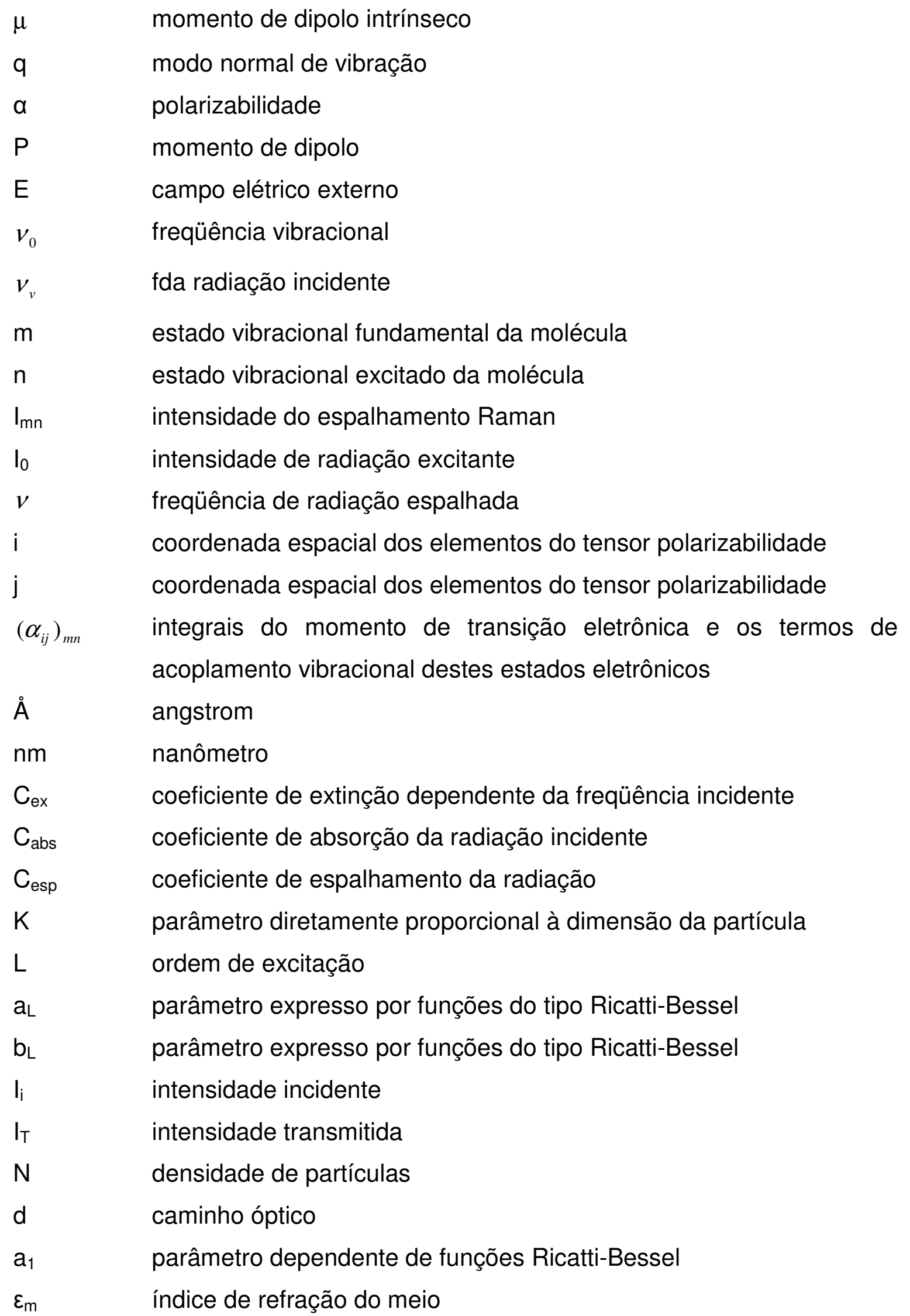




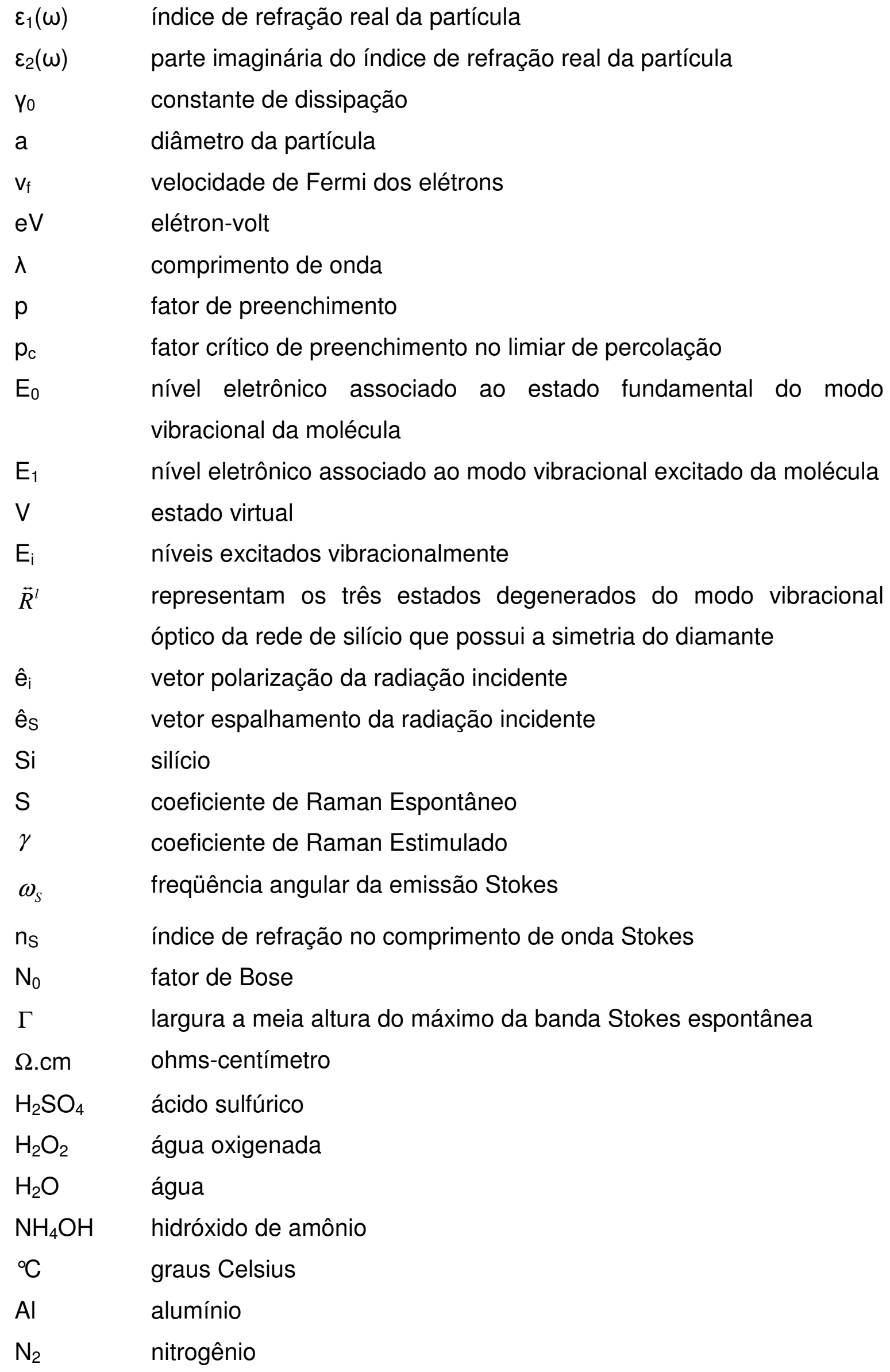




$\begin{array}{ll}\mathrm{HF} & \text { ácido fluorídrico } \\ \mathrm{mA} & \text { miliampères } \\ \mathrm{V} & \text { volts } \\ \mathrm{Pt} & \text { platina } \\ \mathrm{H}^{+} & \text {íon hidrogênio } \\ \mathrm{cm}^{2} & \text { centímetro quadrado } \\ \mathrm{wt} \% & \text { porcentagem em peso } \\ \mathrm{KOH} & \text { hidróxido de potássio } \\ \mathrm{Au} & \text { ouro } \\ \mathrm{SiO} & \text { óxido de silício } \\ \mathrm{MB} & \text { azul de metileno } \\ \mathrm{M} & \text { molar } \\ \mu \mathrm{m}^{2} & \text { micrômetro quadrado } \\ \mathrm{k}_{\mathrm{sp}} & \text { o vetor de onda SPP } \\ \mathrm{k}_{\|} & \text {componente do vetor de onda no plano da luz incidente } \\ \mathrm{G} & \text { vetor da rede recíproca da estrutura periódica de metal } \\ \omega_{\mathrm{S}} & \text { plasma de superfície } \\ \mathrm{mA} / \mathrm{cm} & \text { miliampères por centímetro quadrado } \\ \mathrm{mV} / \mathrm{s} & \text { milivolts por segundo } \\ \mathrm{mW} & \text { miliwatts } \\ \mathrm{C}-\mathrm{Si} & \text { cristal de silício } \\ \Delta \omega & \text { deslocamento Raman } \\ \end{array}$




\section{CAPÍTULO I}

\section{CONSIDERAÇÕES INICIAIS}

A principal motivação do presente trabalho é a fabricação de substratos nanoestruturados para aplicação em sensores químicos de elevada sensibilidade capazes de detectar uma única molécula ("single molecule detection"). A sensibilidade desses tipos de sensores químicos está baseada na intensificação de campo próximo em regiões denominadas de pontos quentes ("hot spots"). Sendo assim, a partir das nanoestruturas de esferas de poliestireno, foi possível obter superfícies SERS ("Surface-Enhanced Raman Spectroscopy") de ouro (Au) sobre substratos de silício para estudo da intensificação de campo próximo. Uma superfície mais limpa e mais organizada levou a um significativo ganho de sinal Raman. Os filmes metálicos obtidos neste trabalho mostraram-se úteis na compreensão do efeito de intensificação de campo próximo sendo que apresentaram ganho de sinal considerável. Nanoestruturas e microestruturas de silício foram obtidas a partir da tecnologia de silício poroso para estudo da intensificação do campo próximo e do efeito SERS no silício. A obtenção da intensificação de campo próximo em silício é uma contribuição completamente inédita, pois este fenômeno devia-se, até o momento, somente a materiais metálicos (nanoestruturas metálicas), mostrando sua existência também no silício.

Sendo assim, o conteúdo da presente tese de Doutorado está sistematicamente distribuído e organizado em sete capítulos. O capítulo I (presente capítulo) tem o intuito de apresentar sucintamente o conteúdo disposto em cada capítulo da tese. No capitulo II, é descrito de forma crítica o estado da arte da pesquisa a qual foi a base para o desenvolvimento deste trabalho. No capítulo III, são apresentados os objetivos do presente trabalho, que são baseados no estado da arte. No capítulo IV, são apresentadas as justificativas que explicam o porquê dos objetivos e o porquê da escolha do tema do trabalho. Em seguida, no capítulo V, são apresentados sistematicamente os procedimentos experimentais para obtenção e caracterização das amostras. No capítulo VI são apresentados os resultados e as discussões destes resultados, sendo que na seção 6.1 são discutidos os resultados a respeito da obtenção das estruturas metálicas periódicas de Au para intensificação de campo 
próximo e na seção 6.2 são discutidos os resultados das estruturas de silício para intensificação de campo próximo. Na seção 6.3 é estudada e discutida a Intensificação do espalhamento Raman do fônon óptico do cristal de silício para aplicação em um dispositivo de emissão laser de silício. Finalmente, no capítulo VII, são apresentadas as conclusões e as perspectivas futuras relacionadas ao presente trabalho. 


\section{CAPÍTULO II}

\section{REVISÃO BIBLIOGRÁFICA E FUNDAMENTAÇÃO TEÓRICA}

Ainda antes dos cientistas desenvolverem instrumentos para ver e manipular átomos individuais, alguns pioneiros mais ousados se colocavam a perguntar: o que aconteceria se pudessem construir novos materiais, átomo a átomo, manipulando diretamente os tijolos básicos da matéria? Um desses pioneiros foi um dos maiores físicos do século XX: Richard Feynman [1]. Feynman, desde jovem, era reconhecido como um tipo genial. Uma de suas invenções foi o primeiro uso de processadores paralelos do mundo. Em Los Alamos, na época do desenvolvimento da primeira bomba nuclear, havia a necessidade de se realizarem rapidamente cálculos muito complexos. Feynman, então, teve a idéia de dividir os cálculos em operações mais simples, que podiam ser realizadas simultaneamente, e encheu uma sala com jovens secretárias, cada qual operando uma máquina de calcular (naquela época não havia computadores, nem calculadoras eletrônicas, e as contas tinham de ser feitas à mão, ou com calculadoras mecânicas limitadas às mais simples operações aritméticas).

Atualmente, essa mesma idéia é usada em computadores de alto desempenho, com microprocessadores de alta velocidade. Em 1959, em uma palestra no Instituto de Tecnologia da Califórnia, Feynman sugeriu que, em um futuro não muito distante, os engenheiros poderiam pegar átomos e colocá-los onde bem entendessem desde que, é claro, não fossem violadas as leis da natureza. Com isso, materiais com propriedades inteiramente novas poderiam ser criados. Esta palestra, intitulada "Há muito espaço lá embaixo" é, atualmente, tomada como o ponto inicial da nanotecnologia [2]. A idéia de Feynman é que não precisamos aceitar os materiais com que a natureza nos provê como os únicos possíveis no universo. Hoje, quaisquer toca-discos de CDs é uma prova da verdade do que Feynman dizia. Os materiais empregados na construção dos lasers desses toca-discos não ocorrem naturalmente, mas são fabricados pelo homem, camada atômica sobre camada atômica [3]. 
O objetivo da nanotecnologia, seguindo a proposta de Feynman, é o de criar novos materiais e desenvolver novos produtos e processos baseados na crescente capacidade da tecnologia moderna de manipular isoladamente átomos e moléculas. A idéia consiste em criar, caracterizar, produzir e aplicar estruturas, dispositivos e sistemas, controlando forma, tamanho e propriedades na escala nanométrica, utilizando técnicas como "bottom-up" e "bottom-down".

Os interesses na manipulação de átomos e moléculas são diversos e dentre eles podemos destacar a curiosidade científica, a necessidade de obtenção de dispositivos com dimensões físicas na escala ULSI ("Ultra Large Systems Integration") [4], a descoberta de novos materiais, novos dispositivos, novos processos eletrônicos e produtos mais eficientes; numerosas aplicações, e benefícios esperados no desenvolvimento de remédios, tratamento de água, tecnologias de informação e telecomunicações, materiais mais resistentes e leves [5], etc.

A manipulação da matéria na escala nanométrica leva ao aparecimento de efeitos quânticos, sendo que efeitos gravitacionais passam a perder importância. Além disso, propriedades ópticas e forças atômicas e moleculares (forças de Van der Waals) podem ser estudadas e exploradas [6].

No Brasil, a nanotecnologia esta sendo estudada e desenvolvida intensamente por diferentes grupos de pesquisa da Física, Química, Biologia e Engenharia com alguns resultados importantes. Mesmo os cientistas mais conservadores projetam um futuro inovador a partir da nanociência e da nanotecnologia. São áreas consideradas emergentes e, também por isso, estratégicas e extremamente promissoras, com possibilidade de alcançar praticamente todos os campos do conhecimento e movimentar quantias astronômicas de dinheiro. Imagina-se que, brevemente, a capacidade de manipular, fabricar e funcionalizar objetos com medida equivalente ao milionésimo do milímetro gerará sistemas capazes de transportar, através de organismo humano, drogas que atingirão o ponto exato de um tumor. A nanotecnologia está totalmente ligada à capacidade dos cientistas de sintetizarem (criarem) novos materiais e de organizá-los, por exemplo, camada molecular por camada molecular, em um sensor que reage eletricamente a diferentes produtos 
químicos. Aplicações em catálise, isto é, na química e na petroquímica [7], em dosadores [8], em sensores [9], em materiais magnéticos [10], em computação quântica [11]; são alguns exemplos da nanotecnologia sendo desenvolvida no Brasil.

As aplicações de novo materiais desenvolvidos a partir da nanotecnologia, são bem abrangentes. Economia de energia, proteção ao meio ambiente, menor uso de matérias primas escassas, são possibilidades concretas agregadas à nanotecnologia da atualidade.

Dentro do contexto do estudo de materiais, processos e dispositivos em nanotecnologia, existem diversas técnicas que podem ser utilizadas na nanotecnologia para o desenvolvimento de novos materiais e novos dispositivos. Dentre as várias técnicas podemos mencionar a microscopia eletrônica de varredura (SEM) e de transmissão (TEM) [12-13], a microscopia de força atômica [14], e espalhamento de raios-X em pequeno ângulo [15], a espectroscopia de fotoluminescência, a espectroscopia de espalhamento Raman [16-17] e a microscopia óptica de campo próximo (SNOM) [18]. Esta última técnica tem se mostrado adequada para a identificação de efeitos de campo próximo e identificação dos pontos quentes ("hot spots"). Outra técnica que permite revelar os efeitos de campo próximo é o espalhamento de Raman ressonante intensificado ("SERS: Surface Enhancement Raman Scattering"). Neste trabalho será explorada a técnica de espalhamento Raman intensificado que associada à técnica de caracterização morfológica realizada por microscopia eletrônica permitirá identificar os efeitos de intensificação de campo próximo nas nanoestruturas metálicas e nas nanoestruturas semicondutoras.

\subsection{A espectroscopia Raman, o efeito SERS ("Surface-Enhanced Raman Spectroscopy") e o Espalhamento Mie}

O espalhamento Raman e a espectroscopia de absorção no infravermelho são técnicas complementares que permitem a identificação de substâncias químicas a partir de espectros vibracionais de moléculas e cristais de estado sólido. O número de bandas, suas freqüências e intensidades relativas associadas a cada modo normal de vibração fornecem informações sobre a estrutura, a conformação, o ambiente químico (interações com o solvente, com a superfície ou no interior do 
retículo cristalino) e a reatividade da espécie molecular em estudo. A absorção no infravermelho é regida pela variação do momento de dipolo intrínseco $\mu$ da molécula associado a um modo normal de vibração q, enquanto que o espalhamento Raman depende da variação da polarizabilidade a com o modo normal de vibração. A propriedade polarizabilidade está associada a quanto um momento de dipolo $(P)$ pode ser induzido em uma molécula pelo campo elétrico externo $(E)$ da radiação excitante [19]. Logo:

$$
P=\alpha E
$$

sendo que a pode ser escrito num desenvolvimento em série da coordenada interna q (única coordenada normal do sistema em estudo):

$$
\alpha=\alpha_{0}+\left(\frac{d \alpha}{d q}\right)_{0} q+\ldots
$$

Supondo que a coordenada q e o campo E sejam descritos por:

$$
q=q_{0} \cos \left(2 \pi v_{v} t\right) \text { e } E=E_{0} \cos \left(2 \pi v_{0} t\right),
$$

onde $v_{0}$ e $v_{v}$ são, respectivamente, a freqüência vibracional e a da radiação incidente, o momento de dipolo induzido será dado por:

$$
P=\alpha_{0} E_{0} \cos \left(2 \pi v_{0} t\right)+\left(\frac{d \alpha}{d q}\right)_{0} q_{0} E_{0} \cos \left(2 \pi v_{0} t\right) \cos \left(2 \pi v_{v} t\right)
$$

Os termos de ordem mais alta podem ser desprezados para pequena variação da coordenada q. Sendo assim, podemos ter:

$$
P=\alpha_{0} E_{0} \cos \left(2 \pi v_{0} t\right)+\frac{1}{2}\left(\frac{d \alpha}{d q}\right)_{0} q_{0} E_{0}\left\{\cos \left[2 \pi\left(v_{0}+v_{v}\right) t\right]+\cos \left[2 \pi\left(v_{0}-v_{v}\right) t\right]\right\}
$$

O primeiro termo contém somente a freqüência de radiação e correspondente ao espalhamento Rayleigh (espalhamento elástico). No segundo termo aparecem radiações espalhadas com freqüências $v_{0}+v_{v}$ (espalhamento Raman Stokes) e $v_{0}-v_{v}$ (espalhamento Raman anti-Stokes). Para os dois últimos termos terem contribuição é necessário que $\left(\frac{d \alpha}{d q}\right)_{0} \neq 0$, ou seja, que haja variação da polarizabilidade com o pequeno deslocamento da coordenada q em torno da posição de equilíbrio. 
No efeito Raman, tanto moléculas diatômicas heteronucleares como homonucleares apresentam atividade, pois em ambos os casos ocorre variação da polarizabilidade com a vibração. No espectro teremos simetricamente em relação à linha Rayleigh (em escala de $\mathrm{cm}^{-1}$ ) uma banda do lado de freqüências mais baixas (a Stokes), e uma do lado de freqüências mais altas (a anti-Stokes). Classicamente, as duas deveriam ter mesma intensidade, mas observa-se que a Stokes é mais intensa que a anti-Stokes. Para explicar este comportamento precisa-se recorrer ao modelo quântico.

Correspondendo ao momento de transição do dipolo, podemos introduzir para a polarizabilidade a expressão:

$$
\alpha_{m n}=\int \psi_{m} \alpha \psi_{n} d \tau
$$

A relação entre as componentes do momento de dipolo induzido e as componentes do campo elétrico é dada pelas equações:

$$
\begin{aligned}
& P_{x}=\alpha_{x x} E_{x}+\alpha_{x y} E_{y}+\alpha_{x z} E_{z} \\
& P_{y}=\alpha_{y x} E_{x}+\alpha_{y y} E_{y}+\alpha_{y z} E_{z} \\
& P_{z}=\alpha_{z x} E_{x}+\alpha_{z y} E_{y}+\alpha_{z z} E_{z}
\end{aligned}
$$

As componentes $\alpha_{i j}$, que relacionam os dois vetores, formam um tensor simétrico no efeito Raman normal, ou seja, $\alpha_{x y}{ }^{=} \alpha_{y x}, \alpha_{x z}{ }^{=} \alpha_{z x}$ e $\alpha_{y z}{ }^{=} \alpha_{z y}$. O tensor pode ser representado por:

$$
\left[\begin{array}{lll} 
& 1 \\
1 & & \\
& &
\end{array}\right] \quad\left[\begin{array}{ll} 
& 1 \\
1 &
\end{array}\right] \quad\left[\begin{array}{lll} 
& \\
& & 1 \\
1 &
\end{array}\right]
$$

Para cada transição entre os estados vibracionais $\mathrm{m}$ e $\mathrm{n}$ devem ser consideradas as componentes $\left(\alpha_{i j}\right)_{m n}$, onde i e j são x, y ou z. Para haver atividade no Raman, pelo menos uma das componentes das seis integrais $\left(\alpha_{i j}\right)_{m n}=\int \psi_{m} \alpha_{i j} \psi_{n} d \tau$ deve ser diferente de zero.

Substituindo a equação (2) em $\alpha_{m n}$, na aproximação considerada, podemos escrever: 


$$
\alpha_{m n}=\alpha_{0} \int \psi_{m} \psi_{n} d \tau+\left(\frac{d \alpha}{d q}\right)_{0} \int \psi_{m} q \psi_{n} d \tau
$$

No espalhamento Raman Stokes ou anti-Stokes, os estados vibracionais m e $\mathrm{n}$ são diferentes e a primeira integral do segundo membro é sempre igual a zero, pela ortogonalidade entre $\psi_{m}$ e $\psi_{n}$. Para o segundo termo ser diferente de zero, é necessário que sejam satisfeitas as duas condições:

a) $\left(\frac{d \alpha}{d q}\right)_{0} \neq 0$, ou seja, dever haver variação da polarizabilidade com a pequena vibração em torno da posição de equilíbrio;

b) $\int \psi_{m} q \psi_{n} d \tau \neq 0$. A regra de seleção para o oscilador harmônico é $\Delta v= \pm 1$, onde o sinal "+" vale para Stokes e o sinal "“" para anti-Stokes.

A intensidade do espalhamento Raman $\left(I_{m n}\right)$ em função da intensidade de radiação excitante $\left(l_{0}\right)$ é dada por:

$$
I_{m n}=K I_{o} v^{4} \sum_{i j}\left|\left(\alpha_{i j}\right)_{m n}\right|^{2},
$$

onde $v$ é a freqüência de radiação espalhada, "i" e "j" são as coordenadas espaciais dos elementos do tensor polarizabilidade, "m" e "n" são os estados vibracionais fundamental e excitado e $\left(\alpha_{i j}\right)_{m n}$ são as integrais do momento de transição eletrônica e os termos de acoplamento vibracional destes estados eletrônicos [20].

A espectroscopia Raman apresenta uma série de características que a torna conveniente em estudos vibracionais. A primeira é que permite a obtenção de espectros de amostras em qualquer estado de agregação, em uma vasta gama de materiais e de forma não destrutiva. A espectroscopia Raman também permite a obtenção do espectro vibracional na região de baixas freqüências, por volta de 50 $\mathrm{cm}^{-1}$, sem necessitar de instrumentação adicional. Além disso, possibilita facilmente a análise de espécies em solução aquosa, pois, diferente da absorção no infravermelho, a água possui baixa secção de choque Raman.

Avanços na tecnologia de instrumentação de espectrômetros Raman têm levado esta técnica a uma posição de destaque. Como exemplos de dispositivos 
desenvolvidos envolvendo a técnica Raman, temos o detector multicanal (CCD), o uso de microscópio óptico acoplado ao espectrômetro e o desenvolvimento de equipamentos de baixo custo com laser de estado sólido e fibra óptica para o transporte de luz incidente e luz espalhada. É importante ressaltar que a espectroscopia Raman ordinária possui baixa secção de choque para 0 espalhamento da molécula livre, sendo da ordem de ca. $10^{-30} \mathrm{~cm}^{2}$ molécula ${ }^{-1} \mathrm{sr}^{-1}$, tornando a técnica pouco sensível quando comparada, por exemplo, à absorção no infravermelho ou à fluorescência, que possuem secções de choques 10 ordens de grandeza maiores [21-22]. No entanto, efeitos de intensificação como o Raman ressonante (RR) e o espalhamento Raman intensificado pela superfície (SERS) levam ao aumento da sensibilidade da técnica. O efeito Raman ressonante é um acoplamento vibracional que ocorre quando a energia da radiação excitante aproxima-se ou coincide com a banda de transição eletrônica permitida da espécie em estudo fazendo com que haja um aumento substancial na intensidade das bandas das vibrações envolvidas com o grupo cromofórico. No efeito SERS, a ressonância deve ocorrer entre as energias da excitação e das transições do plasma de superfície das partículas metálicas do substrato. Isto leva a intensificações de sinal da ordem de $10^{6}$ vezes. Aumentos ainda maiores podem ser verificados em espectros SERS quando a substância em estudo possui transição eletrônica com energia similar à da radiação excitante utilizada. Neste caso, além do SERS ocorre intensificação por RR e este efeito é denominado SERRS ("Surface-Enhanced Resonance Raman Spectroscopy") [23].

A presença do substrato metálico pode levar também à intensificação da absorção no infravermelho. Este fenômeno foi observado por A. Hartstein e seus colaboradores em 1980 [24] e foi nomeado SEIR ou SEIRA ("Surface-Enhanced Infrared Absorption"). Esta técnica pode complementar as informações obtidas nos experimentos SERS, mas os fatores de intensificação SEIRA observados são bem inferiores (da ordem de $10^{2}$ ) aos obtidos em experimentos SERS.

O efeito SERS foi descoberto por Fleishmann e seus colaboradores [25] em 1974, quando estudaram a piridina adsorvida em eletrodo de prata cuja rugosidade superficial tinha sido aumentada eletroquimicamente através de vários ciclos de oxidação e redução do metal. A intensificação do sinal foi associada ao aumento da 
área superficial no eletrodo e, portanto, ao aumento do número de moléculas adsorvidas sobre a superfície metálica. Em 1977, o trabalho de Jeanmarie e Van Duyne [26] mostrou que o fator de intensificação Raman devido ao aumento da área superficial do eletrodo não justifica a elevação do sinal observada. Cálculos mostraram que a intensificação esperada devido ao aumento de área seria da ordem de $10^{2}$ vezes, enquanto que a intensificação observada era da ordem de $10^{6}$ vezes.

Diversos estudos e trabalhos desenvolvidos a partir da espectroscopia Raman levaram a espectroscopia SERS a tornar-se uma técnica de superfície através da qual é possível determinar a identidade e a orientação de moléculas e seus respectivos sítios moleculares envolvidos em adsorções. A partir dos registros dos espectros SERS de uma única molécula realizados, por exemplo, por Kneipp e seus colaboradores [27], associados a intensificações do sinal Raman da ordem de $10^{14}$, as aplicações analíticas desta técnica tornaram-se relevantes. Espectros de fluorescência já tinham sido obtidos de uma única molécula, mas a relevância do SERS deve-se à riqueza de informações que podem ser obtidas em um espectro vibracional.

O espectro SERS, muitas vezes, difere do espectro Raman ordinário da espécie química em fase condensada. A interação da molécula com a superfície produz mudanças nas freqüências e intensidades relativas das bandas em razão das alterações em sua estrutura eletrônica e na simetria molecular. O relaxamento das regras de seleção leva à observação de modos inativos no espectro Raman da molécula. Estas evidências dão origem a um modelo molecular ou químico para a explicação da intensidade observada. Há ainda forte dependência da observação do efeito com a natureza da superfície metálica. Os metais como cobre, prata e ouro mostram-se bastante eficientes em experimentos SERS [28] por apresentarem plasma de superfície na região do visível. Para a ocorrência do efeito faz-se necessária uma rugosidade na superfície metálica de dimensão de dezenas de nanômetros. O efeito, apesar de menos intenso, foi posteriormente observado em outros metais de transição como platina, níquel, cobalto e outros [21,29].

A intensificação dos espectros SERS das moléculas depende de diferentes aspectos relacionados com as propriedades do substrato metálico, levando a outro modelo 
dito eletromagnético para justificar as intensificações observadas. Neste modelo, a intensificação do sinal Raman deve-se, principalmente, a efeitos de ressonância quando há coincidência entre a freqüência do plasma de superfície do metal e as freqüências das radiações incidente e espalhada. Há várias concepções na literatura que envolve discussões sobre os diferentes modelos propostos [30-31] e é aceito que tanto os moleculares [32] quanto os eletromagnéticos [22,33] estejam envolvidos no efeito SERS, pois nenhum deles isoladamente pode justificar a intensificação do espalhamento Raman, na ordem de grandeza que é observada.

Quando falamos do efeito molecular ou químico, a natureza da molécula adsorvida é um importante fator na observação do efeito SERS. Evidências experimentais mostram que a quimissorpção da molécula está associada a fenômenos de transferência de carga entre a molécula e o substrato metálico, com a formação de um complexo de superfície. A especificidade molecular observada nos experimentos SERS foi ressaltada por Moskovits e DiLella ao observarem que o sinal SERS de moléculas de $\mathrm{CO}$ é duas ordens de grandeza maior que a do $\mathrm{N}_{2}$, apesar de ambas possuírem aproximadamente a mesma secção de choque Raman no espaço livre [30]. Sendo assim, moléculas contendo átomos de nitrogênio, enxofre ou oxigênio, que apresentem comportamento de base de Lewis frente ao metal são particularmente fortes candidatas a apresentarem o efeito. Isto permite o uso de complexos metálicos da espécie estudada como padrões espectrais para o estudo da interação química e da geometria de adsorção [34].

Um modelo inicialmente proposto por Burstein [35] para explicar esta interação química propunha a rugosidade em escala atômica com a presença de adátomos metálicos e admoléculas, sendo estes sítios de adsorção particularmente favoráveis ao mecanismo de transferência de carga assistida por fóton. Nestes sítios metálicos ocorreria a formação de um par elétron-lacuna na superfície metálica que levaria à transferência ressonante de um elétron do metal para orbitais vazios da molécula no estado eletrônico excitado. Quando este elétron voltasse ao metal, recombinando o par elétron-lacuna, seria criado um fóton Raman quando a molécula permanecesse vibracionalmente excitada. A geração e recombinação dos pares elétron-lacuna seria o fenômeno responsável pela característica de emissão de fundo nos espectros SERS. Lombardi e seus colaboradores [36] propuseram que os orbitais do admetal e 
da molécula adsorvida se combinariam formando um complexo de superfície, e a variação do potencial aplicado em experimentos SERS in situ permitiria transferência de carga induzida pela radiação da superfície metálica para os estados excitados desta nova espécie. Rubim e seus colaboradores [37] desenvolveram uma equação para a explicação deste mecanismo utilizando o formalismo do espalhamento Raman dependente do tempo e interpretaram os espectros SERS em diferentes potenciais aplicados como variações no recobrimento entre os orbitais dos átomos metálicos e da molécula adsorvida assistidos por fóton. Sendo assim, com o uso de diferentes radiações excitantes e monitorando-se o potencial em que a condição de ressonância é máxima, seria possível determinar se o sentido da transferência de carga no sistema em estudo é metal-molécula ou molécula-metal.

O efeito químico é importante para a intensificação do sinal SERS, mas parte significativa da intensificação observada em experimentos SERS é devida ao efeito eletromagnético. As teorias relacionadas a este modelo explicam a seletividade do efeito SERS em relação ao metal utilizado como substrato e a razão pela qual há uma dependência da atividade SERS com a rugosidade metálica. Um dos primeiros modelos gerados para a explicação do fenômeno foi o dipolo-imagem ("image Field") [38] pelo qual o dipolo elétrico intrínseco da molécula adsorvida levaria ao surgimento de um dipolo induzido na superfície metálica. A soma vetorial de ambos geraria um dipolo maior quando estivessem alinhados à normal da superfície e a resultante seria zero quando estivessem paralelos à superfície. Esta regra de seleção de superfície justificaria a observação preferencial dos modos normais cuja resultante estivesse na direção normal à superfície. Este modelo é válido admitindose uma adsorção física da espécie molecular, com esta muito próxima à superfície (até $2 \AA$ ), mas não explica intensificações observadas quando esta distância é maior [30]. Um modelo mais elaborado foi proposto por Gersten e Nitzan [39] a partir da teoria clássica do eletromagnetismo, envolvendo três mecanismos de intensificação que atuariam juntos na intensificação do sinal: o dipolo-imagem, a curvatura dos sítios de adsorção nos aglomerado metálicos ("lightning rod effect") e a ressonância com o plasma de superfície. Foi obtida uma curva teórica do fator de intensificação em função da energia da radiação excitante, para uma molécula de polarizabilidade de $10 \AA ̊$, a $5 \mathrm{~nm}$ de distância de um hemisferóide de Ag com semi-eixo maior que 50 $\mathrm{nm}$ e semi-eixo menor que $10 \mathrm{~nm}$. O valor máximo do fator de intensificação obtido 
foi de 11 ordens de grandeza, para uma radiação excitante de 2,02 eV (620 nm), que corresponderia ao valor de energia do máximo da banda do plasma de superfície. Neste cálculo não foi considerado o efeito de dipolo-imagem, mostrando que a ressonância com o plasma de superfície e as dimensões e excentricidade da partícula metálica colaboram muito mais para a intensificação do sinal. Considerando-se vários trabalhos utilizando-se diferentes moléculas e diferentes superfícies metálicas, em todos estes trabalhos o máximo de intensificação no perfil SERS foi obtido na região do vermelho, indicando que há um tamanho ideal de aglomerado metálico para o qual a ressonância SERS é máxima. Kneipp e seus colaboradores [40] obtiveram o perfil de excitação SERS do cristal violeta em colóide de Ag com radiações excitantes no infravermelho próximo (entre 750 e $830 \mathrm{~nm}$ ) e observaram um aumento na intensificação na direção do visível. Este trabalho de Van Duyne e seus colaboradores [41] mostrou que o aumento da excentricidade das ilhas de Ag está diretamente relacionado com o aumento de intensificação SERS.

Outra explicação para o aumento da intensificação de sinal é o aprisionamento da molécula adsorvida entre duas estruturas metálicas separadas por uma distância com dimensões próximas à da molécula adsorvida. Neste caso, a polarização do campo elétrico da radiação excitante ao longo do eixo entre as partículas leva ao acoplamento dos plasmas de superfície de ambas, gerando um intenso campo próximo responsável pela intensificação observada. Cálculos da intensificação do campo entre duas esferas metálicas e sua relevância para o efeito SERS foram realizadas por Garcial Vidal e Pendry [42], ao modelarem moléculas localizadas nos interstícios de partículas de prata. Adicionalmente, uma série de trabalhos de Brus e seus colaboradores [43-44] propõem que a adsorção da rodamina $6 G$ na junção de duas partículas de Ag é a responsável pelo SERS de uma única molécula. Foram obtidos os espectros SERS de uma única molécula de rodamina $6 \mathrm{G}$ em um único aglomerado de prata com diferentes polarizações da radiação excitante, confirmando que o sinal é muito maior em uma direção preferencial [45].

Há estudos que correlaciona a presença de estruturas fractais nas superfícies dos substratos com a intensificação do espalhamento Raman das moléculas adsorvidas. Numa série de trabalhos teóricos [46-47] e experimentais [48-49], Shalaev e seus colaboradores investigaram a importância da fractalidade nas superfícies SERS 
ativas, sugerindo que flutuações de campo estão presentes em agregados fractais de partículas cujos dipolos individuais sofrem intenso acoplamento. Estes são sítios com intensificações gigantes do campo elétrico, onde as espécies moleculares adsorvidas podem apresentar fatores de intensificação do espalhamento Raman da ordem de $10^{10}$ vezes.

Em um trabalho muito interessante, Xu e seus colaboradores [50], a partir da teoria eletromagnética clássica, calcularam o campo magnético ao redor de partículas de Au e Ag, admitindo a existência de regiões metálicas com bordas bem agudas. Este efeito, somado à intensificação devida à intercalação de uma molécula entre duas partículas metálicas, levou a um fator de intensificação máximo de $10^{11}$. Devido à raridade destes pontos e à elevada intensificação observada, estes foram associados aos pontos quentes, responsáveis pela obtenção dos espectros SERS de uma única molécula.

O efeito SERS [33] é baseado predominantemente em ressonância plasmônica simples ou coletiva que produz amplificação de campo próximo do laser, sendo chamada de intensificação eletromagnética (EM). Uma segunda fonte de intensificação (fonte química) [51] está sempre presente quando grandes amplificações são observadas. Este mecanismo químico ligado à intensificação Raman envolve excitação de transferência de carga entre as moléculas de prova (analitos) onde há a predominância da excitação plasmônica, levando à formação de pontos quentes ("hot spots") ao redor das nanopartículas metálicas. A composição química das estruturas metálicas e moléculas de prova, e a distância entre as partículas metálicas, são importantes para o estudo dos pontos quentes (hot spots). O desafio para estudo do mecanismo eletromagnético é a dificuldade relacionada à obtenção de estruturas nanométricas com espaçamento entre partículas periódico. Obtendo-se estruturas metálicas periódicas de alta qualidade (alta organização), diferenças na intensificação molecular são minimizadas, e pode-se obter a relação entre a organização das nanoestruturas e a intensificação eletromagnética. Estruturas organizadas têm sido obtidas por "electron beam" [52], mas sistemas químicos e eletroquímicos são vantajosos, pois necessitam de menor infraestrutura e também possuem boa reprodutibilidade. O efeito SERS implica no entendimento da natureza de ressonâncias coletivas de plasmas em nanoestruturas metálicas onde o 
efeito é observado. A oscilação do plasma em um metal é a excitação coletiva de um gás formado pelos elétrons de condução [53]. Esta onda de excitação, ao se propagar em estruturas nanométricas possui uma freqüência que depende da geometria e do tamanho destas partículas, sendo denominada plasma de superfície. O plasma de superfície está associado à rugosidade superficial presente nos substratos SERS ativos. Medidas de absorção de luz pelo plasma de nanopartículas metálicas podem ser obtidas nas regiões do ultravioleta, visível e infravermelho próximo. O aumento no tamanho das partículas resulta em um deslocamento da banda do plasma de superfície do metal para a região espectral de maior comprimento de onda. Para partículas metálicas com dimensões que se aproximam do comprimento de onda do fóton incidente, efeitos provenientes do espalhamento "Mie" devem ser considerados. A teoria de Mie explica adequadamente o desvio da banda de extinção para o vermelho com o aumento do tamanho das partículas, bem como o surgimento de duas bandas de absorção do plasma em elipsóides. Já para partículas não condutoras, podemos considerar o efeito de espalhamento Rayleigh. O espalhamento Rayleigh ocorre quando o diâmetro da partícula é muitas vezes menor que o comprimento de onda da radiação eletromagnética incidente. $O$ espalhamento Rayleigh é inversamente proporcional à quarta potência do comprimento de onda. Portanto, existe uma tendência mais forte a esse tipo de espalhamento para os comprimentos de onda menores que para os maiores. $O$ espalhamento Rayleigh pode ser percebido, por exemplo, ao pôr-do-sol, pois este espalhamento contribui para o pôr-do-sol vermelho em dias claros: a energia atravessa um caminho óptico mais longo no amanhecer e no pôr-do-sol, e os comprimentos de onda do azul e do violeta são ainda mais espalhados para fora da direção de incidência, e os que sobram são os comprimentos de onda do vermelho e laranja, que são raramente afetados. O espalhamento Mie ocorre em materiais metálicos e quando o diâmetro da partícula é aproximadamente igual ao comprimento de onda da radiação eletromagnética incidente. Como as nanoestruturas obtidas neste trabalho têm a mesma ordem de grandeza do comprimento de onda da radiação que interage com as nanoestruturas, o efeito de maior intensidade é o espalhamento Mie principalmente relacionado com os modos de campo próximo que podem ser radiativos e não radiativos. 
As nanopartículas de ouro são bons exemplos para explicar a interação da radiação com nanoestruturas metálicas. O modelo físico aplicado no entendimento da interação da luz com partículas baseia-se no comportamento dos plasmons de superfície. Um plasmon pode ser entendido como uma onda proveniente da oscilação coletiva de cargas em um dado meio; e corresponderia à oscilação dos elétrons de superfície, no caso dos metais. A conseqüência da formação do plasmon é a excitação coletiva dos elétrons livres da partícula gerando uma separação dipolar de cargas. Se a freqüência da radiação incidente estiver em ressonância com a autofrequência da oscilação coletiva, mesmo um campo incidente de baixa intensidade será capaz de gerar intensas oscilações. A magnitude das oscilações depende dos mecanismos de dissipação envolvidos, que podem ser radiativos (espalhamento) ou não-radiativos (absorção). Com isso, o processo de extinção de luz visível, que no caso de sistemas moleculares é dominado pela absorção, passa a ser composto pelos dois processos, absorção e espalhamento, com importância relativa dependente das dimensões do sistema. A freqüência de ressonância está relacionada com a intensidade da força restauradora, ou seja, da separação das cargas e do tamanho da partícula, por conseqüência. Por essa razão, observa-se mudança de cor quando se altera o tamanho das partículas.

A explicação da dependência da cor e do espalhamento com o tamanho das partículas foi concebida inicialmente pelo físico alemão Gustav Mie [54] em 1908. A teoria de Mie, também chamada teoria Lorenz-Mie ou teoria Lorenz-Mie-Debye, é uma solução analítica completa das equações de Maxwell para a dispersão de radiação eletromagnética por partículas esféricas (também chamada dispersão de Mie). A solução de Mie recebeu este nome devido ao seu desenvolvimento pelo físico alemão Gustav Mie. Entretanto, o físico dinamarquês Ludvig Lorenz e outros independentemente desenvolveram a teoria da dispersão da onda plana eletromagnética por uma esfera dielétrica. O termo "teoria de Mie" é um engano, já que não se refere a uma teoria física independente ou lei. A frase "a solução de Mie (às equações de Maxwell)" é conseqüentemente preferível. Atualmente, o termo "solução de Mie" é também usado em contextos mais amplos, como, por exemplo, ao discutir soluções das equações de Maxwell para dispersão por esferas estratificadas ou por cilindros infinitos, ou geralmente quando se trata problemas de dispersão resolvíveis pelo uso das equações exatas de Maxwell nos casos onde se 
podem escrever equações separadas para a dependência radial e angular das soluções. Em contraste à dispersão de Rayleigh, a solução de Mie ao problema da dispersão é válida para todas as possíveis razões entre diâmetros e comprimentos de onda, embora a técnica resulte em soma numérica infinita. Em sua formulação original assume-se um material homogêneo, isotrópico e opticamente linear irradiado por uma infinita onda plana. Entretanto, soluções para esferas em camadas são também possíveis.

Mie resolveu as equações de Maxwell para sistemas esféricos com dimensões da ordem ou menores que o comprimento de onda da radiação incidente. Estabelecendo condições de contorno adequadas, foi possível realizar o cálculo do coeficiente de extinção dependente da freqüência incidente $C_{\text {ext }}$, que é uma combinação dos coeficientes de absorção $C_{a b s}$ e de espalhamento da radiação $C_{\text {esp }}$ :

$$
\begin{gathered}
C_{a b s}=C_{e x t}-C_{e s p} \\
C_{e x t}=\frac{2 \pi}{K^{2}} \sum(2 L+1) \operatorname{Re}\left(a_{L}+b_{L}\right) \\
C_{e s p}=\frac{2 \pi}{K^{2}} \sum(2 L+1) \operatorname{Re}\left(a_{L}^{2}+b_{L}^{2}\right)
\end{gathered}
$$

Nessa equação, $K$ é um parâmetro diretamente proporcional à dimensão da partícula, $L$ refere-se à ordem de excitação $\left(L=1\right.$, excitação dipolar) e $a_{L}$ e $b_{L}$, são parâmetros expressos por funções do tipo Ricatti-Bessel empregadas na resolução das equações de Maxwell (Re indica que a parte real dos parâmetros é empregada). Considerando tanto as excitações dipolares quanto as multipolares, Mie foi capaz de prever com alto grau de concordância os espectros de extinção para partículas de diferentes tamanhos, partindo apenas das constantes dielétricas do meio e da partícula (componentes reais e imaginárias dependentes da freqüência), já que a intensidade de extinção da luz está relacionada ao coeficiente de extinção:

$$
A=\log \frac{I_{i}}{I_{T}}=0,43 \cdot N \cdot d \cdot C_{e x t},
$$


onde $I_{i}$ e $I_{T}$ são as intensidades incidentes e transmitidas, $\mathrm{N}$ é a densidade de partículas e d é o caminho óptico.

A teoria de Mie considera os processos de relaxação como resultantes de colisões entre elétrons, e permite prever corretamente o aumento da largura de banda para partículas maiores, já que as colisões intereletrônicas seriam mais freqüentes (efeitos extrínsecos de tamanho). Entretanto, para partículas pequenas (<10 nm) a teoria de Mie falha [55] ao se observar um aumento na largura de banda com a diminuição do tamanho. De acordo com Mie, para partículas menores, onde excitações dipolares são predominantes, não há uma dependência de $\mathrm{C}_{\text {ext }}$ com o tamanho da partícula [56]:

$$
C_{e x t}=\frac{24 \pi^{2} a_{1}^{3} \varepsilon_{m}^{3 / 2}}{\lambda} \frac{\varepsilon_{2}(\omega)}{\left(\varepsilon_{1}(\omega)+2 \varepsilon_{m}\right)^{2}+\varepsilon_{2}(\omega)},
$$

onde $\mathrm{a}_{1}$ é um parâmetro dependente de funções Ricatti-Bessel, empregadas na resolução das equações de Maxwell, $\varepsilon_{\mathrm{m}}$ é o índice de refração do meio, $\varepsilon_{1}(\omega)$ é o índice de refração real da partícula, $\varepsilon_{2}(\omega)$ é a parte imaginária (associada à absorção) e $\lambda$ é o comprimento de onda da radiação incidente. Experimentalmente, o aumento da largura de banda com a diminuição do tamanho tem demonstrado que os processos de relaxação também são importantes para partículas pequenas, embora as excitações multipolares sejam desprezíveis. O esclarecimento desse ponto só foi possível com a ampliação da teoria de Mie, como nos trabalhos de Kreibig e seus colaboradores [57], que consideram o fato de que para partículas muito pequenas a dimensão do sistema é da ordem do livre caminho médio dos elétrons. Dessa forma, um novo componente foi adicionado à constante de dissipação $Y_{0}$ da partícula, correspondente à perda de coerência devido à colisão dos elétrons com a borda da partícula:

$$
\gamma(a)=\gamma_{0}+\frac{A v_{f}}{a}
$$

onde $Y_{0}$ é a constante de dissipação independente de a (diâmetro da partícula), que leva em conta apenas colisões eletrônicas e $v_{f}$ é a velocidade de Fermi dos elétrons. 
Com isso, a constante dielétrica passa a ter uma dependência com o tamanho, já que ela depende do valor de y e o comportamento espectral pode ser corretamente previsto em qualquer faixa de tamanho. É importante mencionar que a razão $\mathrm{C}_{\text {esp }} / \mathrm{C}_{\text {abs }}$ varia sensivelmente com o tamanho da partícula, sendo que os processos de espalhamento são dominantes para partículas maiores, enquanto processos de absorção são determinantes para a cor de partículas menores. Deve-se enfatizar ainda que os processos de espalhamento em partículas são elásticos, ou seja, a radiação emitida não é resultado de luminescência (inelástico). O fato de o espectro eletrônico exibir uma banda é resultado da perda de coerência dos elétrons que permite a excitação em uma faixa maior de energias (lembrando que na aquisição de um espectro utiliza-se luz branca). Caso se utilize luz monocromática com energia equivalente à autofrequência de oscilação, o espectro de extinção exibiria uma linha, contrastando ao caso dos corantes em que a excitação monocromática pode gerar emissão em diferentes energias (espalhamento não-elástico). Por exemplo, no caso do ouro, a ressonância ocorre por volta de 2,38 eV (520 nm) para partículas próximas a $20 \mathrm{~nm}$ de diâmetro.

$\mathrm{Na}$ verdade, a teoria de Mie parte do pressuposto de que as partículas não possuem nenhum tipo de interação entre si; suposição perfeitamente aplicável a partículas em suspensões coloidais diluídas [58]. Entretanto, sabe-se que quando partículas metálicas apresentam-se desprovidas de uma camada de passivação eficiente, capaz de estabilizar eletrostaticamente ou estericamente, o fenômeno de agregação é observado. No caso do ouro, a agregação gera uma coloração roxa e o espectro eletrônico exibe uma nova banda próxima a $650 \mathrm{~nm}$. Nesse caso, a explicação pode ser formulada a partir dos campos elétricos superficiais das partículas. Considera-se que a geração de plasmon dá origem a um campo elétrico oscilante na superfície da partícula, denominado campo elétrico evanescente, por decair exponencialmente com a distância da superfície. Quando a formação de agregados é observada, os campos evanescentes de partículas adjacentes sofrem interferências mútuas, gerando ressonâncias em energias menores, o que explica o surgimento da banda em $650 \mathrm{~nm}$. Um modelo teórico capaz de explicar eficientemente o comportamento de agregados é assunto de investigação científica, em especial pela área da Física do campo próximo ou "near Field". Nesse ponto, é importante fazer a distinção entre processos de agregação e de fusão de partículas. No processo de fusão duas ou 
mais partículas se unem formando uma nova partícula de tamanho maior. Nesse caso a banda de agregação em $650 \mathrm{~nm}$ não é observada e apenas o deslocamento do máximo de absorção (ressonância plasmônica) e o alargamento da banda ocorrem. O processo de agregação é observado quando duas ou mais partículas se aproximam o suficiente para que a interferência dos campos evanescentes ocorra, mas sem se fundirem. Observa-se então, o surgimento da banda de $650 \mathrm{~nm}$. Esse tipo de comportamento é observado quando a camada de passivação é suficiente para evitar a fusão, mas ineficiente no impedimento da aproximação.

Como a teoria de Mie explica adequadamente o desvio da banda de extinção para o vermelho com o aumento do tamanho das partículas, bem como o surgimento de duas bandas de absorção do plasma em elipsóides, para explicar a diferença observada nas intensidades relativas destas duas bandas Fornasiero e Grieser [59] fizeram uso da teoria excitônica, resolvendo o problema para agregados de partículas e utilizando mecanismos de acoplamento de dipolos.

Acredita-se que os grandes sinais SERS venham dos chamados pontos quentes que são ressonâncias plasmônicas de superfície espacialmente localizadas onde o campo elétrico do laser pode obter grande intensificação local. Os pontos quentes estão, em muitos casos, relacionados à interação com duas partículas (dímeros) em sistemas coloidais, mas há muitos modelos teóricos que acreditam que podem ser também produzidos por excitações coletivas, com relação indireta com a topologia das nanoestruturas metálicas. Acredita-se também que os pontos quentes são responsáveis pela sensitividade de uma única molécula de SERS [60], e utilizandose suas propriedades físicas podem ser aplicadas em SERS e em espectroscopia de uma única molécula. A literatura reporta que os pontos quentes podem ser localizados espacialmente dentro de uma fração do comprimento de onda do laser. Esta propriedade é interessante por algumas razões como poder dizer algo sobre a natureza da localização da ressonância plasmônica que pode ser importante para estudo do próprio fenômeno plasmônico [61-63]; poder explicar a existência de alta intensificação do campo eletromagnético $\left(\sim 10^{12}-10^{15}\right)$ que é necessário para explicar o fenômeno de SERS de uma única molécula; e, além disso, poder demarcar os limites de resolução espacial (sub-comprimentos de onda) no fenômeno SERS como ferramenta alternativa para microscopia com alta especificidade 
química. A literatura reporta a possibilidade do confinamento de pontos quentes ("hot spots") em comprimentos de onda menores que $\lambda$ (sub-comprimentos de onda) $e$ resolução espacial dentro de distâncias menores que $\lambda$ [64]. Estas técnicas podem ser utilizadas para aprofundamento de novos conhecimentos a respeito das causas da intensificação do campo magnético por plasma e pode ser aplicada em Física [65], Química [66], Físico-Química [67] e Biologia [60,68].

Estudos recentes combinam a microscopia óptica de varredura de campo próximo (SNOM), determinação de morfologia de estruturas por microscopia de força atômica, microscopia de varredura e de transmissão, e a teoria eletromagnética em meios randômicos (não contínuos) nanoestruturados [69-70]. Otto reporta em um de seus trabalhos [70] que a SNOM poderá ser utilizada para monitorar a intensidade do campo próximo em uma altura de aproximadamente $10 \mathrm{~nm}$ acima de um filme de ouro sobre vidro com um fator de preenchimento "p" que é aproximadamente igual ao fator crítico " $p_{c}$ " no limiar da percolação. Sítios de junções quentes ("hot junctions") ainda não podem ser monitorados por SNOM porque pontas e fibras são grandes em relação à dimensão dos "hot spots" nos sítios de junções. Sendo assim, haverá flutuações consideráveis que mascararão certos resultados. A SNOM tem uma resolução espacial próxima ao diâmetro da ponta da fibra (100 nm). A intensidade das flutuações teóricas está entre zero e aproximadamente $3.10^{4}$. A estreita intensidade máxima é denominada de pontos quentes. Otto ainda reporta que os espectros teórico e experimental de campo próximo podem mostrar que a intensificação de campo próximo em um dado sítio pode variar muito com pequenas variações do comprimento de onda (entre 700 e $770 \mathrm{~nm}$ ou equivalente em número de onda a $1298 \mathrm{~cm}^{-1}$ ). Esta faixa é pequena se comparada à meia largura que é de aproximadamente $3000 \mathrm{~cm}^{-1}$ da ressonância dipolar de desagregados de colóides de prata e bem pequenos em relação à meia largura da banda de absorção dos filmes de ilhas de prata. No entanto em metais não contínuos, nesta faixa de $1298 \mathrm{~cm}^{-1}$, as intensidades de campo próximo são desdobradas em várias bandas de largura da ordem de aproximadamente $300 \mathrm{~cm}^{-1}$ e em sítios separados de $50 \mathrm{~nm}$, sendo que a última diferença reflete a resolução espacial da técnica SNOM.

Verifica-se que as estruturas metálicas com dimensões nanométricas geram pontos quentes que são utilizados em estudos de efeito SERS e especialmente em SERS 
de uma única molécula, sendo possível a utilização destas estruturas na tecnologia de obtenção de sensores. Alguns trabalhos mostram que a organização da distribuição de estruturas unidimensionais, bidimensionais ou tridimensionais metálicas são importantes na qualidade da intensificação do sinal. Sendo assim, podem-se utilizar sistemas auto-organizados para a obtenção de estruturas metálicas ou semicondutoras para estudo de SERS e de pontos quentes. Neste trabalho foram obtidas estruturas auto-organizadas de Au a partir de esferas de poliestireno e estruturas nano e microporosas de silício (estruturas de silício poroso). Além disso, podem ser utilizadas moléculas específicas como sondas para o estudo do efeito SERS e plasmas de superfície nestas estruturas metálicas e semicondutoras. As moléculas utilizadas neste trabalho foram o cristal violeta e a molécula de azul de metileno.

\subsection{Os sistemas auto-organizados}

Os sistemas auto-organizados têm sido utilizados com freqüência pela comunidade científica, pois são excelentes alternativas para a obtenção de nanomateriais aplicados à nanotecnologia. Por serem de baixo custo e de fácil implementação despertam ainda mais os interesses da comunidade científica. Os materiais obtidos através de técnicas de auto-organização são aplicados em diversos setores de pesquisa como na Engenharia de Materiais, na Engenharia Eletrônica, em especial na Microeletrônica e na Nanoeletrônica, e na Bioengenharia [71].

Sistemas auto-organizados de escala nanométrica datam do início da vida, mas somente nos últimos tempos tornou-se possível a arte de manipulação desta escala. A auto-organização de partículas pode ocorrer de duas maneiras distintas. Numa delas, os pedaços do sistema são formados separadamente e depois se juntam, e na outra, a síntese e a auto-organização ocorrem simultaneamente [72]. Os sistemas auto-organizados podem ser obtidos através de dispersões nas fases sólida, líquida ou gasosa, do emprego de deposição química ou física, além da integração de blocos formados através de reações químicas ou compactação física [73].

Para a formação dos sistemas auto-organizados é muito importante controlar as interfaces e a distribuição dos componentes nanométricos. As forças que originam a organização hierárquica durante o processo de organização são as interações 
moleculares, como por exemplo, as componentes hidrofílica e hidrofóbica, as forças de Van der Walls e de Coulomb, e as ligações de hidrogênio. Estas componentes forçam os nanocomponentes a se unirem ou se separarem em localizações bem específicas. As forças capilares e as tensões superficiais são também importantes precursoras da formação das estruturas auto-organizadas. Os sistemas autoorganizados podem ser obtidos de diversas maneiras, podendo-se obter monocamadas e multicamadas de sistemas auto-organizados de partículas.

A auto-organização de nanocomponentes pode ser realizada utilizando-se precursores nas fases sólida, líquida e gasosa; empregando-se deposições química ou física, reatividade química e compactação física para a obtenção de estruturas integradas dentro da estrutura final obtida. A maneira geralmente utilizada para se obter sistemas auto-organizados é o processo sol-gel, utilizando-se moldes [74]. Uma maneira de utilizar esta técnica é depositando-se esferas de certo polímero e depois infiltrando materiais poliméricos, cerâmicos ou metálicos nos interstícios das estruturas. Estes compostos combinam as melhores propriedades dos óxidos e polímeros e podem ser aplicados em lentes de contato, guias de onda, dispositivos de memória, filtros químicos, biosensores e no preenchimento dental [75]. Em alguns casos os surfactantes são utilizados para proporcionar diferentes condições de reação para a produção dos cristais [60].

Sistemas auto-organizados em monocamadas podem ser obtidos a partir de diferentes tipos de moléculas em diferentes substratos. Um exemplo é a autoorganização de moléculas $\mathrm{S}-\mathrm{H}$ (thiol) numa superfície de ouro (Au). Estas monocamadas moleculares podem ser quimicamente funcionalizadas através de reações promovidas após a auto-organização [76].

Mesoestruturas também são formadas a partir de processos de auto-organização. Estas estruturas apresentam dimensões que vão de poucos nanômetros a dezenas de nanômetros. Geralmente os compósitos mesoestruturados são obtidos por sistemas compostos por polímeros e cerâmicas, através da formação de moldes a partir de um processo sol-gel. Numa estrutura pré-estabelecida pode-se infiltrar materiais inorgânicos ou poliméricos. As moléculas orgânicas arranjam-se em estruturas ordenadas por meio da interação das forças intermoleculares (Van der 
Waals, componentes hidrofílica e hidrofóbica, etc). Ao mesmo tempo as partículas de óxido que são atraídas por partes específicas do material orgânico se arranjam nas redondezas. As razões e composições dos materiais orgânicos e inorgânicos podem ser variados para a formação de estruturas específicas [77].

Os surfactantes, compostos orgânicos que apresentam porções hidrofóbicas e hidrofílicas, têm sido utilizados para a formação de arranjos ordenados de mesofases orgânicas (esferas orgânicas) cuja matriz é preenchida por sílica polimerizada [78]. Blocos copoliméricos também estão sendo utilizados na obtenção de estruturas auto-organizadas [79]. A concentração dos componentes e a natureza específica em que os polímeros se atraem e repelem, determinam a geometria da estrutura enquanto que o peso molecular do polímero define o tamanho da estrutura. Uma estrutura formada por mesoporos é aquela que apresenta poros com tamanhos de 3 nanômetros a dezenas de nanômetros. Estruturas com poros menores que 3 nanômetros são chamadas de estruturas nanoporosas. As estruturas mesoporosas apresentam grande área superficial relativa ao volume. Sendo assim, as estruturas mesoporosas podem ser excelentes catalisadores, e ainda, há a possibilidade de se obter materiais para armazenamento de hidrogênio devido ao pequeno tamanho dos poros e pela possibilidade de controle do tamanho dos poros (reator de hidrogênio). Estas estruturas porosas podem ser aplicadas na fabricação de filtros de elevada seletividade e cristais fotônicos [80].

Os sistemas auto-organizados reportados neste trabalho são as estruturas de esferas de poliestireno funcionando como moldes de estruturas metálicas e as estruturas de silício poroso.

\subsubsection{As esferas de poliestireno e sua auto-organização.}

Os processos de auto-organização de esferas de poliestireno têm sido utilizados para a formação de estruturas periódicas e regulares bidimensionais e tridimensionais e baseia-se no princípio de auto-organização de partículas que envolvem forças hidrodinâmicas [81].

Uma das idéias para a formação de sistemas auto-organizados de poliestireno é utilizar uma suspensão de microesferas monodispersas que é aquecida para a 
evaporação do solvente e deposição do soluto (microesferas monodispersas) sobre um determinado substrato. As esferas são depositadas de forma regular formandose estruturas auto-organizadas. Estas estruturas auto-organizadas podem gerar cristais fotônicos bidimensionais (monocamada de esferas) ou tridimensionais (multicamada de esferas).

O que produz a organização hierárquica durante a auto-organização são as interações moleculares, incluindo as componentes hidrofílica e hidrofóbica, forças de Van der Walls, forças de Coulomb e as ligações de hidrogênio. As forças capilares e as tensões superficiais são as principais precursoras da formação das estruturas auto-organizadas [82].

Uma possível técnica de auto-organização de cristais coloidais reportada pela literatura baseia-se na utilização de substratos padronizados, ou seja, substratos que já apresentam os padrões do tipo de estrutura geométrica que se deseja obter com as esferas em dispersão [82].

Os sistemas auto-organizados podem ser obtidos através da ação de forças gravitacionais, forças de convecção e forças eletro-hidrodinâmicas. Durante a formação destes sistemas há o aparecimento de defeitos na rede que podem ser deslocações, defeitos em linha, vacâncias, etc [83].

A dimensão e geometria dos sistemas auto-organizados obtidos por suspensão podem ser variadas com o uso de dispersões compostas por dois tipos de esferas. Geralmente utilizam-se compostos mesoestruturados (sistema de polímeros e cerâmica) em um processo sol-gel. Estas suspensões compostas por mais de um tipo de esfera têm o objetivo de formar estruturas com poros de paredes cerâmicas [75] ou metálicas [84] através da eliminação das esferas poliméricas que servem como um tipo de mascaramento para a formação do sistema. As esferas poliméricas podem ser removidas através de processos químicos ou térmicos. Existem casos em que são utilizados dois tipos de esferas poliméricas de diferentes dimensões que se diferenciam em sua estabilidade relativa para a obtenção de poros por estruturas auto-organizadas [85]. 


\subsubsection{O silício poroso}

O silício poroso (PS) constitui uma classe de material que exibe diversas propriedades ópticas. Este material é relativamente fácil de fabricar, no entanto mecanicamente frágil e complexo [86]. A distribuição, tamanho e arranjo dos poros definem as características ópticas do cristal fotônico bidimensional.

Filmes de PS não se constituem num material novo, pois sua obtenção já foi relatada na década de 50. Mas, a partir dos anos 90, nota-se um interesse marcante da comunidade científica em estudar as propriedades deste material, principalmente suas propriedades ópticas.

A obtenção do filme de PS é feita através de um processo de anodização eletroquímica das lâminas de silício em uma solução eletrolítica de ácido fluorídrico (HF) concentrado, porém, o controle das suas características estruturais resulta complexo. Basicamente, a estrutura dos filmes de PS é controlada através da densidade de corrente de anodização, da concentração do eletrólito e da condutividade da lâmina de silício [86].

Um número significativo de modificações tem sido introduzido no processo convencional da obtenção dos filmes de PS, com a finalidade de melhorar e controlar a qualidade e as propriedades desses filmes [87]. Por exemplo, Doant e seus colaboradores formaram camadas de PS assistidas por luz com a finalidade de provocar o deslocamento da banda de emissão pra uma faixa de energia que vai do vermelho ao azul. Theib e seus colaboradores [88] formaram estruturas de PS do tipo multicamadas, variando-se periodicamente a densidade de corrente de anodização.

A atenção primária da comunidade científica foi concentrar seus esforços na possibilidade de aplicação deste material em dispositivos ópticos, como guias de onda, moduladores, detectores de luz e diodos emissores de luz [89].

Para a formação do PS pode-se utilizar lâminas tipo $P$ e tipo N. Sabendo-se que a formação do PS necessita da existência de lacunas, o Si tipo $P$ apresenta formação de PS em todas suas regiões. Quando se necessita formar poros em regiões bem 
específicas, utilizamos o Si tipo N. A presença de lacunas permite a dissolução do silício no eletrólito. Sendo os elétrons as cargas majoritárias do Si tipo N, iluminandose as costas da lâmina com energia suficiente (energia acima do band gap), pares elétron-lacuna podem ser gerados por um processo de absorção de fótons. As lacunas geradas por energia luminosa são atraídas eletricamente para regiões de alto campo elétrico, causando a rápida dissolução nestas regiões. Inicialmente, o campo elétrico tenderá a concentrar-se nas descontinuidades da superfície da lâmina. Defeitos nas superfícies atuam como pontos iniciais para a formação dos poros. Definindo-se os defeitos na superfície, determinam-se onde os poros serão propagados. Para esta definição de defeitos, utiliza-se a corrosão por $\mathrm{KOH}$, pois este reagente permite uma corrosão anisotrópica, dando um perfil piramidal na região onde os poros serão formados.

\subsection{O silício, o silício poroso e suas diversas possibilidades de aplicações}

O silício poroso (PS) apresenta diversas aplicações tanto em sistemas ópticos como em sensores porque apresenta diversas propriedades ópticas (moduláveis) e uma enorme área específica da ordem de $600 \mathrm{~m}^{2} / \mathrm{cm}^{3}$ [90]. O silício em si apresenta uma grande vantagem, pois apresenta uma grande importância na indústria de semicondutores e, portanto é muito importante na fabricação de computadores e dispositivos microeletrônicos diversos. Devido às propriedades ópticas moduláveis do silício poroso, seu uso seria interessante para a obtenção de circuitos híbridos eletrônicos e ópticos na tecnologia do silício.

Para a indústria da eletrônica, o silício representa o mesmo papel que o ferro para a indústria mecânica. Suas propriedades mecânicas e eletrônicas são as ideais para aplicação em dispositivos, é barato e abundante na natureza e pode ser manufaturado de diversas maneiras (fisicamente ou eletroquimicamente). A tecnologia para seu uso nos dispositivos eletrônicos é altamente desenvolvida e acumula décadas de experiência. Por outro lado, a fotônica tem um extraordinário potencial de utilização na eletrônica, mais especificamente na transmissão de dados em altas taxas. Portanto, é altamente desejável integrar ambas as tecnologias. E a melhor forma de alcançar este objetivo é fabricar um laser que use o silício como meio. O problema é que a capacidade de emissão de fótons do silício é tão baixa 
que faz dele um dos materiais menos indicados para este fim. É neste cenário que entra a importância do efeito Raman.

\subsubsection{O silício e os efeitos Raman Espontâneo e Raman Estimulado}

Chandrasekhara Venkata Raman (C. V. Raman) foi um cientista indiano nascido em 1888 na cidade de Trichi, no Sul da Índia. Em 1902, com apenas 14 anos, graduouse em primeiro lugar no curso de Física. Concluiu o mestrado em 1907 e, quinze anos depois, publicou o trabalho "Difração molecular da luz", o primeiro de uma série que o levou, em 1928, a descobrir um interessante efeito espalhamento da luz ao atravessar materiais transparentes que tomou seu nome ("Efeito Raman") e Ihe valeu o Premio Nobel de Física em 1930.

Como anteriormente descrito, o espalhamento Raman é um processo inelástico onde a luz incidente interage com a as moléculas ou a rede do cristal, perdendo energia neste processo sendo assim detectado um feixe de luz com energia menor (ou maior) que a luz incidente, para um processo Stokes (ou anti-Stokes). A energia perdida pela luz durante este processo origina a criação de fônons correspondente aos modos normais de vibração das moléculas ou rede do cristal. Este processo foi descrito anteriormente como um fenômeno clássico associado à oscilação de um dipolo induzido na molécula ou rede cristalina representado pelo vetor de polarização induzido. No entanto, este modelamento apresenta severas restrições principalmente em eventos ressonantes e de intensificação. Nesse sentido, o modelamento quântico resulta mais adequado nestes casos.

O efeito Raman pode ser descrito utilizando-se os níveis quânticos de energia dos estados eletrônicos associados aos modos vibracionais da molécula como mostra a Figura 2.1. Na Figura 2.1, $\mathrm{E}_{0}$ corresponde ao nível eletrônico associado ao estado fundamental do modo vibracional da molécula e $E_{1}$ corresponde ao nível eletrônico associado ao modo vibracional excitado da molécula. 


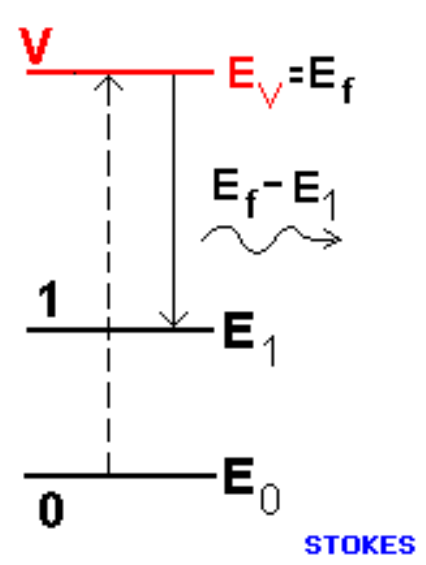

(a)

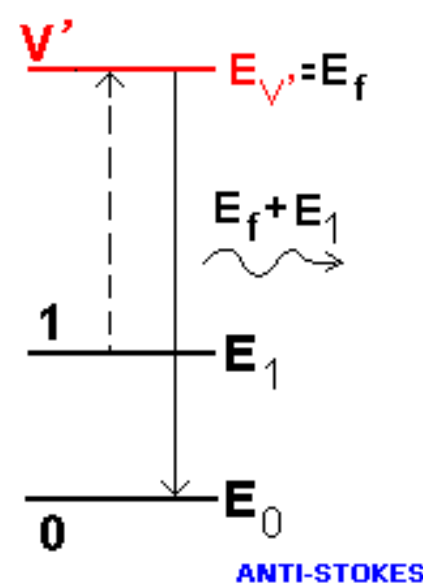

(b)

Figura 2.1 Transferência de energia entre fóton e molécula. (a) Processo Stokes e (b) Processo anti-Stokes.

Considerando-se uma molécula no nível eletrônico fundamental (0) com energia $E_{0}$ correspondente ao seu estado fundamental do modo vibracional, esta pode sofrer interação de um fóton incidente com energia $E_{v}-E_{0}$, passando, desta forma, para um estado virtual (V) (intermediário) de energia $E_{V}$ que não necessita ser o estado estacionário da molécula, e decai em seguida para um estado eletrônico excitado (1) com energia $E_{1}$, tendo-se um fóton espalhado com energia $E_{V}-E_{1}$. Este processo onde o fóton espalhado apresenta energia $\left(E_{V}-E_{1}\right)$ menor que o fóton incidente é chamado de espalhamento Stokes (Figura 2.1(a)). No espalhamento anti-Stokes, um fóton com energia $E_{V},-E_{1}$ incide na molécula que se apresenta no nível eletrônico excitado (1) com energia $E_{1}$ associada ao seu modo vibracional. Com esta energia incidente ( $E_{V}$ ' - $\left.E_{1}\right)$, a molécula eleva-se a um nível eletrônico virtual (V') com energia $E_{V}$, e decai em seguida para o nível eletrônico fundamental $(0)$ de energia $E_{0}$, resultando um fóton espalhado com energia $E_{V}{ }^{\prime}+E_{1}$. Neste caso, o fóton espalhado apresenta energia $\left(E_{V+}+E_{1}\right)$ maior que o fóton incidente (Figura 2.1(b)). Estes espalhamentos Stokes e anti-Stokes descrevem o espalhamento Raman espontâneo. É importante mencionar que se $E_{v}$ corresponde ao um nível eletrônico da molécula, o espalhamento denomina-se Raman ressonante que normalmente é varias ordens de grandeza maior que o espalhamento Raman simples.

A intensidade da luz espalhada depende da existência dos níveis $E_{i}$ excitados vibracionalmente e que por conseqüência depende dos vários modos vibracionais da 
molécula ou rede de cristal. No caso do silício, existem vários modos vibracionais sendo o mais importante o modo óptico longitudinal que espectralmente está situado em $520 \mathrm{~cm}^{-1}$. Para este modo, a eficiência de espalhamento Raman espontâneo é determinada através de seguinte expressão [91]:

$$
S=A \sum_{l=1}^{3}\left[\hat{e}_{i} \cdot \stackrel{\leftrightarrow}{R}^{l} \cdot \hat{e}_{S}\right]^{2}
$$

onde os tensores $\vec{R}^{l}$ representam os três estados degenerados do modo vibracional óptico da rede de silício que possui a simetria do diamante. No sistema de coordenadas dos vetores de translação da rede cristalina primitiva (cúbica), os tensores $\vec{R}^{l}$ são dados por

$$
\left[\begin{array}{lll} 
& 1 \\
1 & & \\
& &
\end{array}\right] \quad\left[\begin{array}{ll} 
& 1 \\
1 &
\end{array}\right] \quad\left[\begin{array}{lll} 
& & \\
& & 1 \\
1 &
\end{array}\right] \text {. }
$$

Os vetores $\hat{e}_{i}$ e ês representam respectivamente a polarização e o espalhamento da radiação incidente. É evidente que $S$ tem uma forte dependência em relação à geometria de espalhamento e à orientação cristalográfica da amostra. $O$ parâmetro A tem as mesmas dimensões da eficiência de espalhamento $S\left(\mathrm{~cm}^{-1} . \mathrm{sr}^{-1}\right)$, mas não apresenta dependência angular e assim pode ser utilizada totalmente para caracterizar a intensificação Raman. O valor de A para o silício, avaliado experimentalmente segundo reportado pela literatura, foi da ordem de $3,05.10^{-8} \mathrm{~cm}^{-}$ ${ }^{1} \mathrm{sr}^{-1}[92]$.

O espalhamento Raman estimulado é um efeito não linear que pode limitar a performance de sistemas de comunicações ópticas. Porém este mesmo efeito pode ser aplicado para a amplificação do sinal óptico no meio. Ao incidir luz através de um material sempre acontece o efeito Raman, porém em níveis muito baixos. Aplicandose uma densidade de potência relativamente alta em um meio por uma longa distância estes efeitos podem ser mais facilmente observados. Se a interação ocorrer espontaneamente, a luz emitida é incoerente e segue para direções aleatórias. Na presença de uma densidade de potência alta, ou seja, um campo intenso, as emissões são coerentes levando-se à possibilidade de amplificação de um sinal que passa por uma fibra, por exemplo. Uma vez que o campo estimulado aparecer, ele irá crescer exponencialmente até a estimulação de ganho da fonte ser 
saturada. Assim ele pode transferir energia do comprimento de onda do bombeio para incrementar mais fótons nos outros comprimentos de onda maiores.

Para o Raman estimulado, um feixe de luz de energia $E_{v^{-}} E_{0}$ excita elétrons do nível $E_{0}$ para o nível $E_{v}$. Se a concentração de elétrons no nível $E_{v}$ é maior que no nível $E_{0}$, então teremos um estado com inversão de população que junto a outro feixe incidente com energia igual a $E_{v}-E_{1}$ promoverá a geração de outros fótons com esta energia devido à recombinação $E_{v} \rightarrow E_{1}$, amplificando desta forma a intensidade do feixe de energia $E_{v}-E_{1}$ devido ao efeito de Raman estimulado (Figura 2.2).

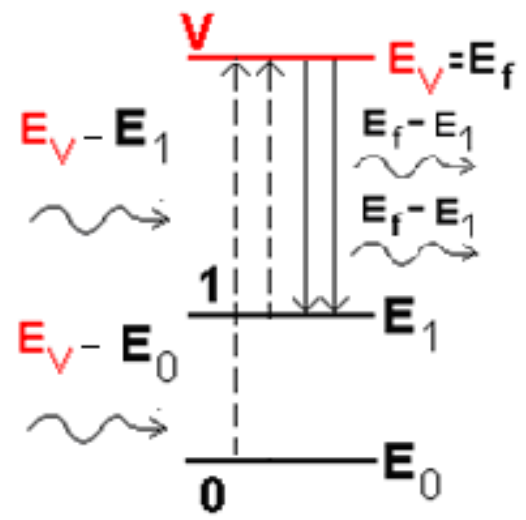

Figura 2.2 Transferência de energia entre fóton e molécula. Processo de espalhamento Raman estimulado.

O coeficiente de Raman Estimulado para o silício pode ser obtido a partir de um cálculo baseado na eficiência de espalhamento espontâneo e sua largura de linha. A relação entre o coeficiente de Raman Estimulado $(\gamma)$ e o coeficiente de Raman Espontâneo (S) é dada por [93]:

$$
\gamma=\frac{8 \pi^{2} c^{2}}{\hbar \omega_{S}^{3}} \frac{S}{n_{S}^{2}\left(N_{0}+1\right) \Gamma}
$$

sendo $\gamma=\frac{g_{S}}{I}$ o ganho Stokes estimulado por unidade de intensidade bombeada, $\omega_{S}$ é a freqüência angular da emissão Stokes, $\mathrm{n}_{\mathrm{S}}$ é o índice de refração no comprimento de onda Stokes (dado por 3,56), $\mathrm{N}_{0}$ o fator de Bose (desprezível a temperatura de 77K), Гé largura a meia altura do máximo da banda Stokes espontânea que é dada em unidades de freqüência angular e $S$ é a eficiência do 
espalhamento espontâneo e é dependente da orientação cristalográfica. O ganho estimulado $(\gamma)$ é obtido da potência incidente multiplicada pela intensidade relativa do Stokes. Chandrasekharan [94] mostrou que o espalhamento Raman é maximizado para cristais cúbicos ao longo da direção [111]. Para um cristal bem orientado, tem-se $\mathrm{S}=0,83 \mathrm{~A}(\mathrm{Si}, 1,06 \mu \mathrm{m})$, com incidência de luz não polarizada no plano da polarização da radiação Stokes e considerando-se $\Gamma=0,8 \mathrm{~cm}^{-1}$ a $77 \mathrm{~K}$, Ralston obteve $\gamma=0,19 \mathrm{~cm} / \mathrm{MW}$. Este resultado equivale a quase uma ordem de grandeza maior que o coeficiente de ganho calculado para $\mathrm{Li}_{6} \mathrm{NbO}_{3}$ por Johnston e seus colaboradores [95]. No entanto, resultados experimentais reportados em [91] mostraram que o valor calculado de $\gamma$ resultou sendo mais elevado que ao determinado experimentalmente. Esta discrepância de valores foi atribuída à participação de outros efeitos não lineares relacionados à absorção de dois fótons que naturalmente promovem o crescimento de elétrons livres na banda de condução do silício. Estes elétrons livres absorvem a luz originada no Raman estimulado promovendo um decrescimento da sua intensidade. Outro efeito que potencialmente pode provocar este decrescimento de $I_{\text {stokes }}$ está relacionado ao efeito de espalhamento Brillouin estimulado principalmente quando a intensidade do feixe de bombeamento é elevada [96]. Quando tratamos do espalhamento Raman, a mudança de direção dos fótons varia de acordo com as moléculas da substância atravessada pelo feixe de luz e sua intensidade é proporcional ao número de moléculas no caminho do raio luminoso (o que permite que o efeito Raman seja usado para efetuar análises qualitativas e quantitativas de substâncias). Ou seja, cada material tem uma diferente capacidade de gerar o efeito Raman quando atravessado por um feixe de luz (Figura 2.3).

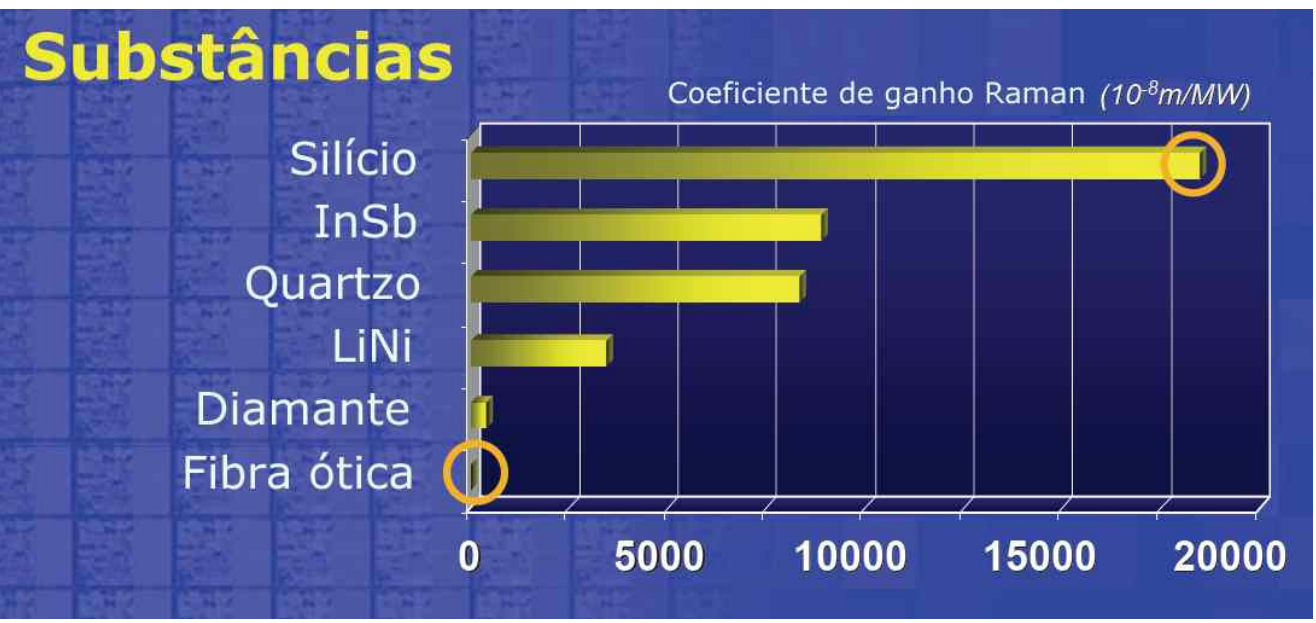

Figura 2.3 Capacidades de diferentes materiais para gerar Efeito Raman. 
Embora sendo uma das substâncias menos indicadas para gerar um feixe de raio laser comum, o silício é uma das mais apropriadas para produzir Raman estimulado podendo ser aplicado na fabricação de um Laser de Raman estimulado. O ganho de um dispositivo Laser de Raman estimulado depende diretamente da eficiência de espalhamento Raman espontâneo (como descrito acima) que no caso do silício é elevado como mostra a Figura 2.3. O efeito Raman se manifesta nele com uma potência dez mil vezes maior que na fibra óptica. Isso permite que o efeito de Raman estimulado seja extremamente amplificado em percursos da ordem de centímetros no interior do silício, uma amplificação que exigiria quilômetros de percurso em filetes de fibra óptica. Essa amplificação denomina-se espalhamento Raman estimulado (ou "Stimulated Raman Scattering", ou ainda SMS). Assim, se injetarmos um feixe luminoso em um filete de silício, este feixe funcionará como "bomba de energia", ou fonte de energia luminosa (fótons) que, devido ao espalhamento provocado pelo efeito Raman, será altamente amplificada. O resultado será semelhante ao exibido na Figura 2.4, onde o efeito de espalhamento de Raman estimulado provoca significativa amplificação do feixe de luz incidente. Combinandose a amplificação obtida através do espalhamento de Raman estimulado, resultarse-á em uma amplificação da luz que junto a uma cavidade ressonante resultarão em um dispositivo laser de silício. A cavidade ressoante estará constituída de dois espelhos semitransparentes de tal forma a permitir a passagem e reflexão do feixe incidente e gerado for efeito Raman. O dispositivo teoricamente capaz de gerar este raio laser de silício seria semelhante ao mostrado na Figura 2.5.

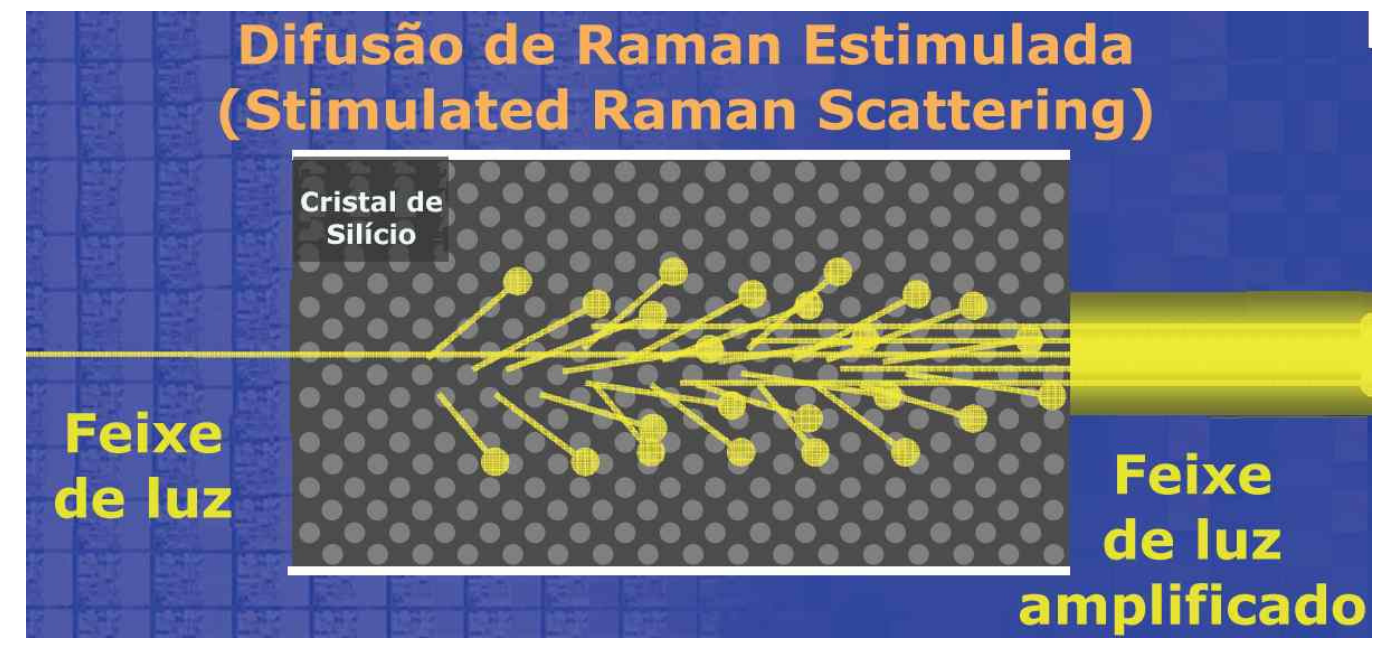

Figura 2.4 Geração de Raman estimulada (SRS). 


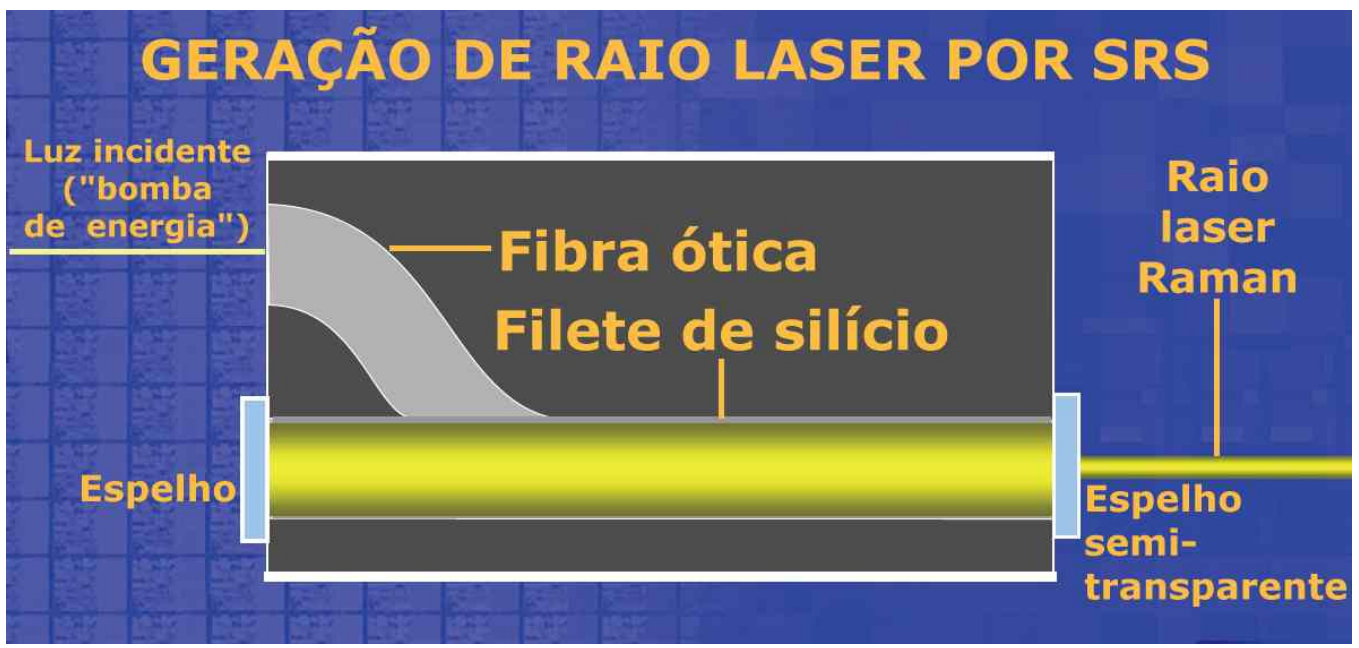

Figura 2.5 Geração de raio laser por SRS.

Neste sentido, o raio laser que emerge através do espelho semitransparente é o resultado da imensa amplificação que o feixe de luz sofre ao ser refletido sucessivamente de um espelho a outro. Os feixes refletidos vão se somando aos novos feixes gerados pelo efeito Raman estimulado. Se a amplificação da energia luminosa não atingir o nível necessário para transpor o espelho semitransparente, não haverá formação de feixe laser. Nesse caso, como a energia amplificada é proporcional à energia "bombeada" para o interior do meio, para chegar ao nível necessário para gerar o laser, basta aumentar a potência do feixe incidente, ou seja, "bombear" mais energia. No caso do silício, o ganho Laser começa a satura-se à medida que a intensidade de bombeamento cresce devido a um efeito não linear que promove transições inter-banda por absorção de dois fótons. A Figura 2.6 mostra a variação da energia amplificada pelo efeito Raman no interior de um filete de silício em função da energia fornecida pelo raio incidente. 


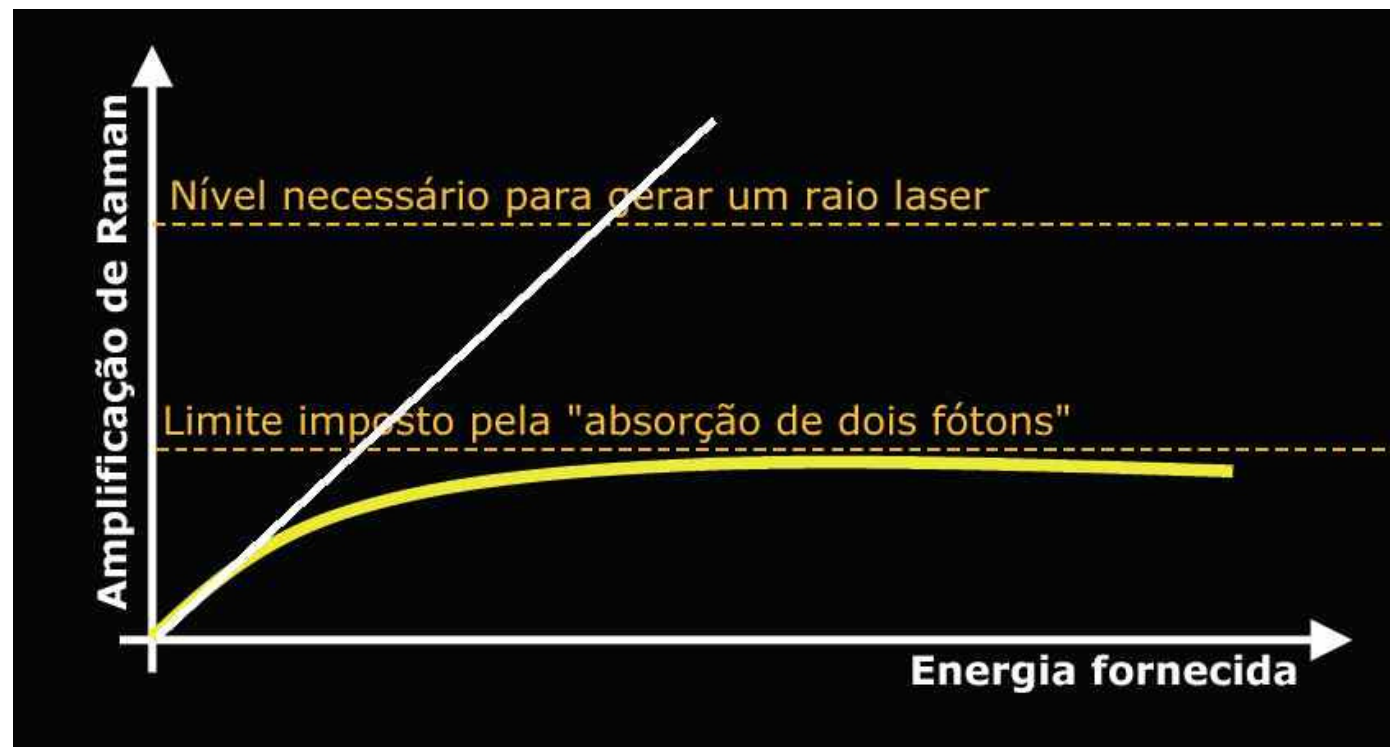

Figura 2.6 Curva que mostra o Limite imposto pelo fenômeno "absorção de dois fótons".

O esperado seria que esta variação fosse expressa pela linha branca na qual a energia amplificada aumenta proporcionalmente com a energia fornecida, ou seja, quanto maior a potência do feixe incidente, maior a potência da energia amplificada. Se fosse assim, ela atingiria facilmente o nível necessário para gerar um raio laser, mostrado pela linha pontilhada superior. Infelizmente não era isso que ocorria na prática. Ao invés disso, o crescimento da amplificação de Raman seguia a tendência exibida pela linha amarela: crescia proporcionalmente à energia fornecida apenas no início. Depois, o aumento se tornava cada vez menor, até um ponto onde a linha se tornava horizontal, atingindo um limite acima do qual, por mais que se aumentasse a energia fornecida, não havia aumento da amplificação de Raman. E como esse limiar se situava muito abaixo do nível de energia necessário para gerar um raio laser, não se conseguia produzir o tão desejado laser de silício. Este comportamento como descrito anteriormente acontecia devido ao efeito de absorção de dois fótons gerando portadores livres em excesso que comprometem a eficiência do Raman estimulado, promovendo-se a absorção de fótons por estes portadores.

Depois de identificado o problema a solução ficou fácil. Se o que absorve os fótons são os elétrons liberados no meio, para impedir a absorção de fótons basta remover os elétrons. Para remover os elétrons os pesquisadores adotaram uma técnica bastante simples: estenderam de cada lado do filete de silício, duas canaletas 
preenchidas com silício ao qual se adicionaram impurezas que tornaram o silício de uma delas do tipo "N" (onde "sobram" elétrons) e da outra do tipo "P" (onde sobram "lacunas" receptoras de elétrons). Em seguida, conectaram essas canaletas a uma fonte de alimentação elétrica de corrente contínua de tal modo que o pólo negativo fosse ligado à canaleta de silício tipo "P" e o positivo à canaleta de silício tipo "N" (polarização reversa). O resultado é o exibido esquematicamente na Figura 2.7: os elétrons livres são removidos do filete de silício porque são atraídos para a canaleta ligada ao pólo positivo da fonte [97].

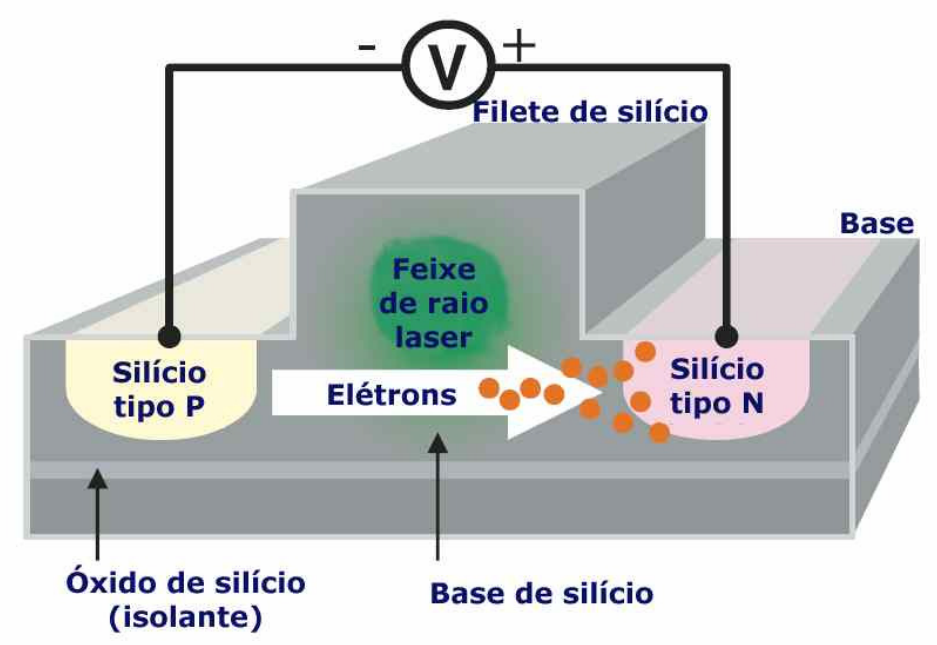

Figura 2.7 Processo de remoção de elétrons livres.

Sendo assim, os lasers de silício poderão ter diversas aplicações. Evidentemente as primeiras aplicações práticas visarão substituir os caros e delicados dispositivos ópticos utilizados atualmente na transmissão de dados. Em seu lugar serão usados componentes de fins similares empregando a fotônica do silício. O que já bastaria para justificar as pesquisas. E a razão é simples: usar silício como meio óptico permite integrar, nos mesmos circuitos eletrônicos, fabricados com a mesma tecnologia de fabricação, dispositivos ópticos e semicondutores comuns. Diversificar a tecnologia é algo também bastante importante, e a idéia de se utilizar as estruturas de silício poroso para amplificar o sinal Raman é interessante, pois o processo de obtenção do silício poroso é bastante simples e barato. Nas estruturas metálicas, o efeito Raman já é bem estudado, mas tem sido estudado em outros materiais como em semicondutores e pode-se também procurar estudar em algumas estruturas isolantes como, por exemplo, o óxido de alumínio poroso (alumina porosa). 
O dispositivo Laser baseado no Raman estimulado em silício depende diretamente da seção transversal de espalhamento de Raman espontâneo. Neste sentido, no presente trabalho foram desenvolvidas nanoestruturas de silício que intensificam a secção transversal de espalhamento em até duas ordens de grandeza em relação a substratos normais de silício. 


\section{CAPÍTULO III}

\section{OBJETIVOS}

O objetivo principal do presente trabalho é a obtenção de nanoestruturas metálicas e de silício para a intensificação de campo próximo denominada de pontos quentes ("hot spots"). Os pontos quentes são efeitos eletromagnéticos de fundamental importância nas possíveis aplicações das nanoestruturas metálicas em sensores de elevada sensibilidade, podendo detectar apenas uma única molécula. A intensificação de campo próximo em semicondutores, principalmente no silício, poderá servir para aperfeiçoar efeitos de emissão de Raman estimulado em dispositivos de emissão laser em silício. Para tal fim foram utilizados processos de fabricação de sistemas auto-organizados metálicos de Au e formação de estruturas porosas de silício (silício poroso).

A partir da obtenção de estruturas auto-organizadas de ouro e da absorção de moléculas de prova (sondas) na superfície destas estruturas, foi possível avaliar o efeito de intensificação de campo próximo através da monitoração do efeito SERS.

Adicionalmente, a partir da tecnologia de silício poroso, foram obtidas estruturas nanoporosas e microporosas de silício para serem utilizadas em nanoestruturas geradoras de pontos quentes. A contribuição relevante da intensificação de campo próximo em silício deve-se à totalidade de nanoestruturas geradoras de campo próximo intenso terem sido obtidas até hoje em materiais metálicos, e adicionalmente, este efeito no silício permitirá a fabricação de dispositivos de emissão laser de silício, sendo que a emissão laser em silício é baseada na amplificação do sinal através da emissão de Raman estimulado do silício. Similarmente às estruturas metálicas, moléculas de prova foram adsorvidas nas estruturas de silício para monitorar o efeito SERS destas estruturas. É importante mencionar que este fenômeno ainda não havia sido reportado pela literatura, pois só havia sido reportado o efeito SERS em estruturas metálicas.

Sendo assim, os objetivos alcançados geraram publicações em revistas indexadas. Os resultados obtidos a respeito do efeito de intensificação de campo próximo em 
estruturas organizadas de ouro $(\mathrm{Au})$ com moléculas de cristal violeta adsorvidas foram publicados em um artigo intitulado "Regular ordered gold metallic array and Raman scattering intensification" na revista "Physica Status Solidi A" [Phys. Stat. Sol. (a) 204, n 4, 973-978 (2007)], o que mostrou a relevância e a contribuição científica destes resultados. Adicionalmente, quanto aos resultados obtidos a respeito do efeito SERS no silício, não reportado anteriormente pela literatura, o artigo intitulado "Surface enhancement Raman scattering and photoluminescence intensification of methylene blue adsorbed on the silicon surface" foi aceito para publicação na revista "Brazilian Journal of Physics", sendo que a data de publicação está no aguardo e não foi comunicada até o momento. 


\section{CAPÍTULO IV}

\section{JUSTIFICATIVAS}

A nanotecnologia é uma área de grande interesse da comunidade científica atual e apresenta-se como uma das áreas mais promissoras ao desenvolvimento da ciência e da tecnologia. O estudo de novos materiais na área de microeletrônica para aplicação em sensoriamento e aplicações em dispositivos ópticos é de grande interesse para o desenvolvimento tecnológico e o conhecimento e desenvolvimento de determinadas técnicas.

Dentro do campo da nanotecnologia aplicada à fabricação de dispositivos da tecnologia de silício, existem diversos processos envolvidos na fabricação de nanoestruturas, mas muitos deles são muito custosos e exigem alta infraestrutura. A utilização de sistemas auto-organizados e processos eletroquímicos para a fabricação de nanoestruturas podem resolver o problema de alta resolução e ainda são processos que não exigem grande infraestrutura e são relativamente simples de serem realizados.

Fabricar nanostruturas em silício é de grande interesse para a ciência e a tecnologia porque existe a grande possibilidade da integração de diversos tipos de dispositivos, sendo possível fabricarem sistemas híbridos para diversas aplicações tecnológicas. A possibilidade da alta densidade de integração óptica com dispositivos de dimensões nanométricas leva a comunidade científica a desenvolver diversas pesquisas para estudo de dispositivos ópticos. Por exemplo, os dispositivos lasers têm diversas aplicações na indústria e na ciência, principalmente na área de comunicações e processamento de sinais.

A tecnologia de silício e, em especial, a tecnologia de silício poroso, é uma tecnologia muito promissora para a fabricação de dispositivos lasers já que com o material semicondutor, devido sua propriedade de espalhamento Raman, é possível ter a geração de um Raman estimulado para ser utilizado num laser de silício. A partir de estruturas de silício poroso e de estruturas metálicas organizadas obtidas por moldes de esferas de poliestireno pode-se atribuir certas características às 
superfícies do material como o espalhamento Raman na superfície a ser utilizado para sensores moleculares. Os efeitos SERS e pontos quentes ("hot spots") são importantes porque juntos possibilitam a obtenção de SERS de uma única molécula, sendo que esta característica pode ser utilizada para a obtenção de sensores de moléculas ou átomos.

Sendo assim, o desenvolvimento e estudos de novos materiais, especialmente aqueles com propriedades moduláveis é uma área de pesquisa que vem recentemente crescendo intensamente e a caracterização de sistemas por SERS ganha relevância ao permitir estudo das interações ópticas e químicas dos diversos materiais.

Desde a construção do primeiro feixe laser, em 1960 - construído a partir de um rubi - os cientistas conseguiram construir lasers de inúmeros materiais, do neon até a safira. O silício, entretanto, nunca foi considerado um candidato viável, já que sua estrutura apresenta uma banda proibida indireta sendo um fator limitante para fazer com que esse elemento semicondutor emita luz. Mas alterando-se e modulando-se a estrutura original do silício a partir de processos físicos como, por exemplo, implantação iônica de hidrogênio $\left(\mathrm{H}^{+}\right)$; e a partir de processos eletroquímicos como, por exemplo, utilizando anodização eletroquímica do silício para a produção do silício poroso, é possível alterar as propriedades do silício a fim de abrir ainda mais o leque de aplicações ópticas deste material.

Então, um material com as propriedades eletrônicas do silício e as propriedades ópticas de um laser deverá ter inúmeras aplicações, tanto na indústria eletrônica quanto na de telecomunicações, ajudando na construção de computadores mais potentes e redes de fibras ópticas mais rápidas. 


\section{CAPÍTULO $v$}

\section{PROCEDIMENTOS EXPERIMENTAIS}

Os procedimentos para a obtenção das estruturas de silício poroso (PS), das estruturas de esferas de poliestireno auto-organizadas (EP) e das estruturas metálicas organizadas (EMO) são apresentados detalhadamente neste capítulo, juntamente com os procedimentos de caracterização óptica e morfológica das estruturas obtidas.

\subsection{Obtenção de estruturas de silício poroso (PS)}

O processo de obtenção de silício poroso (PS) que foi utilizado consiste na anodização de lâminas de silício do tipo P com resistividade de 10-20 $\Omega . c m$.

Para a formação do silício poroso, primeiramente as lâminas de silício foram limpas utilizando-se a limpeza convencional da microeletrônica (limpeza completa) que segue o seguinte roteiro:

- 15 minutos em $\mathrm{H}_{2} \mathrm{SO}_{4}: \mathrm{H}_{2} \mathrm{O}_{2}(3: 1)$ a $105^{\circ} \mathrm{C}$;

- 10 minutos em água deionizada;

- 5 minutos em cascatinha

- 15 minutos em $\mathrm{H}_{2} \mathrm{O}: \mathrm{NH}_{4} \mathrm{OH}: \mathrm{H}_{2} \mathrm{O}_{2}(5: 1: 1)$ a $75^{\circ} \mathrm{C}$;

- 10 minutos em água deionizada;

- 5 minutos em cascatinha

Em seguida, as lâminas foram metalizadas nas costas utilizando-se a técnica de vaporização por filamento incandescente em vácuo a $4 \times 10^{-6}$ Torr. A pureza do alumínio depositado é de $99,999 \%$ e a espessura depositada é de aproximadamente $500 \mathrm{~nm}$. Após o processo de metalização, as lâminas foram submetidas a um processo de recozimento térmico a $450^{\circ} \mathrm{C}$ em ambiente de Nitrogênio $\left(N_{2}\right)$ durante 30 minutos, para promover a formação da liga alumínio-silício (Al-Si) e assim garantir um bom contato ôhmico.

Após a realização do recozimento térmico, as lâminas foram submetidas a uma limpeza de desengorduramento utilizando-se tricloroetileno, acetona e isopropanol 
ferventes, nesta ordem, por 10 minutos cada, com o propósito de remover resíduos superficiais e garantir a fabricação de filmes de PS de boa qualidade.

Após a limpeza de desengordurameto as lâminas estão prontas para serem processadas a fim de obter as estruturas de silício poroso através do processo de anodização. Para a formação do silício poroso a lâmina de silício cristalino (c-Si) é colocada na célula eletrolítica de teflon contendo a solução eletrolítica de $\mathrm{HF}$ :solvente, cujo solvente pode ser etanol, metanol, dimetilformamida (DMF), água ou uma mistura de alguns destes componentes. O esquema da célula eletrolítica utilizada é mostrado na Figura 5.1. Em seguida, polariza-se anodicamente o c-Si em condição galvanostática. Para tal fim foi utilizada a fonte corrente contínua Keithley 236 modulável na faixa entre $0-100 \mathrm{~mA}(0-110 \mathrm{~V})$ controlada por um computador através do software "Labview". Um fio ou placa de platina foi utilizado como contraeletrodo, sendo a lâmina de silício o eletrodo de trabalho. Durante o processo de anodização agitou-se o eletrólito utilizando-se um agitador mecânico de teflon com a finalidade de eliminar as bolhas de hidrogênio da interface Si/Solução eletrolítica. Este processo permite obter estruturas porosas mais homogêneas. Após a formação do filme de PS a amostra é enxaguada em água DI durante 10 minutos com a finalidade de eliminar resíduos de HF. O processo de secagem é realizado primeiramente com um tratamento em etanol durante 5 minutos com a finalidade de remover as moléculas de água do interior dos poros. Em seguida, é realizado um tratamento em pentano durante 5 minutos com a finalidade de remover os resíduos de etanol, evitando desta forma, mudanças abruptas da tensão superficial nos poros, o que promoveria a quebra do filme de PS. Finalmente, a amostra é seca utilizandose num jato suave de nitrogênio. Sendo assim, resumidamente, o pós-tratamento das amostras de PS é realizado através da seguinte seqüência
a) 10 minutos na cascatinha com $\mathrm{H}_{2} \mathrm{O}$
b) 5 minutos em etanol
c) 5 minutos em pentano
d) Secagem com jato suave de nitrogênio 


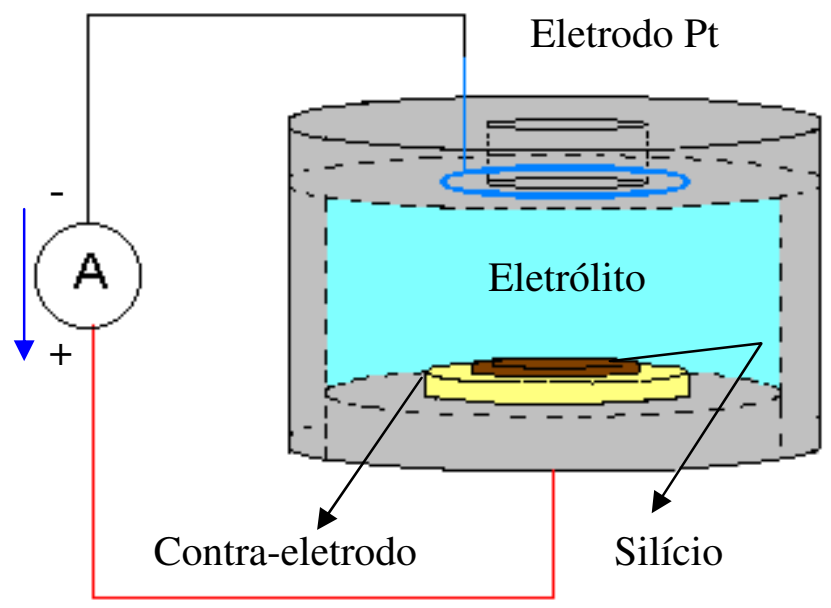

Figura 5.1 Esquema da célula eletrolítica utilizada para a formação do PS a partir do processo de anodização eletroquímica das lâminas de silício.

Algumas estruturas de silício poroso foram obtidas utilizando-se lâminas de silício tipo $\mathrm{P}$, que após passarem pelos processos de limpeza convencional da microeletrônica, metalização, recozimento térmico e limpeza de desengorduramento, e antes de serem anodizadas para a formação do silício poroso, passaram por um processo de implantação iônica de hidrogênio $\mathrm{H}^{+}$na superfície. A dose utilizada no processo de implantação iônica foi de $1 \mathrm{E} 16 \mathrm{H}^{+} / \mathrm{cm}^{2}$ e a energia utilizada foi de 50 $\mathrm{KeV}$. Algumas lâminas foram recozidas termicamente após a implantação, para garantir o aprisionamento dos íons $\mathrm{H}^{+}$. Lâminas com íons $\mathrm{H}^{+}$implantados foram utilizadas para a obtenção de silício poroso, sendo que algumas foram recozidas e outras não, após o processo de implantação iônica. O processo de secagem realizado após a obtenção das estruturas de silício poroso foi realizado da mesma forma que nas estruturas sem $\mathrm{H}^{+}$implantado.

\subsection{Obtenção de estruturas metálicas organizadas (EMO) a partir de monocamadas de esferas de poliestireno}

Para a fabricação de estruturas metálicas organizadas foi utilizada uma monodispersão de esferas de poliestireno de concentração $0.22 \%$ em peso (wt\%), cujas esferas apresentavam diâmetro de $(660 \pm 3 \%) \mathrm{nm}$. Estas esferas de poliestireno serviram de molde para a fabricação de máscaras metálicas com padrões organizados. Então, para a deposição das esferas foram utilizados os seguintes parâmetros: 
- Temperatura de deposição: $50^{\circ} \mathrm{C}$

- Concentração da monodispersão de esferas de poliestireno: $0.22 \%$ em peso (wt\%)

- Utilização de substratos de silício oxidados termicamente

- Pré-tratamento da superfície com solução de $\mathrm{KOH}(1 \%)$ na proporção $\mathrm{KOH}+$ $\mathrm{H}_{2} \mathrm{O}(1: 1)$

- Posicionamento do substrato na solução: posição vertical.

Após a deposição das esferas (monocamada), foi depositada uma camada de ouro $\mathrm{Au}$ ) de aproximadamente $12 \mathrm{~nm}$ de espessura através do processo de Sputtering (deposição física). Após a deposição do Au, foi realizado um tratamento térmico em um forno RTP (Recozimento Térmico Rápido) a $200^{\circ} \mathrm{C}$ para melhorar a aderência do metal no substrato (metal das regiões intersticiais das esferas). Depois do recozimento térmico, as esferas de poliestireno foram removidas quimicamente (dissolução química) utilizando-se clorofórmio em ultra-som durante 10 minutos. Com a remoção das esferas verificou-se que o padrão obtido nas estruturas autoorganizadas de esferas foi transmitido ao filme de $A u$, tornando-se assim, uma máscara metálica com estrutura organizada.

Estas estruturas organizadas obtidas no filme de ouro ( $\mathrm{Au}$ ) podem ser utilizadas para intensificação de sinal na superfície e também como máscaras em diversas aplicações como na obtenção de poros organizados na estrutura do silício e na obtenção de regiões organizadas de silício poroso (PS) através da anodização do silício nas regiões dos poros do filme de Au.

O esquema das etapas do processo para a fabricação das máscaras metálicas é mostrado na Figura 5.2. 


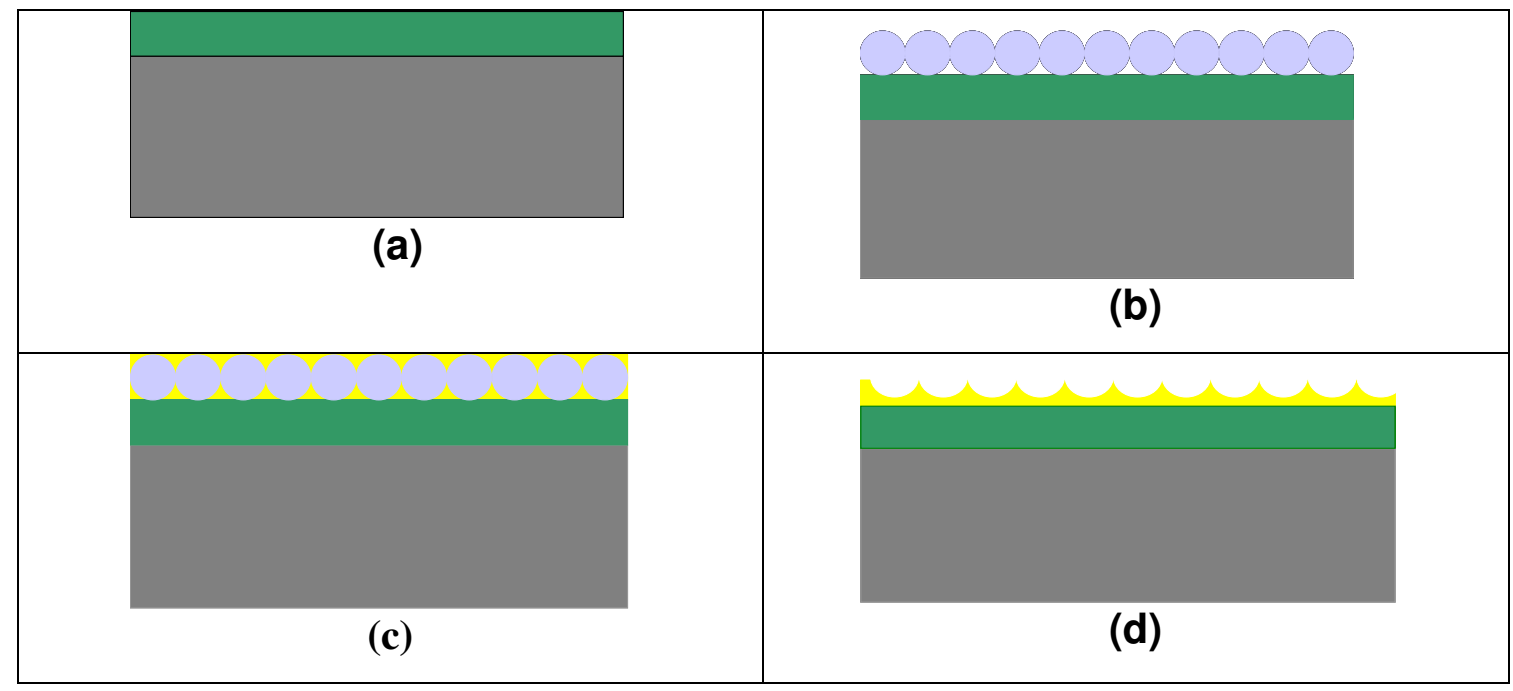

Figura 5.2 Esquema do processo de obtenção das máscaras metálicas (Au). Está representado: o substrato de silício (em cinza), o $\mathrm{SiO}_{2}$ (em verde), as esferas de poliestireno (em azul) e o Au (em amarelo). (a) indica a etapa de oxidação, (b) a etapa de deposição das esferas, (c) a etapa de deposição de metal e (d) a remoção das esferas.

\subsection{Adsorção de moléculas sobre as estruturas de silício poroso (PS) e sobre as estruturas metálicas organizadas (EMO)}

Foram adsorvidas moléculas de azul de metileno (MB) sobre as estruturas de silício poroso. As moléculas de azul de metileno foram adsorvidas na superfície do PS através de simples imersão e posterior enxágue em soluções de etanol, metanol e aquosa, e através de processos eletroquímicos de voltametria cíclica utilizando-se as mesmas soluções (etanólica, metanólica e aquosa). As soluções apresentavam uma concentração de $10^{-3} \mathrm{M}$ de $\mathrm{MB}^{+}$.

Nas estruturas metálicas (de $\mathrm{Au}$ ) organizadas foram adsorvidas moléculas de violeta (CV) utilizando-se soluções aquosas da molécula. A adsorção foi realizada através de simples imersão em solução seguida de enxágüe com o mesmo solvente.

Algumas estruturas ou medidas realizadas que não foram citadas e detalhadas nesta seção serão explicadas e/ou detalhadas juntamente com os resultados e discussão de resultados. 


\subsection{Caracterização das estruturas}

A etapa de caracterização das estruturas de silício poroso e estruturas metálicas organizadas compreende a caracterização morfológica e a caracterização óptica.

A caracterização morfológica foi realizada por Microscopia Eletrônica de Varredura (SEM). A obtenção de imagens por Microscopia Eletrônica de Varredura foi realizada no Laboratório de Sistemas Integráveis (LSI) e no Laboratório de Caracterização Tecnológica (LCT) da Escola Politécnica da USP. Os microscópios utilizados no LCT foram: a) microscópio eletrônico de varredura LEO, modelo Stereoscan 440 com espectrômetro de dispersão de energia (EDS) com cristal de Ge (germânio) da Oxford, com software para microanálise, INCA, também da Oxford e; b) microscópio eletrônico de varredura FEI, modelo Quanta 600 FEG com espectrômetro de dispersão de energia (EDS) da Bruker, com software para microanálise, Sprit, também da Bruker. O MEV utilizado no LSI foi um microscópio modelo SEM 515 da Philips. Para as análises de Microscopia Eletrônica foi utilizada a técnica de elétrons secundários.

A caracterização óptica das estruturas foi realizada através de um Espectrômetro Raman (Renishaw) do Laboratório de Espectroscopia Molecular (LEM) do Instituto de Química da USP. A caracterização óptica utilizando-se o equipamento Renishaw compreende medidas Raman e de Fotoluminescência (PL).

Algumas medidas foram realizadas utilizando-se o microscópio Óptico Triocular modelo Optiphot da Nikon do LME. 


\section{CAPÍTULO VI}

\section{RESULTADOS E DISCUSSÃO}

Neste capítulo iremos apresentar os resultados obtidos do estudo de intensificação de campo próximo em nanoestruturas metálicas e de silício e discutiremos as conseqüências para possíveis aplicações em sensores e dispositivos de emissão laser. Serão apresentadas as caracterizações estruturais e propriedades ópticas das estruturas. Alguns detalhes a respeito da preparação das amostras também serão apresentados a fim de diferenciar melhor as características de cada uma das amostras.

\subsection{Nanoestruturas metálicas periódicas de Au para intensificação de campo próximo}

As estruturas metálicas de Au com distribuição periódica foram obtidas utilizando-se sistemas auto-organizados de esferas de poliestireno como molde. Posteriormente, para o ensaio experimental para analisar o efeito de intensificação de campo próximo, foi adsorvida uma monocamada de moléculas de cristal violeta na superfície da estrutura metálica. Assim, as moléculas adsorvidas serviram de sondas para avaliar o efeito de intensificação de campo próximo. Para tal fim foi analisado o espectro de espalhamento Raman da molécula de cristal violeta adsorvida na estrutura metálica. Os detalhes do processo de formação dos sistemas autoorganizados e a formação das estruturas metálicas serão discutidos a seguir.

\subsubsection{Formação de estruturas auto-organizadas de microesferas de poliestireno.}

As estruturas de poliestireno obtidas sobre substratos de silício oxidados para o estudo da influência da umidade relativa do ambiente de deposição das esferas são mostradas nas Figuras 6.1 (a)-(e). As estruturas foram obtidas a $50^{\circ} \mathrm{C}$, utilizando-se uma monodispersão de esferas de poliestireno de concentração $2,13 \mathrm{wt} \% \mathrm{com}$ esferas que apresentavam distribuição do tamanho do diâmetro de $(660 \pm 3 \%) \mathrm{nm}$. As umidades relativas (RHs) utilizadas foram de $50 \%, 60 \%, 70 \%, 80 \%$ e $90 \%$.

Verificamos que com o aumento da concentração de esferas na monodispersão há o aumento do número de camadas de esferas de poliestireno depositadas. 


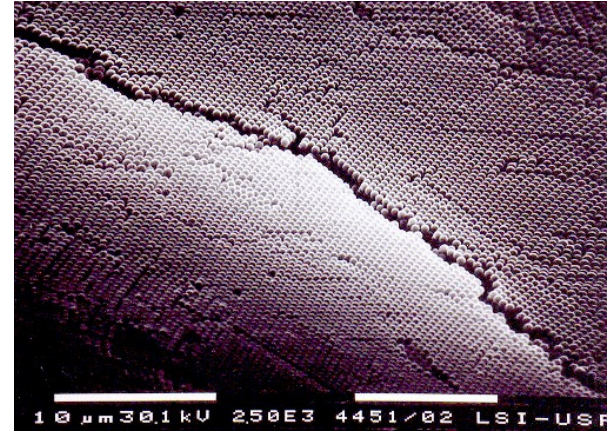

(a)

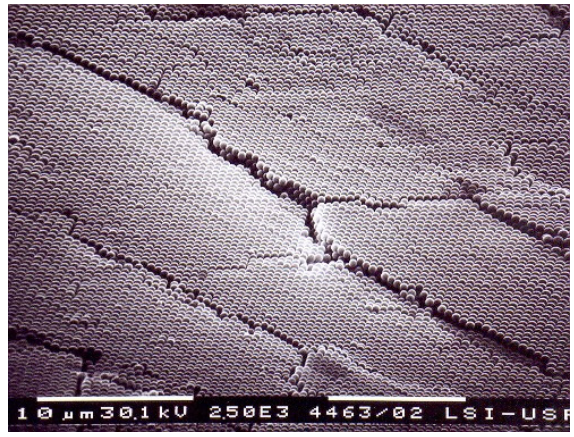

(c)

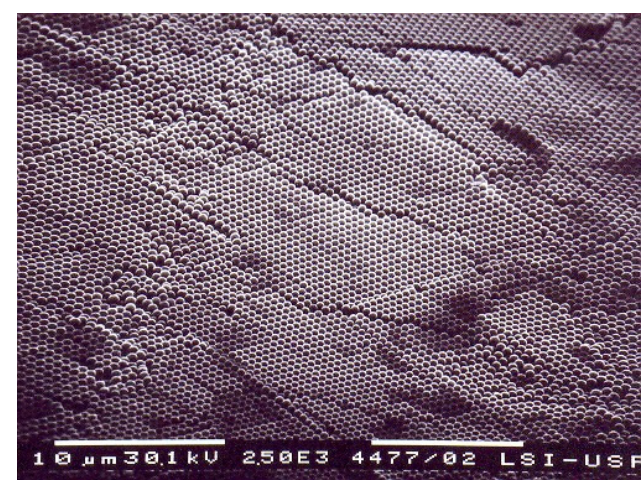

(e)

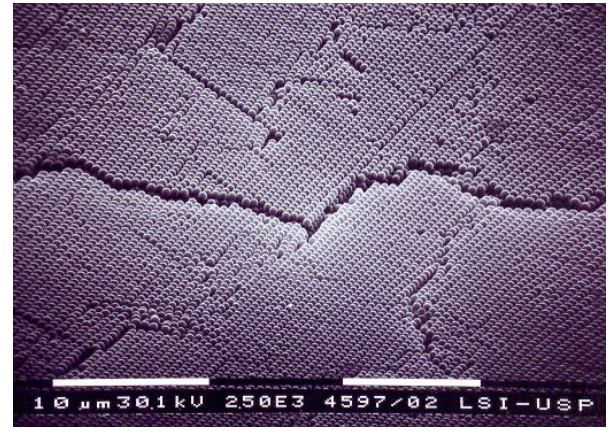

(b)

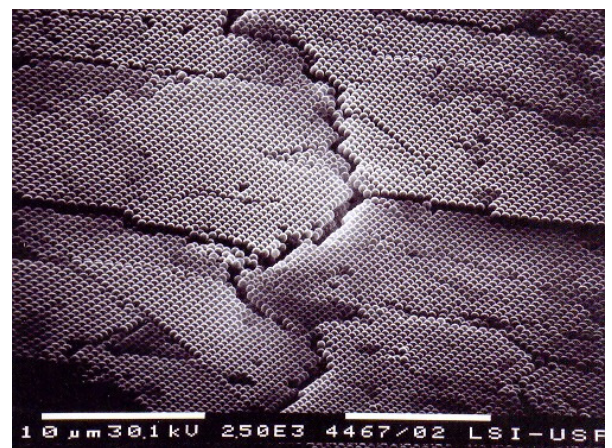

(d)

Figura 6.1 Imagens SEM das estruturas de esferas de poliestireno obtidas sobre substratos de vidro, a $50^{\circ} \mathrm{C}$, utilizando-se monodispersões de concentração $2.13 w t \%$, com umidades relativas de (a) $50 \%$, (b) $60 \%$, (c) $70 \%$, (d) $80 \%$ e (e) $90 \%$. A barra de escala apresenta comprimento de $10 \mu \mathrm{m}$ para todas as imagens, e todas as imagens apresentam aumento de 2500X.

A Figura 6.1 (a) mostra a estrutura obtida com uma umidade relativa de $50 \%$. A estrutura obtida apresentou alto grau de organização, formando filmes com áreas contínuas da ordem de, aproximadamente, $800 \mu \mathrm{m}^{2}$.

A Figura 6.1 (b) mostra a estrutura obtida com uma umidade relativa de $60 \%$. Este filme apresentou áreas auto-organizadas com valores similares à estrutura anterior 
(obtida a $50 \%$ de umidade), de aproximadamente $800 \mu \mathrm{m}^{2}$. Nesta estrutura temos áreas auto-organizadas com menor densidade de defeitos. Então, quanto às características gerais do filme, podemos dizer que este apresentou características muito similares àquelas obtidas com umidade de $50 \%$, apresentando apenas menor densidade de defeitos nos domínios organizados. As trincas também aparecem neste filme devido ao processo final de secagem que causa o relaxamento abrupto do sistema, fornecendo altas tensões ao filme, sendo necessário então, maior controle da temperatura de resfriamento do sistema. Nele, a homogeneidade de espessura é mantida sobre toda a superfície do substrato, assim como para o filme obtido a $50 \%$ de umidade. Sendo assim, verificamos que não ocorreu crescimento instável do filme, o tornado bem uniforme sobre a superfície do substrato.

A Figura 6.1 (c) mostra a estrutura obtida com uma umidade relativa de $70 \%$. Este filme apresentou áreas auto-organizadas da ordem de $1200 \mu \mathrm{m}^{2}$ com defeitos estendidos de pequena largura. Este comportamento deve-se à baixa taxa de evaporação do solvente aderido à superfície do substrato. Quanto à uniformidade da espessura, verifica-se que este filme apresenta desuniformidade (espessura desuniforme com alguns degraus na superfície), pois a alta concentração promoveu crescimento instável do filme devido ao fluxo de grande quantidade de esferas.

Os filmes obtidos em substrato de vidro foram de melhor qualidade que os obtidos sobre óxido de silício para as condições de $50 \%$ e $60 \%$ de umidade relativa. No presente caso (substrato de oxido de silício), o filme de melhor qualidade foi obtido na condição de umidade relativa de $70 \%$. Esta diferença de comportamento pode ser devido à condição superficial do vidro (hidrofílica) e do óxido de silício (hidrofóbica).

A Figura 6.1 (d) mostra a estrutura obtida com uma umidade relativa de $80 \%$. Este filme apresentou áreas auto-organizadas da ordem de aproximadamente $400 \mu \mathrm{m}^{2}$. $\mathrm{O}$ aumento da umidade relativa em relação à situação anterior (de 70\% de umidade) não provocou aumento da área auto-organizada. Neste caso, os domínios autoorganizados apresentaram menores densidades de defeitos. Aumentando-se a $\mathrm{RH}$ tem-se diminuição da força capilar lateral e da taxa de deposição, resultando em 
melhor qualidade cristalina. Verificamos que nestas condições não ocorreu crescimento instável do filme, tornando-o bem uniforme (em relação à espessura) sobre a superfície. O resultado nestas condições mostrou-se melhor sobre o substrato de silício (Figura 6.1(d)) que sobre o substrato de vidro. Este filme, obtido sobre silício a $\mathrm{RH}$ de $80 \%$, apresentou densidade de defeitos muito menor que na estrutura obtida sobre o vidro. Isso se deve, talvez, à condição menos hidrofílica da superfície no caso do silício.

A Figura 6.1 (e) mostra a estrutura obtida com uma umidade relativa de $90 \%$. Este filme apresentou áreas contínuas da ordem de aproximadamente $800 \mu \mathrm{m}^{2}$. Dentro dos domínios auto-organizados formou-se grande densidade de defeitos em linha e defeitos pontuais. A condição hidrofóbica da superfície pode ter contribuído no equilíbrio entre a taxa de evaporação do solvente e o fluxo de partículas até o menisco de deposição, pois não houve desuniformidade na espessura do filme.

Analisando-se as cinco condições de umidade relativa estudada (50\%, 60\%, 70\%, $80 \%$ e $90 \%$ ), verificou-se que as três condições de maior umidade relativa (70 \%, $80 \%$ e $90 \%$ ) são as melhores para a obtenção de filmes bem contínuos (grandes áreas) de esferas de poliestireno auto-organizadas sobre substratos de silício oxidados, mesmo não havendo uma densidade de defeitos tão baixa nos domínios organizados (no caso da umidade de $90 \%$ ). Na condição de $90 \%$ de umidade a área de organização é grande, mas apresenta maior densidade de defeitos, enquanto que na condição de $80 \%$ de umidade a área é menor, mas apresenta menor densidade de defeitos.

O controle da umidade relativa do meio promoveu filmes de áreas extensas com estruturas auto-organizadas, tanto em substrato de vidro quanto em substratos de óxido de silício. No caso do substrato de vidro, com uma superfície previamente hidrofilizada, as condições de umidades relativas de $50 \%$ e 60\% resultaram as mais adequadas para a obtenção de filmes de boa qualidade. Já nos substratos de oxido de silício, os filmes de boa qualidade foram obtidos em umidades relativas acima ou iguais a 70 \%. Este resultado mostrou que a condição inicial da superfície do substrato é um importante parâmetro na necessidade de obtenção de filmes com áreas extensas. Por outro lado, a existência de defeitos, mesmo após o controle da 
umidade relativa, sugere a necessidade de um controle mais cuidadoso da temperatura de resfriamento na fase final do processo de obtenção dos filmes autoorganizados. Analisando-se as estruturas obtidas tanto sobre substratos de vidro quanto sobre substratos de silício oxidados, verificamos que as estruturas obtidas em ambos tipos de substratos apresentam boa qualidade estrutural, sendo que as estruturas obtidas sobre óxido silício são vantajosas porque podem ser aplicadas na tecnologia do silício possibilitando a integração a essa tecnologia. Sendo assim, estas estruturas de esferas de poliestireno podem ser utilizadas amplamente nos processos de microeletrônica para obtenção de dispositivos ópticos, fotônicos, eletrônicos e optoeletrônicos.

\subsubsection{Formação das estruturas metálicas periódicas de Au}

Definidas as condições favoráveis para a formação de estruturas auto-organizadas de esferas de poliestireno foram formadas monocamadas auto-organizadas de poliestireno em substratos de óxido de silício. Estas estruturas foram utilizadas como moldes para a obtenção de estruturas metálicas periódicas de Au.

Após a obtenção da monocamada de esferas de poliestireno, uma fina camada (aproximadamente $20 \mathrm{~nm}$ ) de metal (ouro) foi depositada sobre o filme através da técnica de Sputtering. Com a remoção das esferas através da dissolução química da monocamada via clorofórmio (solvente orgânico), obteve-se a estrutura de ouro organizada, apresentando os mesmos padrões da estrutura de poliestireno (estrutura hexagonal). A Figura 6.2 mostra as estruturas de Au obtidas sobre o substrato de silício oxidado. 


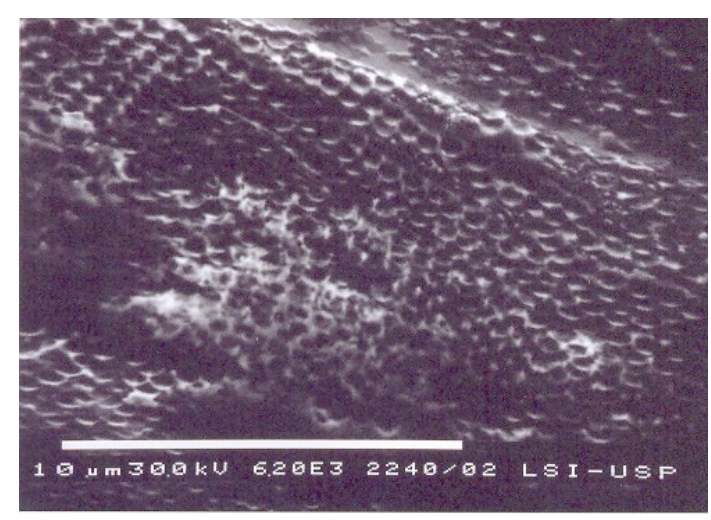

(a)

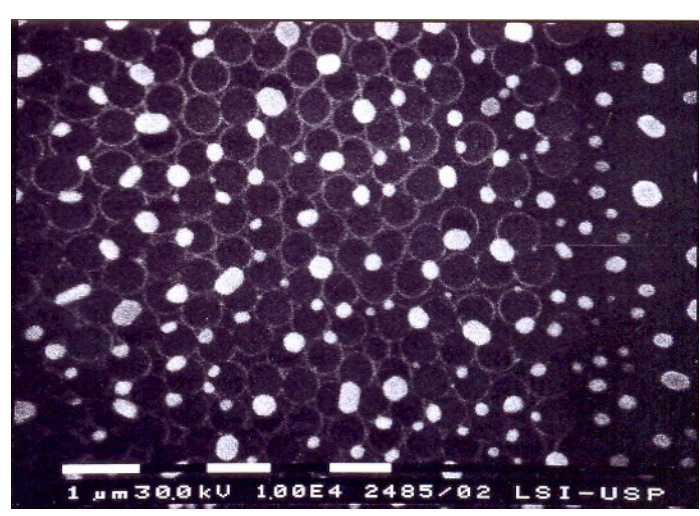

(b)

Figura 6.2 Imagens SEM de uma máscara de Au obtida sobre substrato de silício oxidado utilizando-se as esferas de poliestireno de $660 \mathrm{~nm}$ de diâmetro. A imagem (a) mostra a vista a $60^{\circ}$ e a imagem (b) mostra a vista a $0^{\circ}$. A imagem (a) apresenta aumento de $6200 \mathrm{X}$ e barra de escala que representa um comprimento de $10 \mu \mathrm{m}$. A imagem (b) apresenta aumento de $10000 \mathrm{X}$ e barra de escala que representa um comprimento de $1 \mu \mathrm{m}$.

\subsubsection{Estudo da intensificação do campo próximo nas estruturas metálicas de} Au por monitoramento do espalhamento Raman da molécula de cristal violeta (CV)

O efeito de intensificação de campo próximo nas estruturas auto-organizadas de $\mathrm{Au}$ foi realizado através do monitoramento do espalhamento Raman das moléculas de cristal violeta adsorvidas na superfície das estruturas.

As moléculas de cristal violeta são muito utilizadas para o estudo de intensificação de sinal Raman em dispersões coloidais metálicas de diversos tipos de metais.

A espectroscopia Raman é uma importante técnica para análises químicas e biológicas, pois possibilita obter informações de estruturas moleculares, processos de superfície e reações de interface que podem ser extraídas dos dados experimentais [98]. No entanto, as análises realizadas por Raman têm sido utilizadas em diversas aplicações. Um novo interesse da comunidade científica é a utilização de superfícies metálicas organizadas para a intensificação do fenômeno de espalhamento Raman. Estas superfícies metálicas organizadas, chamadas de cristais fotônicos metálicos, mostram que há grandes possibilidades de 
intensificação de campo próximo devido ao pequeno tamanho das partículas metálicas e sua distribuição periódica [99]. Características Raman e de fotoluminescência podem ser evidenciadas através da intensificação do espalhamento em estruturas metálicas organizadas e periódicas.

Foram obtidas estruturas regulares de ouro $(\mathrm{Au})$ a partir da auto-organização de esferas de poliestireno na configuração vertical, utilizando-se as esferas de $660 \mathrm{~nm}$ de diâmetro. Sendo assim, estas estruturas regulares de Au podem ser utilizadas como excelente substrato para a intensificação Raman e de fotoluminescência de moléculas adsorvidas nestas superfícies. Todas as amostras com monocamada de esferas de poliestireno foram recobertas por um filme fino de (aproximadamente $12 \mathrm{~nm}$ ) e foram recozidas a $150^{\circ} \mathrm{C}$ em ambiente de $N_{2}$ (inerte) para melhorar a aderência do filme de ouro com o óxido de silício $\left(\mathrm{SiO}_{2}\right)$. Depois disso as amostras II, III, IV, V, VI e VII foram recozidas às temperaturas de 250, 300, 400, 500, $750 \mathrm{e}$ $900^{\circ} \mathrm{C}$ respectivamente, em ambiente de $\mathrm{N}_{2}$. Em seguida, as esferas foram removidas através da dissolução em clorofórmio com o auxilio de ultra-som. As imagens SEM das amostras I, II, III, IV, V e VI são mostradas na figura 6.3.

Os espectros Raman das amostras I, II, III, IV, V e VI são mostrados na figura 6.4. Estes espectros correspondem às estruturas organizadas de ouro com uma monocamada de cristal violeta adsorvido na superfície. A monocamada destas moléculas foi garantida, pois as amostras foram enxaguadas em água deionizada (DI) durante 15 minutos, eliminando-se os clusters das moléculas de cristal violeta.

As diferentes bandas Raman observadas na Figura 6.4, exceto a banda em $520 \mathrm{~cm}^{-1}$ que corresponde ao fônon óptico do silício, correspondem aos diferentes modos normais de vibração da molécula de cristal violeta (CV). Estas bandas Raman do CV mostraram-se concordantes como os resultados reportados por Liang e seus colaboradores [100] que atribuíram classificações tentativas para os modos vibracionais da molécula de cristal violeta listados na Tabela I. 
Tabela I - Números de onda $\left(\mathrm{cm}^{-1}\right)$ de maior intensidade observados nos Espectros Raman da molécula de cristal violeta (CV) em estruturas de Au (figura 6.4), em pó e as atribuições tentativas dos modos vibracionais [100].

\begin{tabular}{|c|c|c|}
\hline CV em estruturas de Au & CV em pó [100] & $\begin{array}{l}\text { Modos de vibração } \\
\text { (atribuições tentativas) }\end{array}$ \\
\hline 423 & 426 & $\begin{array}{c}\text { dobramento Ph-C }-P h \\
\text { (fora do plano vibracional) }\end{array}$ \\
\hline 800 & 810 & $\begin{array}{c}\text { dobramento do anel C-H } \\
\text { (fora do plano vibracional) }\end{array}$ \\
\hline 1170 & 1182 & $\begin{array}{c}\text { dobramento do anel C-H } \\
\text { (no plano vibracional) }\end{array}$ \\
\hline 1375 & 1377 & alongamento N-Fenil \\
\hline 1625 & 1625 & alongamento do Anel C-C \\
\hline
\end{tabular}

As mais altas intensidades do espectro Raman CV sobre as estruturas regulares de Au foram obtidas a partir das amostras IV e $\mathrm{V}$ que foram recozidas termicamente às temperaturas de 400 e $500^{\circ} \mathrm{C}$, respectivamente. O fenômeno de intensificação do espectro Raman está correlacionado com o ordenamento das estruturas nanométricas de Au das amostras. É importante considerar que não foi observada intensificação Raman em um filme contínuo de $A u$, mostrando que o efeito de espalhamento Raman é intensificado com as estruturas metálicas de distribuição periódica de Au. O aumento da intensificação do sinal Raman é observado com o aumento da temperatura de recozimento de 150 a $500^{\circ} \mathrm{C}$, e uma diminuição desta intensificação é observada à $750^{\circ} \mathrm{C}$. A amostra recozida a $900^{\circ} \mathrm{C}$ não mostrou intensificação Raman. 


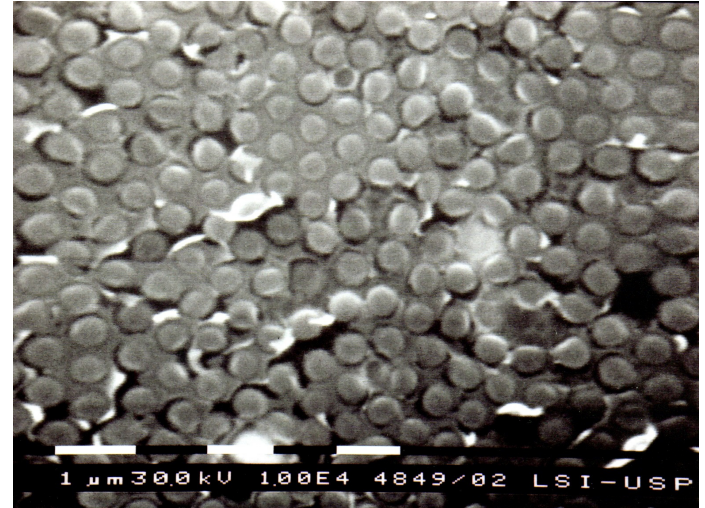

(a)

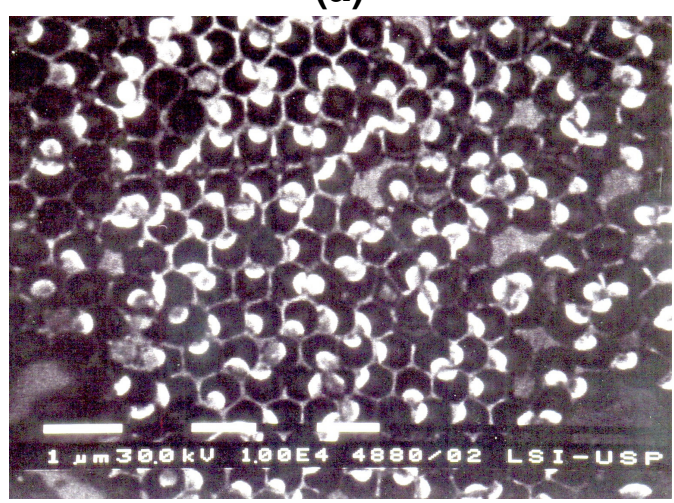

(c)

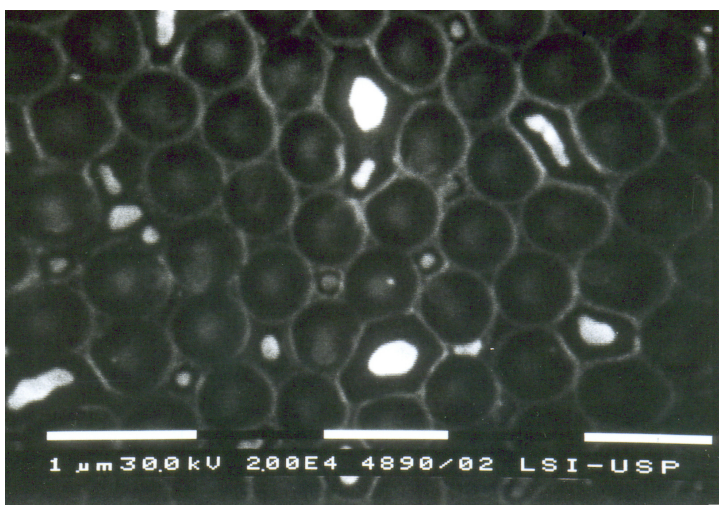

(e)

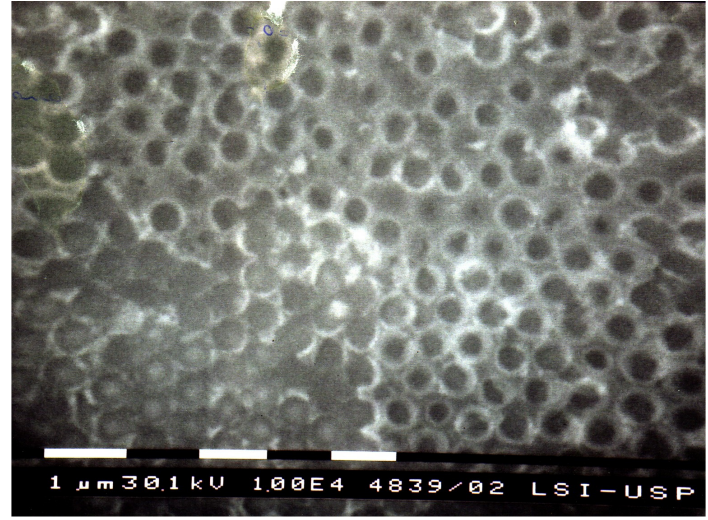

(b)

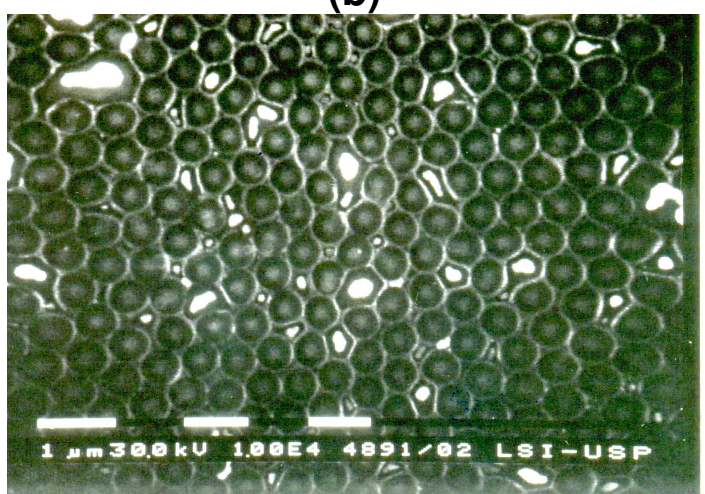

(d)

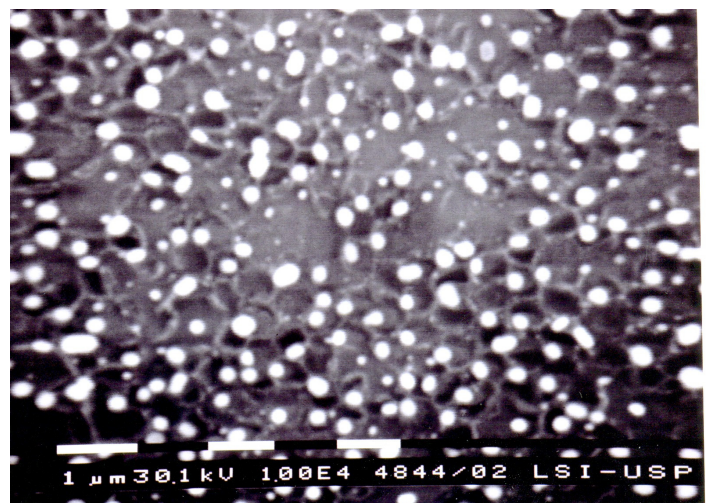

(f)

Figura 6.3 Imagens SEM das amostras após deposição de Au, recozimento térmico e dissolução das esferas de poliestireno com clorofórmio e ultra-som. (a) Amostra I recozida a $150^{\circ} \mathrm{C}$, (b) Amostra II recozida a $250{ }^{\circ} \mathrm{C}$, (c) Amostra III recozida a 300 ${ }^{\circ} \mathrm{C}$, (d) Amostra IV recozida a $400{ }^{\circ} \mathrm{C}$, (e) Amostra V recozida a $500{ }^{\circ} \mathrm{C}$ and (f) Amostra VI recozida a $750{ }^{\circ} \mathrm{C}$ (veja texto para detalhes).

A imagem de microscopia eletrônica de varredura (SEM) da amostra I (Figura 6.3 (a)) recozida somente a $150^{\circ} \mathrm{C}$ mostra que as esferas de poliestireno não foram totalmente removidas da estrutura. 


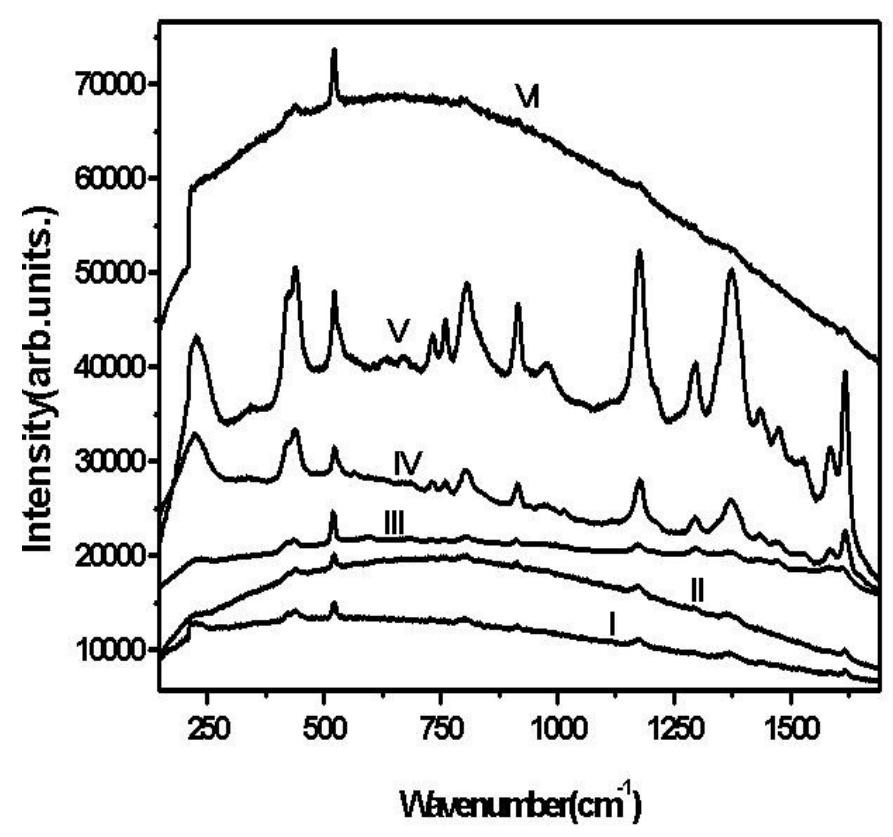

Figura 6.4 Espectros Raman de moléculas de cristal violeta adsorvidas na superfície das amostras I, II, III, IV, V e VI respectivamente. As amostras foram excitadas com uma radiação laser de 632,8 $\mathrm{nm}$.

A imagem da amostra II (Figura 6.3 (b)) recozida a $250^{\circ} \mathrm{C}$ mostra uma estrutura com pequenos buracos centrados nos locais onde as esferas de poliestireno se encontravam. Neste caso, todas as esferas foram removidas pelo solvente orgânico (clorofórmio). A imagem da amostra III (Figura 6.3 (c)) recozida a $400^{\circ} \mathrm{C}$ apresentou uma estrutura composta por pequenos buracos com o mesmo diâmetro das esferas de poliestireno. As amostras IV e V (Figuras 6.3 (d) e (e), respectivamente) recozidas a 400 e $500^{\circ} \mathrm{C}$ respectivamente, apresentaram espectros de maiores intensidades e mostraram a estrutura inversa da matriz de esferas de poliestireno em monocamada. A principal característica das amostras IV e $V$ são as regiões 'em cunha' com o tamanho de aproximadamente $600 \mathrm{~nm}$ centrada na região onde se encontrava a esfera, com paredes de aproximadamente $40 \mathrm{~nm}$ entre as esferas. A imagem da amostra VI (Figura 6.3 (f)) recozida a $750^{\circ} \mathrm{C}$ mostrou que houve destruição parcial da estrutura regular de $\mathrm{Au}$. $\mathrm{Na}$ amostra recozida a $900^{\circ} \mathrm{C}$ observou-se que houve destruição total da estrutura organizada de $A u$, não havendo intensificação do efeito Raman. Através dos resultados obtidos verifica-se que a intensificação do efeito de espalhamento Raman se dá devido às estruturas 
periódicas e regulares de Au. Isto pode ser explicado pelo efeito de intensificação espalhamento Raman que ocorre na superfície da estrutura metálica devido ao efeito de intensificação de campo próximo que podemos argumentar da seguinte forma:

O espalhamento Raman de superfície (SERS) é conseqüência direta da intensificação de campo próximo (NF) na estrutura metálica. No caso de estruturas periódicas de poros (buracos) num filme metálico, como no caso das estruturas do presente trabalho, a intensificação do campo próximo deve-se á contribuição de três modos diferentes: modo polarizado do plasma de superfície radiativo (SPP), do modo não radiativo e do modo de propagação radiativa [101-102]. Darmanyan e seus colaboradores [102] mostraram a partir de resultados teóricos que a contribuição mais importante para a intensificação de campo próximo é o modo SPP não radiativo ( $10^{4}$ vezes) que é dez vezes maior que o modo SPP radiativo. A contribuição do modo de propagação mostrou-se desprezível. Os resultados de Darmanyan [102] sugerem que a intensificação de campo próximo à região de ressonância do plasma é maior que $10^{4}$ vezes em relação à amplitude da luz incidente. No entanto, excitar o modo de plasma de superfície (SSP) é uma tarefa difícil quando a estrutura metálica é um filme plano desde que os modos excitados predominantemente são de tipo longitudinal, já que os modos da luz incidente são completamente transversais. No caso de estruturas periódicas de metal, esta regra de seleção pode ser quebrada já que o acoplamento entre os modos da luz de excitação (luz incidente) e os modos de plasma superficiais podem ser permitidos desde que o vetor de onda dos modos plasmônicos, neste caso, sejam dependentes da projeção do vetor de onda da luz incidente $\left(k_{\|}\right)$sobre a superfície da estrutura, mais o vetor da rede recíproca da estrutura periódica. Assim, as interações são permitidas pelo acoplamento através do momento do cristal de uma rede periódica e obedece a lei de conservação do momento [103] dada por:

$$
k_{s p}=k_{\|}+G \text {, }
$$

onde $\mathrm{k}_{\mathrm{sp}}$ é o vetor de onda SPP, $\mathrm{k}_{\|}$é a componente do vetor de onda no plano da luz incidente e $\mathrm{G}$ é o vetor da rede recíproca da estrutura periódica de metal.

Outro fator importante para a eficiente excitação dos modos de plasma na estrutura periódica de metal de Au proposta no presente trabalho é a característica 
nanoestruturada do material, já que as regiões de metal de Au apresentam dimensões nanométricas da ordem de $30 \mathrm{~nm}$. As nanoestruturas metálicas podem permitir a existência de um grande número de modos plasmônicos. Por exemplo, em cristais fotônicos metálicos constituídos por pequenas partículas metálicas (esferas de Au com diâmetro menor que o comprimento de onda da luz incidente $(\lambda)$ ) em meio dielétrico, as oscilações de plasma das esferas metálicas isoladas apresentam uma característica de plasma multimodos, cujas freqüências de oscilação podem ser expressas pela seguinte equação:

$$
\omega_{l}=\omega_{P} \sqrt{\frac{l}{2 l+1}}
$$

Estes modos de plasma, chamados de esferas de plasma, têm autofreqüências de $\omega_{\mathrm{p}} \sqrt{ } 1 / 3, \omega_{\mathrm{p}} \sqrt{ } 2 / 5, \ldots$ para $I=1,2,3, \ldots$ e $\omega_{\mathrm{p}} \sqrt{ } 1 / 2=\omega_{\mathrm{S}}$ (plasma de superfície no limite $\mathrm{I} \rightarrow \infty)$. Assim a existência de múltiplos modos de plasma facilita o acoplamento da luz incidente com os modos SSP das nanopartículas metálicas.

$\mathrm{O}$ argumento descrito acima pode explicar porque as amostras IV e V obtidas apresentaram a maior intensificação Raman. Os resultados teóricos reportados pela literatura apontam que estruturas organizadas (matriz) de esferas metálicas promovem uma elevada intensificação do campo elétrico próximo (campo somente na superfície das esferas) da ordem de $10^{4}$ vezes em relação à intensidade da luz incidente [104]. No caso das estruturas obtidas, as estruturas metálicas apresentam espessuras de $40 \mathrm{~nm}$ e 120nm e altura de 300nm que são menores que o comprimento de onda dos lasers utilizados na excitação Raman (632,8nm e 514nm). Outro fator que pode ter contribuído na intensificação Raman está relacionado à característica estrutural das amostras já que as matrizes de Au obtidas são estruturas interconectadas (estrutura esquelética de Au), que segundo Kneipp, condicionam também a intensificação. Kneipp e seus colaboradores [98], utilizando um espalhamento não linear de moléculas de cristal violeta em uma solução coloidal de nanoesferas de Au, conseguiram uma enorme intensificação somente quando núcleos metálicos formaram-se na solução coloidal, ou seja, quando houve percolação entre esferas metálicas. De forma similar, Paliakov e seus colaboradores [105] obtiveram um enorme ganho de intensificação, alcançando valores da ordem de $10^{15}$. Os pesquisadores relatam que o enorme fator de ganho deve-se à 
excitação de modos de dipolos fortes não homogêneos do filme, como em uma superfície fractal.

Como o sinal Raman de moléculas adsorvidas está relacionado ao ganho de sinal na posição onde a molécula está posicionada, o enorme ganho do campo próximo mostra que o ganho de espalhamento Raman é bastante promissor em estruturas de cristais fotônicos metálicos. É importante mencionar que partículas metálicas com tamanhos da ordem de $10 \mathrm{~nm}$ permitem a ocorrência de efeitos de confinamento quântico nas estruturas eletrônicas. O efeito direto do confinamento eletrônico é mostrado pela existência de níveis discretos em níveis contínuos. Estes níveis discretos podem afetar o tempo de vida de modos de plasma, desde que os modos discretos sejam aproximados à cavidade ideal para a oscilação dos elétrons.

Sendo assim, é importante considerar que o método de auto-organização mostrouse favorável para sua utilização na formação de estruturas metálicas organizadas e podem ser aplicadas na fabricação de cristais fotônicos metálicos. A melhor estrutura organizada foi obtida a partir da estrutura recozida a $400^{\circ} \mathrm{C}$ em ambiente inerte $\left(\mathrm{N}_{2}\right)$. Estas estruturas permitiram a obtenção de espectros Raman de moléculas de violeta adsorvidas sobre as estruturas. A intensificação do espalhamento Raman foi atribuída à intensificação do campo próximo na superfície metálica devido aos modos de plasma na superfície nas regiões nanométricas periódicas de interconexões de Au. Estes resultados mostraram que o cristal fotônico metálico pode ser um excelente substrato para a detecção de uma única molécula por causa da reprodutibilidade e da possibilidade do controle do tamanho da rede metálica regular como as obtidas neste trabalho. Adicionalmente, estas estruturas podem ser utilizadas no estudo do espalhamento Raman intensificado não-linear. 


\subsection{Estruturas de silício para intensificação de campo próximo}

A fabricação de dispositivos sensores com capacidade de detecção de um elétron, átomo ou molécula tem atraído a atenção da comunidade científica principalmente após a possibilidade de manipulação dos materiais em dimensão nanométrica. No caso de estruturas nanométricas de silício, a importância de fabricar dispositivos sensores de elevada sensibilidade radica na possibilidade de integração dos dispositivos em um único chip. O problema principal para a fabricação de dispositivos sensores de silício que possam detectar um único átomo ou molécula está relacionado com a intensificação de campos próximos. A proposta do presente trabalho foi de fabricar nanoestruturas de silício baseadas na tecnologia de silício poroso com a finalidade de intensificar campos próximos na superfície destas estruturas. A intensificação do campo próximo de superfície foi estudada através da monitoração do espalhamento Raman de uma molécula de prova (azul de metileno) previamente adsorvida na superfície das nanoestruturas.

A espectroscopia Raman é uma importante técnica analítica para análises química e biológica que possibilita a extração de dados de estruturas moleculares, processos de superfície e reações de interface. Atualmente, a espectroscopia Raman tem ampliado seu leque de aplicações em diversos campos. Um importante exemplo é a intensificação do espalhamento Raman nas superfícies metálicas dependendo do arranjo das estruturas nas superfícies [106]. Recentemente, algumas estruturas chamadas de cristais fotônicos metálicos têm reportado a existência de uma intensificação de campo próximo devido ao pequeno tamanho das partículas metálicas e a peridiocidade das estruturas [107-109]. Uma intensificação de campo próximo em sítios de moléculas adsorvidas tem possibilitado a intensificação dos sinais Raman e de Fotoluminescência (PL).

Nenhum fenômeno de intensificação em estruturas não-metálicas tinha sido reportado até o momento. A presente seção deste trabalho reporta a amplificação do sinal Raman e PL de moléculas de azul de metileno (MB) adsorvidas sobre a superfície de silício macroporoso que se trata de uma superfície não-metálica. A intensificação do sinal Raman e de fotoluminescência das moléculas adsorvidas foi atribuída tentativamente a uma interação fônon-fônon ou fônon-exciton desde que as 
estruturas de silício poroso utilizadas apresentam uma intensificação do sinal Raman.

O método para a obtenção destes tipos de características compreende três etapas importantes: a obtenção de estruturas de silício macroporoso, a adsorção das moléculas de azul de metileno nas estruturas macroporosas e as caracterizações das estruturas através de espectroscopia Raman e de fotoluminescência. $O$ processo de obtenção das estruturas macroporosas de silício consiste numa anodização de lâminas de silício do tipo $P$, com orientação cristalográfica $<100>$ e resistividade de 10-20 $\Omega . \mathrm{cm}$. Inicialmente as lâminas de silício são limpas através de uma limpeza inicial convencional da microeletrônica (RCA). Depois disso, foi realizada uma metalização das costas da lâmina para a formação do contato do substrato. As estruturas de silício macroporoso foram obtidas a partir de um processo de anodização das lâminas de silício (Si) utilizando uma solução HF:DMF (ácido fluorídrico : dimetilformamida) com frações de volume de 4, 8, 12 e 16\% (de HF). Foi utilizada uma corrente de anodização da ordem de $8 \mathrm{~mA} / \mathrm{cm}^{2}$ por 10 minutos. As moléculas de azul de metileno foram adsorvidas através da imersão das estruturas macroporosas em uma solução de azul de metileno de $10^{-3} \mathrm{M}$ em etanol durante 5 horas. Após a imersão nesta solução, as amostras foram lavadas em água deionizada corrente para eliminar possíveis estruturas de particulados.

A caracterização morfológica das estruturas foi realizada a partir de medidas SEM (Microscopia Eletrônica de Varredura), e a caracterização óptica foi realizada através da espectroscopia Raman e da técnica de Fotoluminescência utilizando-se fontes laser de comprimentos de onda de 632,8; 514 e $488 \mathrm{~nm}$.

A Figura 6.5 mostra as estruturas de silício macroporoso obtidas com as concentrações de HF de $8 \%$ e 16\% em DMF. Pode-se observar que quando há o uso da concentração de HF de 16\%, há a quebra dos poros. A quebra destes poros pode ser explicada através da ação oxidante. A quebra dos poros pode ter ocorrido, pois o DMF é um solvente oxidante e o crescimento dos poros neste tipo de solvente é um processo de ruptura elétrica [108]. Sendo assim, para o estudo das características Raman e de Fotoluminescência foram utilizadas as estruturas de silício macroporoso obtidas com DMF com proporções de 8\% e 12\% (de HF) para evitar a ocorrência de quebra dos poros no momento de obtenção das estruturas. 


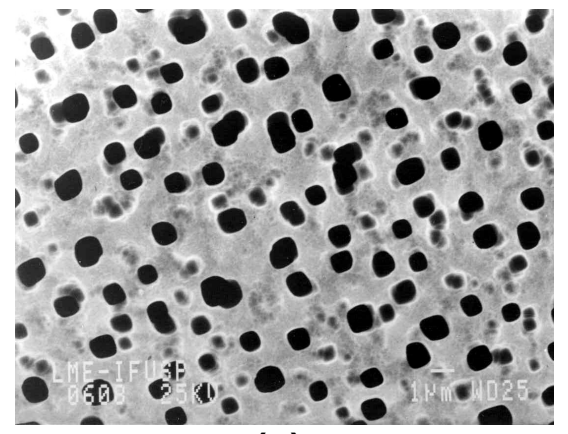

(a)

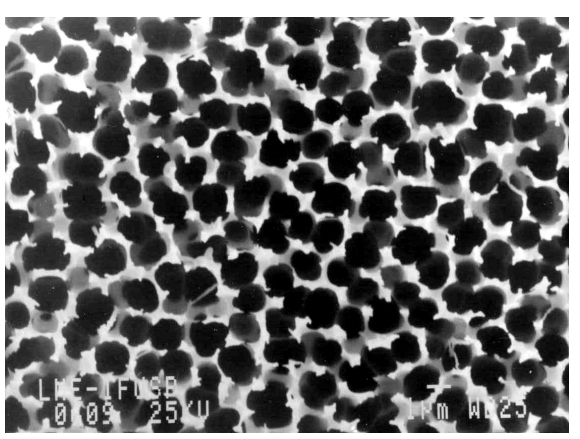

(b)

FIGURA 6.5 IMAGENS SEM dAS ESTRUTURAS OBTIDAS COM SOLUÇões DE DMF COM (A) $8 \%$ DE HF E COM (B) $16 \%$ DE HF.

O controle da estrutura de poros das amostras macroporosas é muito importante para o estudo das características Raman e PL e possíveis aplicações em sensores baseados na intensificação de campo próximo. A estrutura e distribuição dos cristalitos são muito importantes para definir a intensificação nos sinais Raman e PL. Sendo assim, foram realizados outros ensaios para a obtenção de estruturas macroporosas de $\mathrm{Si}$, e alguns resultados interessantes são mostrados nas Figuras 6.6 e 6.7 a partir de imagens SEM (Microscopia Eletrônica de Varredura).

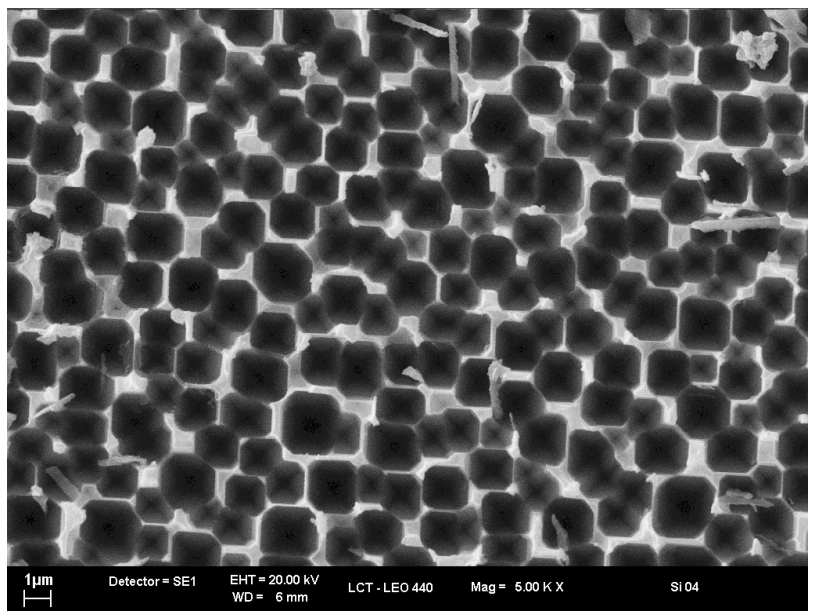

Figura 6.6 Imagem SEM da estrutura macroporosa de Si obtida por anodização em DMF+HF com $12 \%$ de HF em 30 s seguida de Voltametria Cíclica em solução de MB para recobrir a superfície, a $\mathrm{V}=20 \mathrm{mV} / \mathrm{s}$ e $-0.4 \mathrm{~V}<\mathrm{V}<0.6 \mathrm{~V}$ com $\mathrm{V}_{0}=0$ em 5 ciclos. 


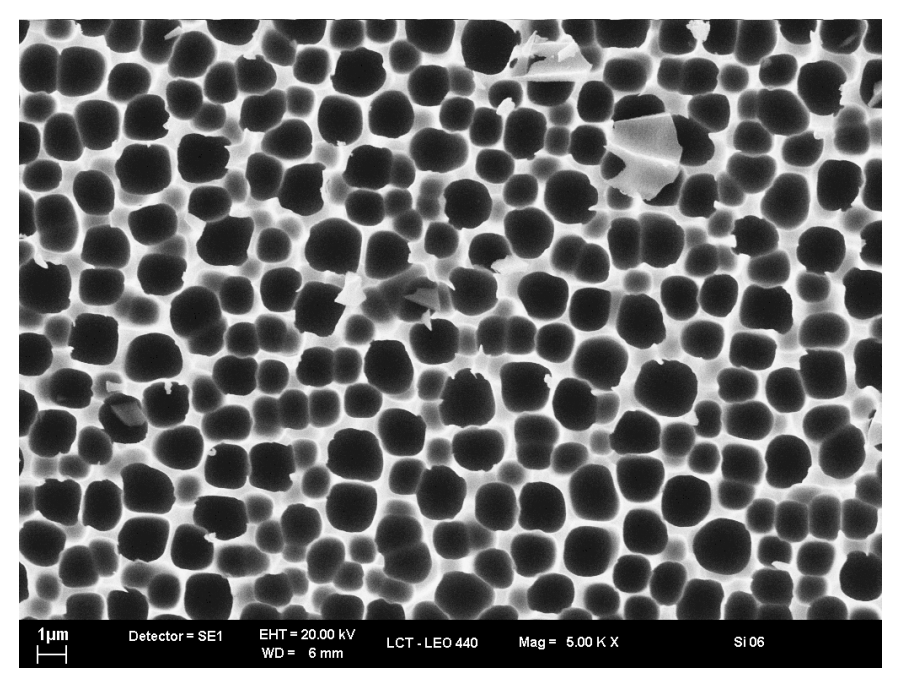

Figura 6.7 Imagem SEM da estrutura macroporosa de Si obtida por anodização em $\mathrm{DMF}+\mathrm{HF}$ com $12 \%$ de HF por 10 minutos, seguida de oxidação térmica.

O espectro Raman da amostra de $12 \%$ de HF em DMF é apresentado na figura 6.8 juntamente com o espectro do silício monocristalino (c-Si).

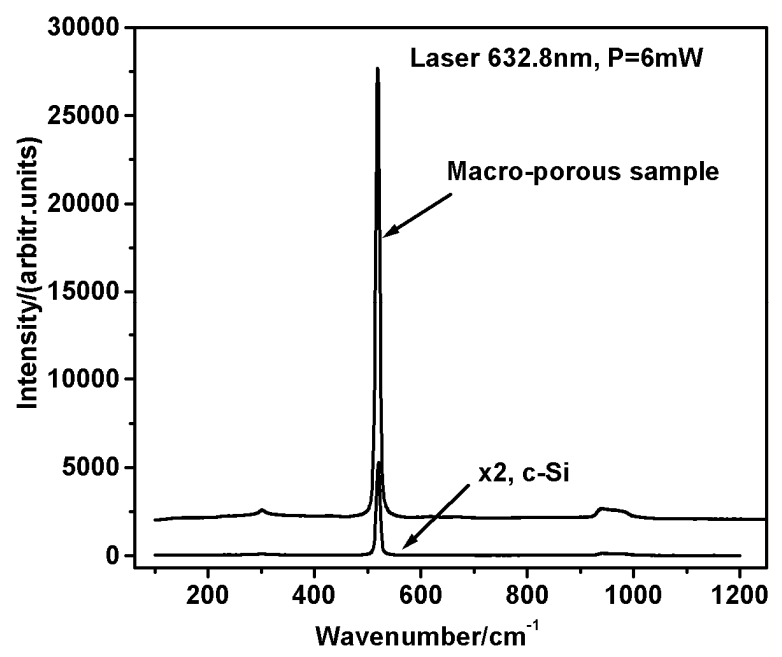

Figura 6.8 Espectros Raman do silício monocristalino (c-Si) (x2,c-Si) e do silício macroporoso (Macro-porous sample) obtido a partir de uma solução de DMF com $12 \%$ de ácido fluorídrico (HF). Os espectros foram obtidos a partir da excitação das amostras com um laser de $\lambda=632.8 \mathrm{~nm}$ e $\mathrm{P}=6 \mathrm{mw}$. 
A intensificação Raman relacionada ao fônon óptico do modo de vibração do Si-Si para ambas as amostras (c-Si e 12\% de HF) encontram-se em $520 \mathrm{~cm}^{-1}$, sugerindo que os cristalitos na estrutura macroporosa não apresentaram efeitos de tamanho quântico, desde que a banda Raman para estruturas microporosas com cristalitos de 3 nm mostraram uma diminuição e alargamento da banda [110]. O Raman de segunda ordem de ambas as amostras apresentaram a mesma posição de energia (Figura 6.8).

A diferença marcante no espectro da Figura 6.8 mostra uma intensificação do silício macroporoso da ordem de 10 vezes maior que a do silício monocristalino (c-Si). Resultados posteriormente descritos neste trabalho mostraram que há a intensificação do sinal Raman em estruturas macroporosas de silício obtidas por implantação prévia de íons $\mathrm{H}^{+}$. A intensificação Raman foi atribuída ao fenômeno Raman ressonante devido à alta intensificação que ocorria quando a energia da fonte de excitação estava próxima da banda de absorção dos macroporos. Sendo assim, com as estruturas macroporosas desta parte do trabalho, o mesmo efeito ocorre.

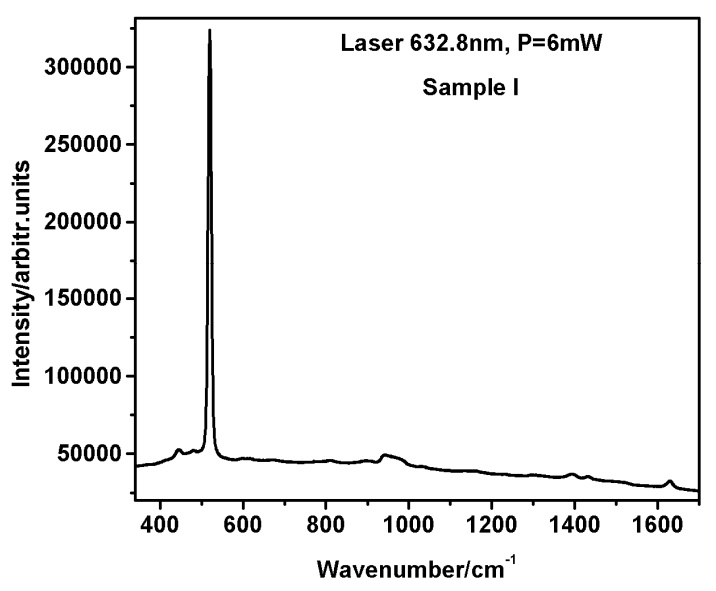

(a)

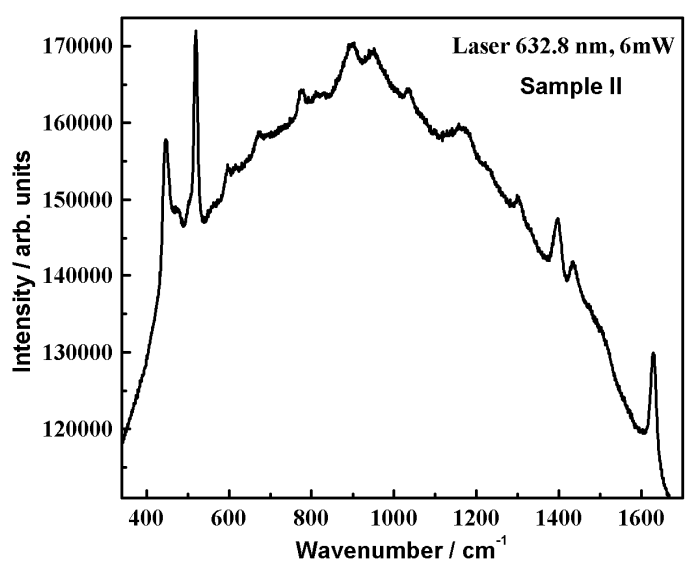

(b)

Figura 6.9 Espectros Raman de estruturas de silício do silício macroporoso obtido a partir de uma solução de DMF com (a) $8 \%$ de ácido fluorídrico (HF) e (b) $12 \%$ de HF, com moléculas de azul de metileno (MB) adsorvidas na superfície (em a e b). Os espectros foram obtidos a partir da excitação das amostras com um laser de $\lambda=632,8 \mathrm{~nm}$ e $\mathrm{P}=6 \mathrm{~mW}$. 
As moléculas de azul de metileno foram adsorvidas na superfície dos macroporos através da imersão das estruturas em uma solução $10^{-3} \mathrm{M}$ de moléculas de azul de metileno em etanol. Em seguida, as amostras foram lavadas em solvente de etanol para eliminar particulados das moléculas, garantindo a presença de uma monocamada de moléculas de azul de metileno na superfície porosa de silício. Após este processo, foram obtidos os espectros Raman destas estruturas. Para a amostra de $12 \%$ de HF em DMF é possível identificar as bandas do modo vibracional do azul de metileno juntamente com o modo fonônico vibracional Si-Si em $520 \mathrm{~cm}^{-1}$ (Figura 6.9(b)). No caso da amostra obtida com uma fração de HF em DMF de 8\%, as bandas Raman correspondentes às moléculas de azul de metileno mostraram baixa intensidade (Figura 6.9(a)). Por outro lado, nenhuma banda Raman do azul de metileno foi observada em uma amostra de silício cristalino (c-Si) com moléculas de azul de metileno adsorvidas na superfície (espectro não mostrado). É importante considerar que a intensificação do sinal Raman do azul de metileno adsorvido na amostra de silício macroporoso obtida com 12\% de HF em DMF está relacionada à banda fonônica óptica $\left(520 \mathrm{~cm}^{-1}\right)$ que não ocorre na amostra de $8 \%$. Este fenômeno de intensificação Raman não poderia ser explicado de acordo com os efeitos de espalhamento Raman intensificado por superfície (SERS) porque o substrato de silício poroso é um material de baixa condutividade. Sendo assim, a intensificação Raman observada na amostra de $12 \%$ de HF em DMF está relacionada ao decréscimo na banda fonônica óptica do filme macroporoso. Então, propõe-se que há uma interação fônon-fônon responsável pela intensificação Raman na amostra de $12 \%$. Este mecanismo proposto envolve dois diferentes processos fonônicos. Então, a contribuição para o tensor Raman tem três termos no denominador que podem gerar a grande intensificação Raman se estiverem em ressonância entre si. Todos os resultados reportados nesta seção são totalmente diferentes dos resultados reportados na literatura já que aqueles anteriormente reportados envolvem somente substratos condutores. Em superfícies condutoras o fenômeno de intensificação está relacionado ao efeito de intensificação de superfície plasmon-fônon conhecida como espalhamento Raman intensificado por superfície (SERS). 
A diferença marcante no espectro da Figura 6.9 (a) mostra uma intensificação da ordem de 10 vezes maior que a do silício macroporoso (Figura 6.8) e 60 vezes maior que a do silício monocristalino (c-Si).

Os resultados dos picos de espalhamento Raman das moléculas de azul de metileno absorvidas sobre o silício macroporoso correspondem aos diferentes modos normais de vibração da molécula (Figura 6.9(b)). Considerando-se os grupos metila como pontos de massa, a molécula de $\mathrm{MB}^{+}$pode ser referida ao grupo de ponto $\mathrm{C}_{2 \mathrm{~V}}$. Baseados nessa consideração, Keskinova e colaboradores [111] calcularam o número de modos normais pertencentes a cada espécie de simetria, obtendo que os 60 modos normais de vibração da molécula de $\mathrm{MB}^{+}$se encontram distribuídos como:

$$
\Gamma_{v}=19 \cdot A_{1}+11 A_{2}+11 B_{1}+19 B_{2}
$$

Todos esses modos vibracionais são ativos no Raman e os modos de simetria $A_{1}, B_{1}$ e $B_{2}$ são ativos no infravermelho. Acrescentados a esses modos vibracionais, essa molécula apresenta, também, as vibrações do grupo $\mathrm{N}\left(\mathrm{CH}_{3}\right)_{2}$, que não foram consideradas no cálculo. Na Tabela II são apresentadas as atribuições dos diferentes modos normais da molécula de azul de metileno que foram calculados teoricamente e em alguns casos realizados atribuições tentativas a partir de resultados experimentais [112].

Tabela II - Freqüências vibracionais $\left(\mathrm{em} \mathrm{cm}^{-1}\right)$ observadas nos espectros Raman (excitados em $514,5 \mathrm{~nm}$ ) do $\mathrm{MB}^{+}$no estado sólido e em solução, com as respectivas atribuições tentativas [112].

\begin{tabular}{|c|c|c|}
\hline $\begin{array}{c}\mathbf{M B}^{+} \text {- sólido } \\
\mathbf{5 1 4 , 5} \mathbf{~ n m}\end{array}$ & $\begin{array}{c}\mathbf{M B}^{+} \text {- solução } \\
\mathbf{5 1 4 , 5} \mathbf{~ n m}\end{array}$ & Atribuição tentativa \\
\hline $1626(\mathrm{mF})$ & $1624(\mathrm{mF})$ & $v_{(C C) \text { anel }}+v_{(C N C) \text { anel }}$ \\
\hline$\sim 1490(\mathrm{f})$ & $\sim 1490(\mathrm{f})$ & $v_{(C C) \text { anel }}$ \\
\hline $1479(\mathrm{~F})$ & $1479(\mathrm{~F})$ & $v_{(C C) \text { anel }}$ \\
\hline $1453(\mathrm{~m})$ & $1453(\mathrm{~m})$ & $v_{(C C) \text { anel }}$ \\
\hline $1442(\mathrm{~m})$ & $1442(\mathrm{~m})$ & $v_{(C C) \text { anel }}$ \\
\hline $1396(\mathrm{~F})$ & $1397(\mathrm{~F})$ & $v_{(C C) \text { anel }}+v_{(C N C) \text { anel }}$ \\
\hline $1364(\mathrm{~m})$ & $1362(\mathrm{~m})$ & \\
\hline $1338(\mathrm{f})$ & & $v_{(C N)}$ \\
\hline
\end{tabular}




\begin{tabular}{|c|c|c|}
\hline $1303(\mathrm{~m})$ & $1301(\mathrm{~m})$ & $v_{(C C) \text { anel }}$ \\
\hline $1282(\mathrm{f})$ & $1282(\mathrm{f})$ & $\beta_{(C H)}$ \\
\hline $1183(\mathrm{~m})$ & $1178(\mathrm{~m})$ & $\beta_{(C H)}$ \\
\hline $1159(\mathrm{~m})$ & $1160(\mathrm{~m})$ & $v_{\text {as CSC })}$ \\
\hline $1074(\mathrm{~m})$ & $1070(\mathrm{~m})$ & \\
\hline $1038(\mathrm{~m})$ & $1038(\mathrm{f})$ & \\
\hline $954(\mathrm{f})$ & $951(\mathrm{f})$ & $\delta_{(C C C)}$ \\
\hline $900(\mathrm{f})$ & $901(\mathrm{f})$ & $v_{s(C S C)}$ \\
\hline$\left(884^{*}\right)$ & $885(\mathrm{f})$ & $\delta_{(C C C)}$ \\
\hline $861(\mathrm{~m})$ & $860(\mathrm{~m})$ & $\delta_{(C N C)}+$ def.esq. \\
\hline $771(\mathrm{~m})$ & $772(\mathrm{~m})$ & $\delta_{(C N C)}+$ def.esq. \\
\hline $671(\mathrm{f})$ & $(675)^{* *}$ & \\
\hline $599(\mathrm{f})$ & $666(\mathrm{f})$ & \\
\hline $501(\mathrm{~m})$ & $591(\mathrm{f})$ & \\
\hline $449(\mathrm{~m})$ & $500(\mathrm{~m})$ & \\
\hline$(251)$ & $447(\mathrm{f})$ & \\
\hline
\end{tabular}

Intensidade dos picos: $\mathrm{mF}=$ muito forte $/ \mathrm{F}=$ forte $/ \mathrm{m}=$ média $/ \mathrm{f}=$ fraca

$v=$ estiramento ( $v_{s}=$ estiramento simétrico e $v_{a s}=$ estiramento anti-simétrico)

$\beta=$ deformação angular no plano

$\delta$ = deformação angular no plano

def. esq. = deformação do esqueleto

( ${ }^{*}$ ) pico observado utilizando-se apenas o comprimento de onda de excitação de $632,8 \mathrm{~nm}$.

$\left({ }^{* *}\right)$ pico observado utilizando-se apenas o comprimento de onda de excitação de $457,9 \mathrm{~nm}$ e $568,2 \mathrm{~nm}$.

A atribuição de modos vibracionais em moléculas complexas como $\circ \mathrm{MB}^{+}$pode ser apenas aproximada devido ao grande acoplamento existente entre esses modos e é, usualmente, feita por comparação com os espectros de moléculas semelhantes e/ou mais simples. Assim, para se realizar a atribuição vibracional da molécula de $\mathrm{MB}^{+}$, fez-se uso principal das atribuições realizadas para moléculas de tionina [113], fenotiazina [114-116], e seu cátion radical [116], fenazina [117], quinolina [118] e para outros compostos mais simples com enxofre (difenilsulfeto) e nitrogênio (anilina) [119]. De acordo com as comparações com as moléculas citadas anteriormente, as moléculas de $\mathrm{MB}^{+}$receberam atribuições tentativas do modo vibracional de acordo com a Tabela II. No espectro Raman da Figura 6.9 (b) pode-se verificar os diferentes modos normais de vibração correspondente às moléculas de azul de metileno apresentadas na Tabela II. Os picos mais intensos correspondem 
às bandas na região próxima a $1626 \mathrm{~cm}^{-1}$ e na região próxima a $1396 \mathrm{~cm}^{-1}$, sendo atribuído a estes picos o modo de vibracional de estiramento dos anéis da molécula sendo este resultado totalmente correlacionado com o previsto pela literatura (Tabela II). Outros picos de fraca intensidade também aparecem no espectro correspondente aos outros modos normais atribuídos na Tabela II.

Espectros de fotoluminescência $(\mathrm{PL})$ das amostras de $8 \%$ e $12 \%$ de HF em DMF foram obtidos com a excitação através de uma fonte laser de $488 \mathrm{~nm}$, e são mostrados na figura 6.10. Através dos espectros podemos verificar que a emissão do azul de metileno encontra-se em $670 \mathrm{~nm}$ e é mais intensa na amostra de $12 \%$ de HF. Este resultado mostra que a estrutura macroporosa da amostra de $12 \%$ promoveu a intensificação da emissão PL do azul de metileno que está diretamente correlacionada ao decréscimo na intensidade da banda fonônica óptica. Como no caso da intensificação Raman, há também uma ressonância e podemos dizer que a intensificação PL está relacionada à alta intensidade da banda fonônica Raman observada antes mesmo da adsorção das moléculas de azul de metileno, que podem ter promovido uma eficiente interação fônon-êxciton.

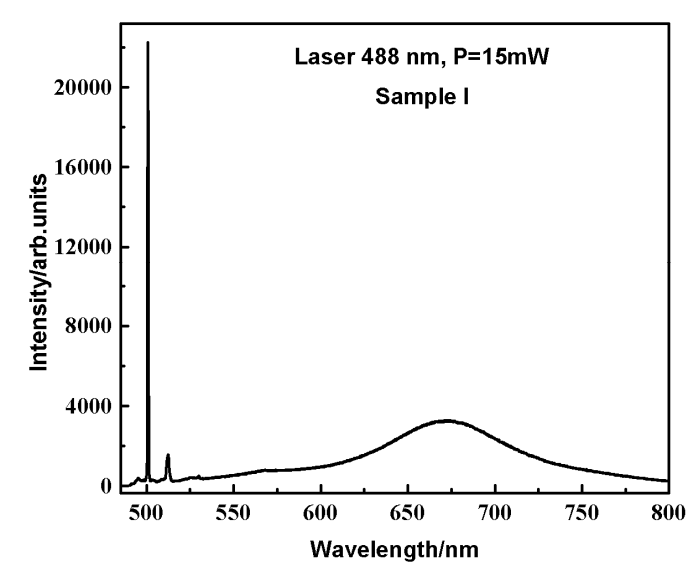

(a)

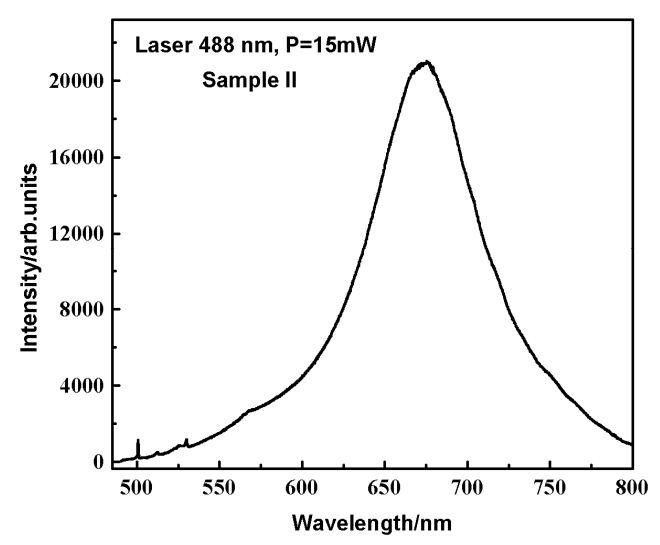

(b)

Figura 6.10 Espectros PL das estruturas macropororosas de silício obtidas com (a) $8 \%$ de HF em DMF e (b) $12 \%$ de HF em DMF, após a adsorção de moléculas de azul de metileno a partir de uma solução de azul de metileno em etanol de $10^{-3} \mathrm{M}$. 


\subsection{Intensificação do espalhamento Raman do fônon óptico do cristal de silício}

para aplicação em um dispositivo de emissão laser de silício

Como descrito na introdução, a partir dos anos 90, o silício tem recebido especial atenção nas suas propriedades ópticas decorrentes de efeitos de confinamento quântico. Em particular, dispositivos de emissão laser em silício tem sido um grande desafio para a comunidade científica. Um dispositivo de emissão laser em silício é baseado na amplificação do sinal através da emissão de Raman estimulado do silício. A eficiência do sinal Raman estimulado depende principalmente da eficiência de espalhamento Raman do silício, isto é, a intensidade de emissão de Raman estimulado depende fortemente da secção transversal de espalhamento Raman do silício. O problema é determinar uma metodologia que permita maximizar o valor da secção transversal Raman. O método convencional utilizado consiste em alinhar o cristal de silício numa direção adequada em relação à direção do feixe incidente. Com este procedimento é possível obter uma intensidade de espalhamento de até duas vezes em relação à configuração de mesmo espalhamento. Neste trabalho foi proposta uma metodologia inédita para intensificar o espalhamento Raman de silício conseguindo valores de intensificação de até 70 vezes em relação à intensidade Raman convencional do silício em sua configuração de máximo espalhamento.

\subsubsection{Introdução}

O silício poroso é um material com grande potencial de aplicação na área da fotônica [120-130]. As propriedades ópticas são dependentes da sua estrutura [131-150]. Uma grande variedade de artigos relacionados à modulação das propriedades ópticas foi publicada como: controle dos parâmetros eletroquímicos durante a formação [136-137,140-142,145], utilização de luz durante a anodização eletroquímica [132,142-144,146], utilização de campos magnéticos durante a anodização [150] e finalmente o controle da dopagem das lâminas de Si utilizadas na anodização [141,145,147-149]. O parâmetro mais sensível mostrou ser o controle da dopagem nas lâminas de Si [149]. Neste sentido, controlar a resistividade das lâminas de Si resulta um excelente meio para modular as propriedades ópticas do filme de PS. 
Lâminas de silício implantadas com hidrogênio apresentam mudança da sua condutividade elétrica. No caso de silício tipo $\mathrm{P}$ sugere-se que o aumento da resistividade seja conseqüência da formação de bolhas de $\mathrm{H}$ no interior do filme [151]. A mudança da resistividade provoca mudança na formação estrutural do filme de silício poroso.

6.3.2 IMPLANTAÇÃO DE HIDROGÊNIO E RECOZIMENTO TÉRMICO RÁPIDO EM LÂMINAS DE SILÍCIO

Foram utilizadas lâminas de silício tipo $\mathrm{P}$ com orientação $<100>$ e com resistividade de 10-20 $\Omega \mathrm{cm}$. A implantação de Hidrogênio foi realizada com uma energia de 70 $\mathrm{keV}$, e uma dose de $1 \times 10^{16} \mathrm{H}^{+} / \mathrm{cm}^{2}$. Após a implantação, algumas lâminas de silício foram submetidas a um recozimento térmico rápido, a uma temperatura de $450^{\circ} \mathrm{C}$ durante 5 minutos em atmosfera de Argônio. Foi utilizada uma rampa de $50^{\circ} \mathrm{C} / \mathrm{s}$ para atingir a temperatura final $\left(450^{\circ} \mathrm{C}\right)$. As Lâminas com implantação de Hidrogênio e recozimento térmico rápido são apresentadas na tabela III.

Tabela III - Lâminas de silício implantadas com $\mathrm{H}^{+}$e submetidas a recozimento térmico rápido.

\begin{tabular}{lcc}
\hline Amostras & Implantadas com $\mathrm{H}^{+}$ & Com recozimento térmico rápido (RTA) \\
\hline Amostra S & $\mathrm{XX}$ & \\
Amostra E & $\mathrm{XX}$ & \\
Amostra R1 & $\mathrm{XX}$ & $\mathrm{XX}$ \\
Amostra R2 & $\mathrm{XX}$ & $\mathrm{XX}$ \\
\hline
\end{tabular}

XX: Indica o processo ao qual a amostra foi submetida.

\subsubsection{Formação de silício poroso}

O processo de formação de silício poroso foi similar ao descrito no capítulo de metodologia. As lâminas já implantadas com $\mathrm{H}^{+}$e algumas submetidos a processos de recozimento térmico rápido (RTA) foram anodizadas numa solução eletrolítica de $\mathrm{HF}$ :Etanol com uma densidade de corrente de $20 \mathrm{~mA} / \mathrm{cm}^{2}$ durante 10 minutos. 


\subsubsection{Caracterização dos filmes de PS modulados por implantação de $\mathrm{H}^{+}$}

Os filmes foram caracterizados por técnicas de espectroscopia Raman, PL e microscopia eletrônica de varredura. Para a caracterização por microscopia eletrônica de varredura foi utilizado o equipamento gentilmente oferecido pelo laboratório de microscópica eletrônica (LME) do Laboratório Nacional de Luz Sincrotron (LNLS).

\subsubsection{Resultados Preliminares e Discussão}

A imagem do microscópio de varredura (SEM) revela a existência de duas camadas claramente definidas no silício poroso (Figura 6.11). A camada superior (layer I) apresenta uma espessura da ordem de $2 \mu \mathrm{m}$ e a camada inferior (layer II) apresenta uma espessura da ordem de $10 \mu \mathrm{m}$. A imagem SEM da segunda camada apresenta um brilho branco típico de materiais isolantes que se carregam pela incidência de feixe de elétrons.

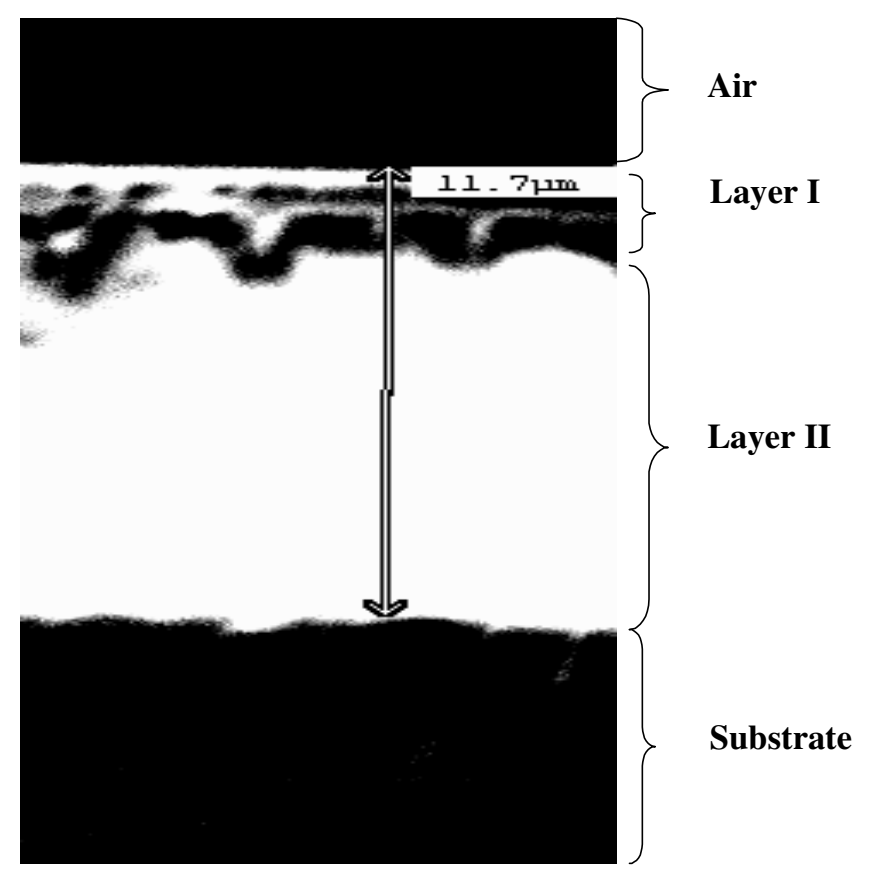

Figura 6.11 Imagem SEM da amostra R2 clivada

Por outro lado, foram realizadas medidas de espalhamento Raman na amostra R2 clivada, focalizando o feixe em cada uma das camadas mostradas na imagem SEM (Figura 6.11). A segunda camada (inferior) mostrou uma estrutura de banda similar às bandas de espalhamento observadas em estruturas de PS. Nesse sentido, utilizando o deslocamento e alargamento da banda de espalhamento e o modelo de 
confinamento de fônons [152-155], foi determinado o tamanho efetivo de cristalitos sendo em torno de 2,5 nm. A camada superficial apresentou uma banda de espalhamento principal em $520 \mathrm{~cm}^{-1}$ similar ao do c-Si. No entanto, foi possível observar uma pequena contribuição da estrutura do PS devido ao tamanho do feixe focalizado $(3 \times 3 \mu \mathrm{m} \times \mu \mathrm{m})$.

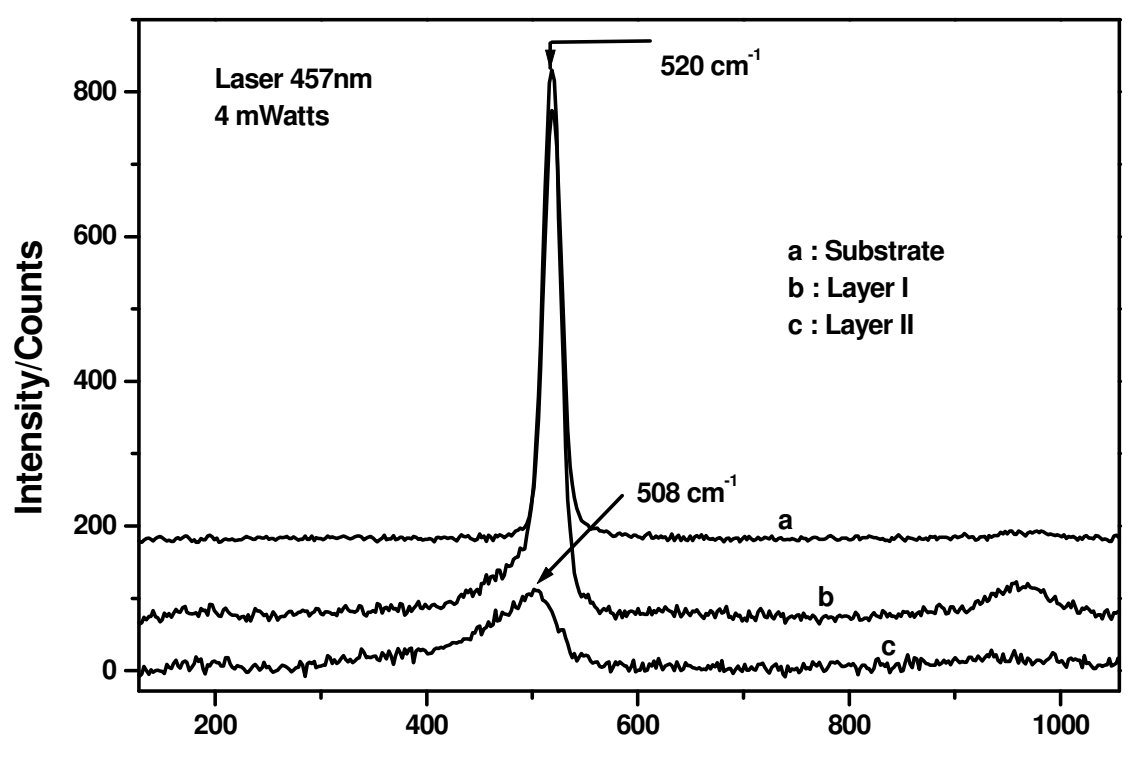

Raman Shift $/ \mathrm{cm}^{-1}$

Figura 6.12 Espectros Raman da amostra clivada R2 com o feixe de excitação focalizado na camada I (layer I), camada II (layer II) e substrato (substrate) respectivamente. Os espectros foram excitados com laser de 457,0 nm.

Os resultados da espectroscopia Raman (Figura 6.12) revelam que a camada superficial apresenta uma estrutura das ligações Si-Si igual ao do c-Si. Apesar da excitação parcial da primeira camada (tamanho do feixe $3 \times 3 \mu m \times \mu m$ ), é possível observar uma pequena intensificação relativa com relação à banda de espalhamento do c-Si. A banda de espalhamento Raman da segunda camada apresenta uma intensidade 7 vezes menor em relação à banda de espalhamento na camada superficial. 
Foram obtidos os espectros de emissão PL das duas camadas (Figura 6.13). Observa-se na Figura 6.13 que a emissão PL da camada profunda é mais intensa em relação à primeira camada. A emissão $P L$ da primeira camada deve incluir também a contribuição da segunda camada, devido ao tamanho da área de excitação $(3 \times 3 \mu m \times \mu m)$.

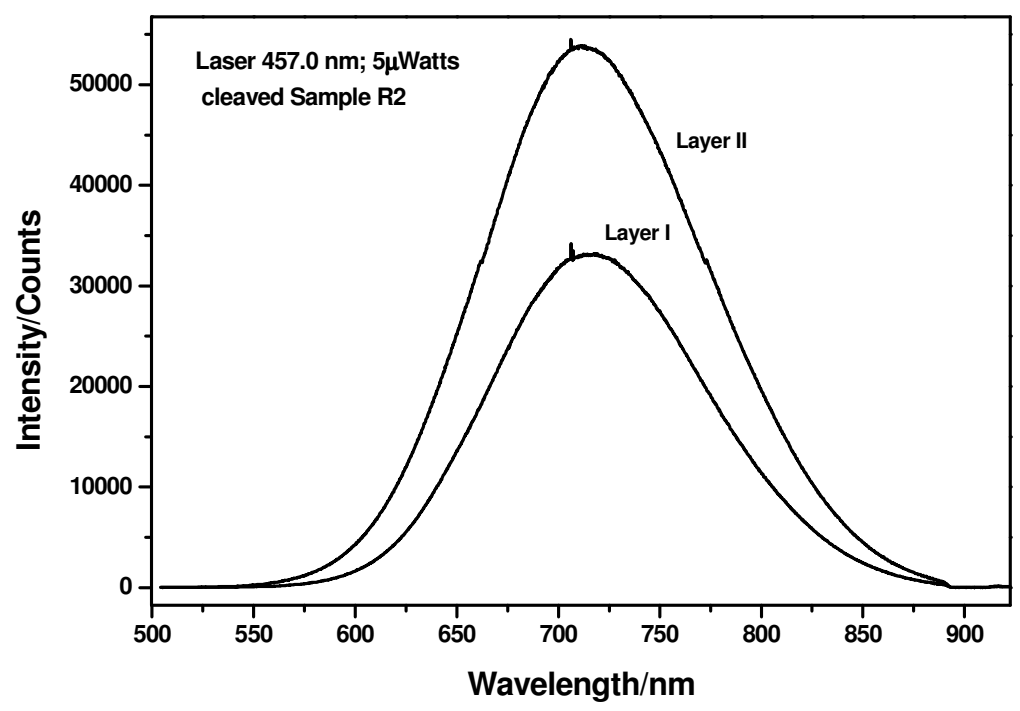

Figura 6.13 Espectros de emissão PL na amostra R2 (clivada). O espectro de emissão PL foi excitado com laser de 457,0 nm.

Para analisar a nova camada superficial, amostras não clivadas foram excitadas com fonte laser de 514,5 nm, 632,8 nm e 457,0 nm. Os espectros Raman são mostrados nas Figuras 6.14 a 6.19. 


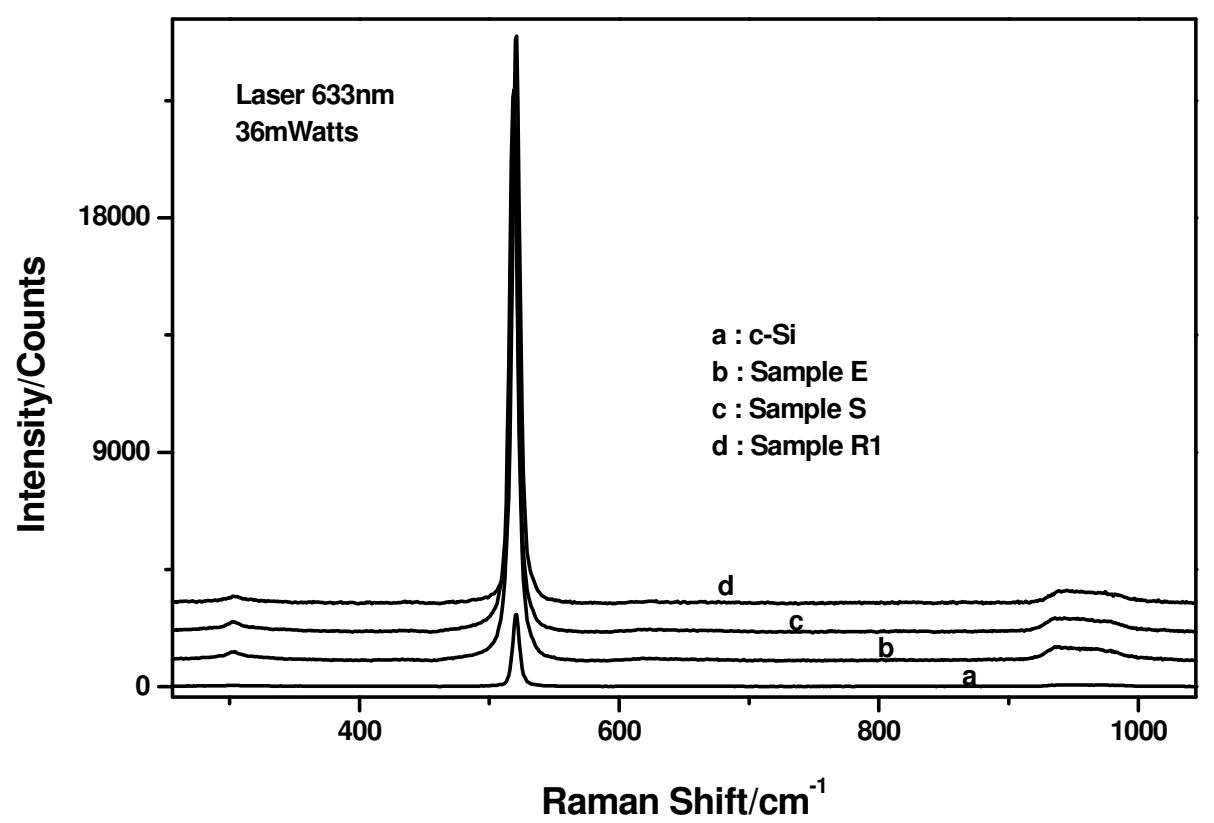

Figura 6.14 Espectros Raman das amostras (não clivadas) E, S, R1 e c-Si. Os espectros Raman foram excitados com laser de 632,8 nm.

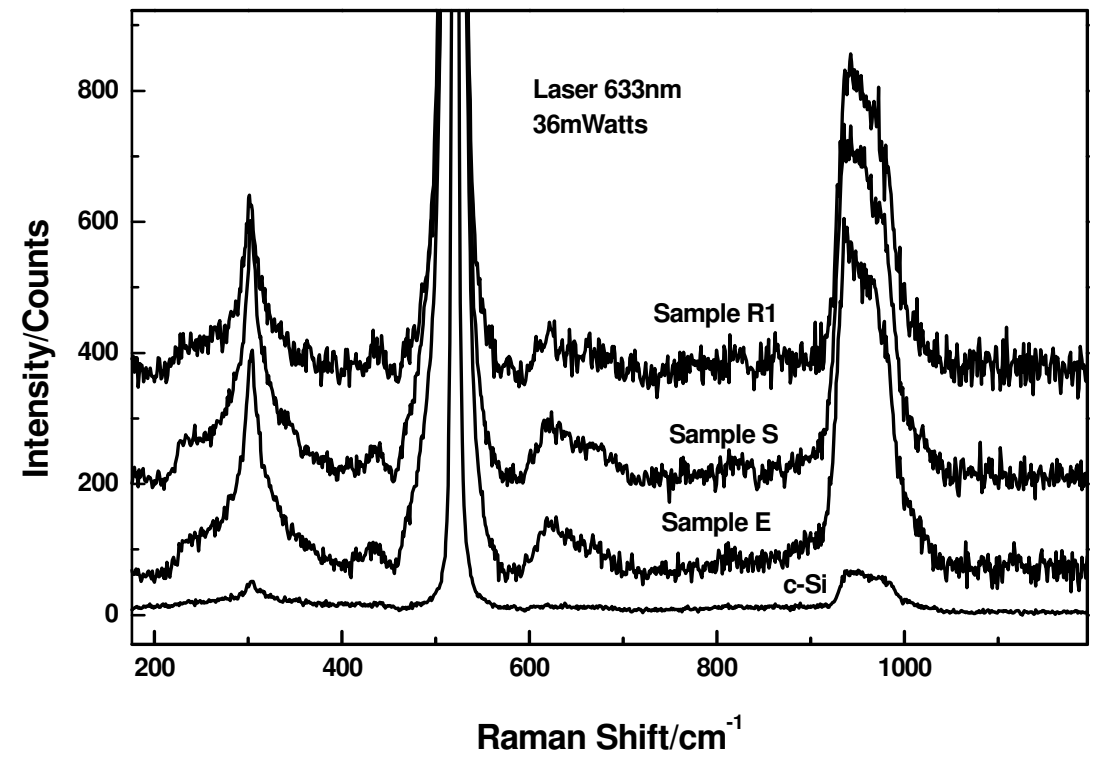

Figura 6.15 Espectros Raman de Segunda ordem das amostras (não clivadas) E, S, R1 e c-Si. Os espectros Raman foram excitados com laser de 632,8 nm. 


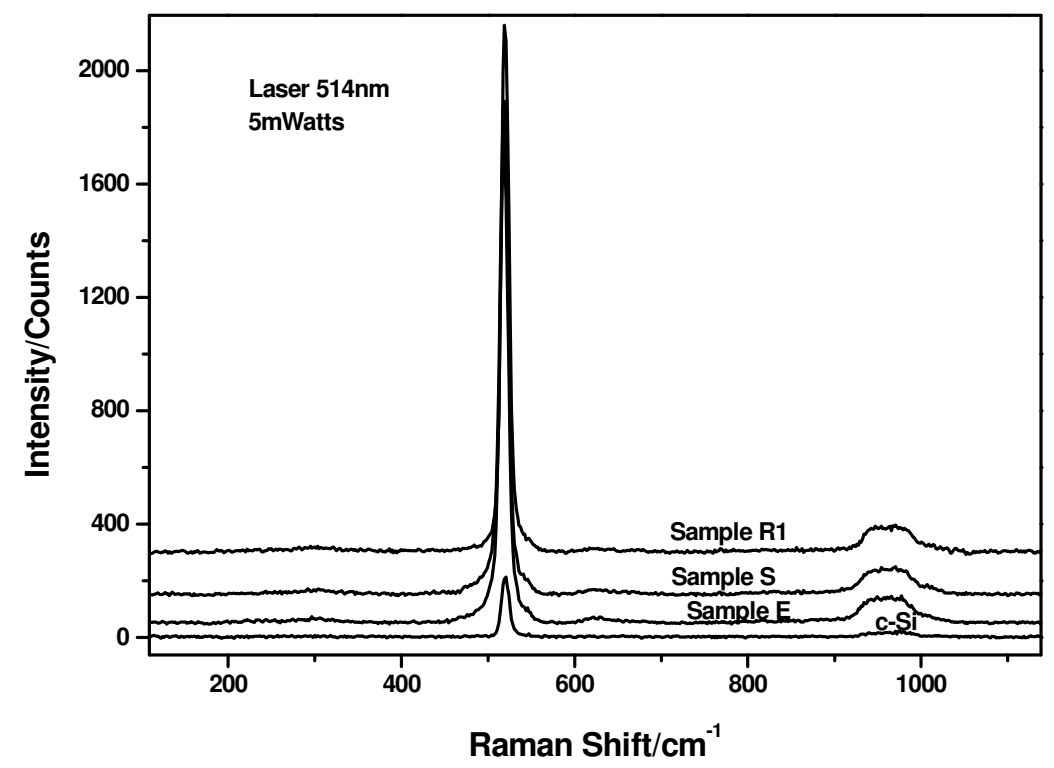

Figura 6.16 Espectros Raman das amostras (não clivadas) E, S, R1 e c-Si. Os espectros Raman foram excitados com laser de $514,5 \mathrm{~nm}$.

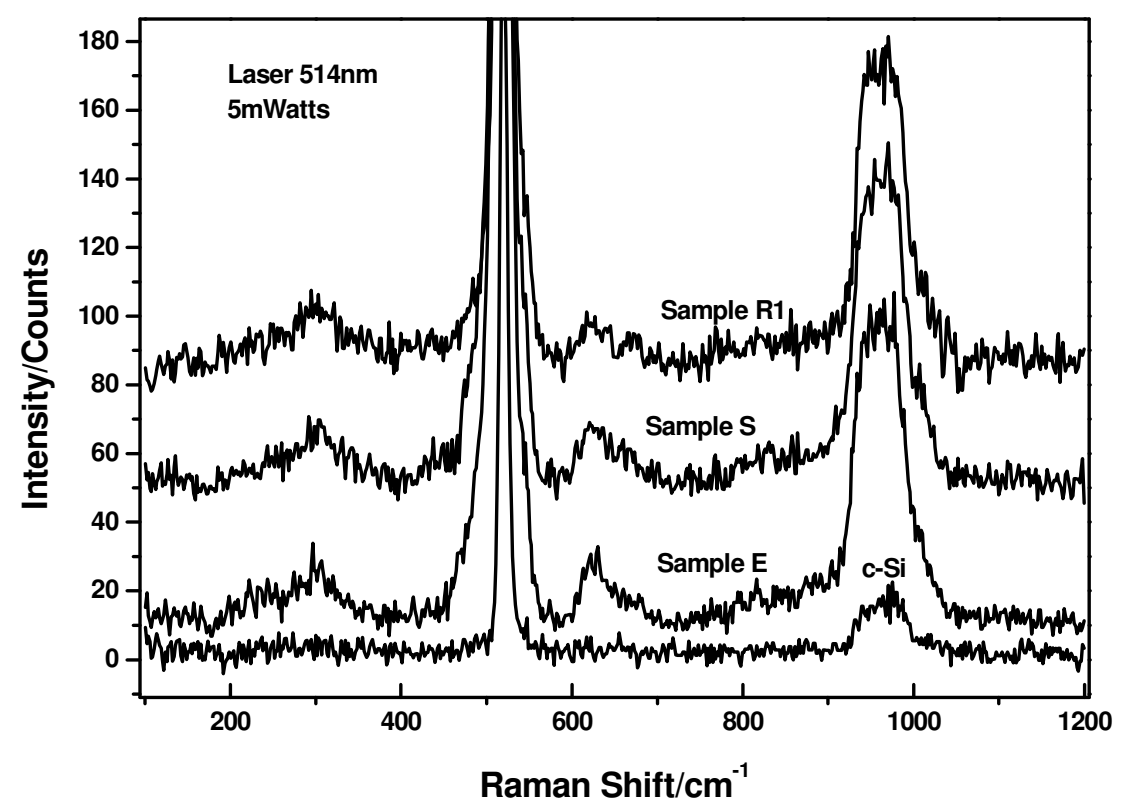

Figura 6.17 Espectros Raman de segunda ordem das amostras (não clivadas) E, S, R1e c-Si. Os espectros Raman foram excitados com laser de 514,5 nm. 


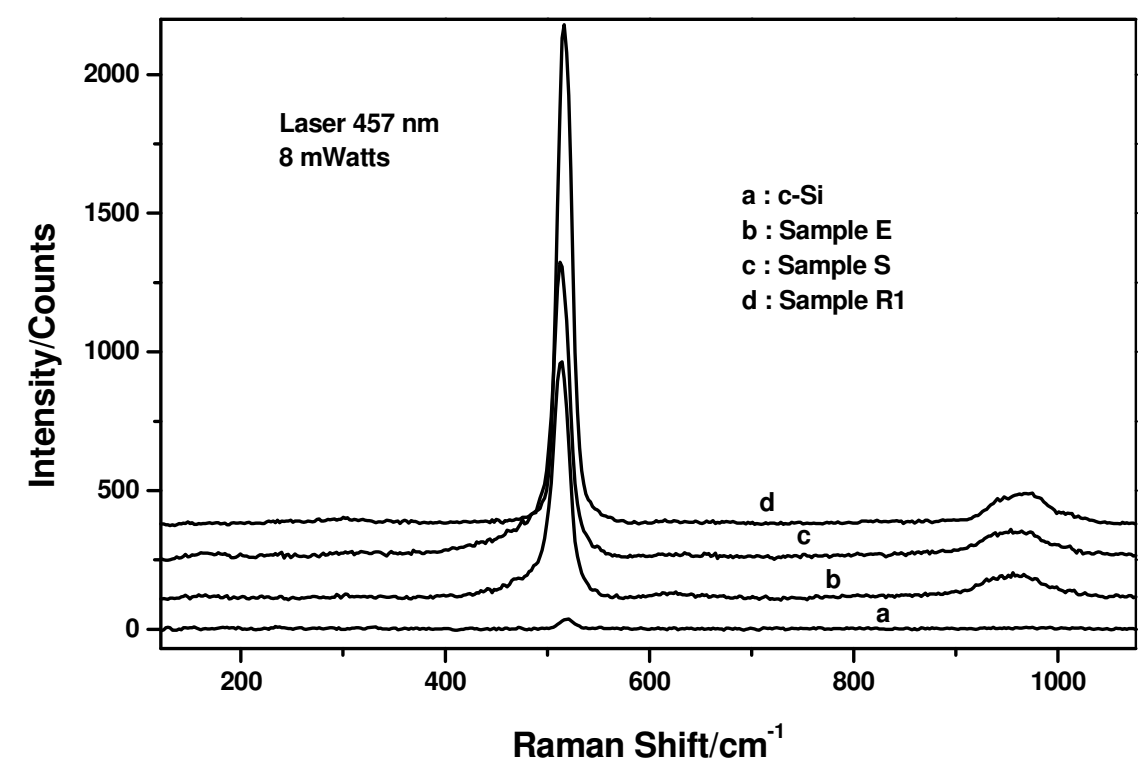

Figura 6.18 Espectros Raman das amostras (não clivadas) E, S, R1 e c-Si. Os espectros Raman foram excitados com laser de $457,0 \mathrm{~nm}$ e potência de $8 \mathrm{~mW}$.

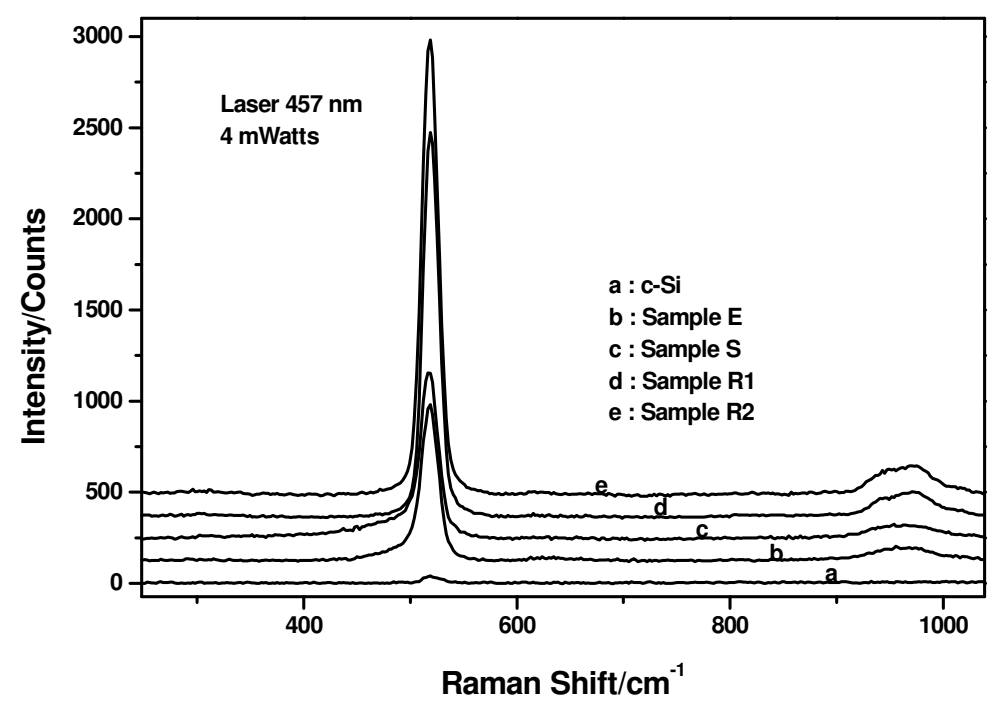

Figura 6.19 Espectros Raman das amostras (não clivadas) E, S, R1, R2 e c-Si. Os espectros Raman foram excitados com laser de $457,0 \mathrm{~nm}$ e potência de $4 \mathrm{~mW}$.

Observa-se que os espectros Raman em todos os casos apresentam a mesma característica do espectro Raman no c-Si, porém em materiais amorfos a banda de 
espalhamento apresenta um deslocamento e alargamento [155]. As bandas de espalhamento não apresentaram uma contribuição da estrutura do PS (camada II), e conseqüentemente podemos afirmar que os espectros Raman observados correspondem à camada superficial. As bandas de espalhamento de primeira ordem $\left(520 \mathrm{~cm}^{-1}\right)$ foram integradas e comparadas com a banda de espalhamento no c-Si com superfície polida. As intensidades relativas são mostradas na Figura 6.20.

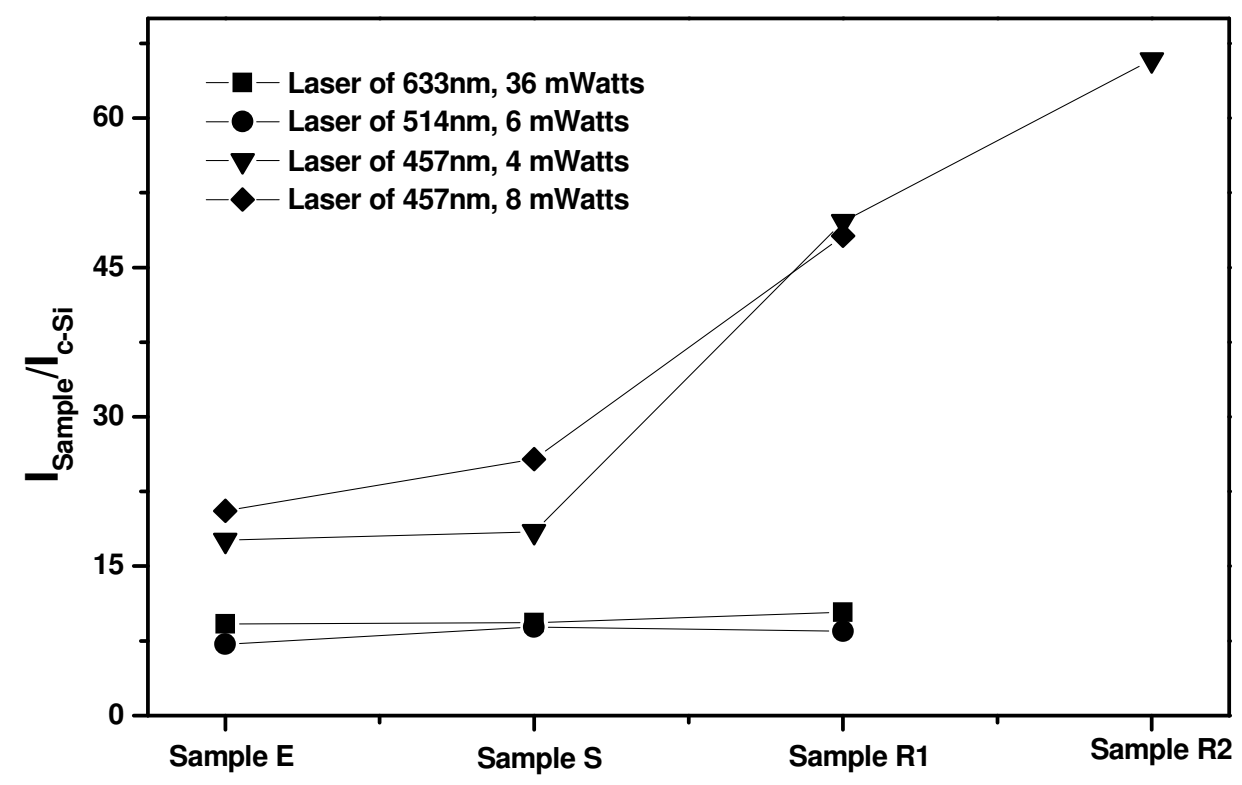

Figura 6.20 Intensidades relativas das bandas de espalhamento de primeira ordem relativa ao do c-Si com superfície polida.

Observa-se na Figura 6.20 que a intensificação relativa das bandas de espalhamento na camada superficial varia de 9 a 70 vezes. As bandas de segunda ordem apresentaram os mesmos valores de intensificação em cada caso. A intensificação depende da forma de preparação dos filmes. Filmes de PS que não incluíram o processo RTA (E, S) apresentaram menor grau de intensificação daquelas que além da implantação foram submetidas ao processo RTA (amostras $\mathrm{R} 1, \mathrm{R} 2$ ). Processos de RTA fazem com que os íons $\mathrm{H}^{+}$formem ligações com os átomos de Boro e Si [151].

Para explicar o fenômeno de intensificação observada, discutiremos os possíveis mecanismos de intensificação: o primeiro mecanismo pode ser devido à quebra das 
regras de seleção q (quantidade do movimento do fônon) induzindo o espalhamento proibido. Como não foi observado um alargamento das bandas de espalhamento, a contribuição deverá estar restrita a um domínio próximo de $q=0$. A ativação do espalhamento Raman proibido pode ser devido à quebra da simetria. A implantação de $\mathrm{H}^{+}$poderia provocar a quebra da simetria local. Para verificar este possível efeito, uma lâmina de c-Si foi corroída anisotropicamente numa solução de KOH [156-157] com a finalidade de aumentar a área superficial. Posteriormente foi implantado $\mathrm{H}^{+}$na mesma energia e dose anteriormente utilizadas. O espectro Raman desta estrutura é mostrado na Figura 6.21. Observa-se que o espectro Raman desta estrutura é igual ao do c-Si sem tratamento. O resultado observado mostra que a implantação de íons $\mathrm{H}^{+}$não contribui com o mecanismo de intensificação $q$ induzido.

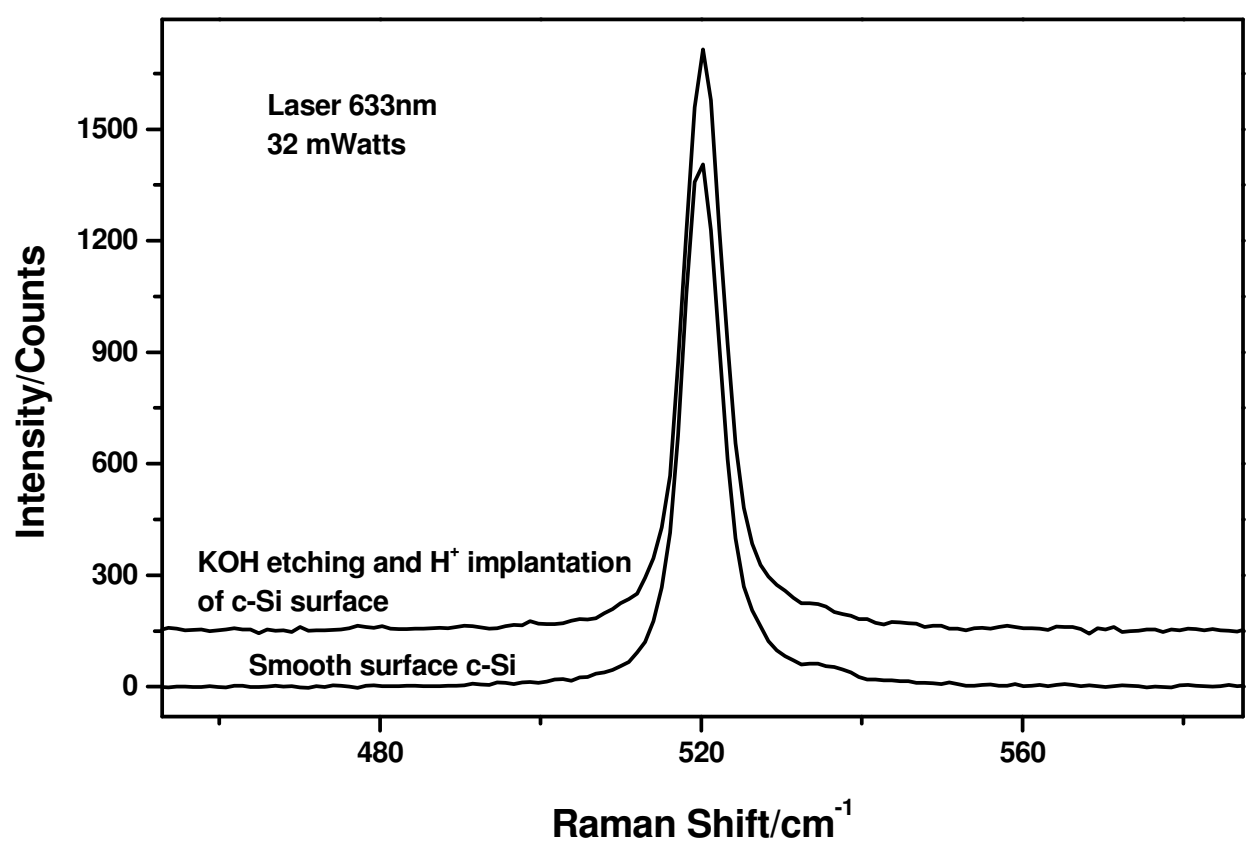

Figura 6.21 Espectros Raman de uma amostra de c-Si corroída, implantada com $\mathrm{H}^{+}$ e submetida a processo de RTA. Para comparação é mostrada a banda de espalhamento Raman do c-Si de superfície polida e sem implantação de $\mathrm{H}^{+}$.

A segunda camada da amostra R2 apresenta uma elevada emissão PL (Figura 6.13). Portanto pode-se supor que a primeira camada está submetida a duas 
freqüências de estimulação: $\omega_{\llcorner}$correspondente ao laser e $\omega_{\mathrm{PL}}$ correspondente à emissão PL. O fenômeno de excitação estimulada é possível desde que a potência do laser utilizado seja de $0.4 \mathrm{MWatt} / \mathrm{cm}^{2}$ a $36 \mathrm{MWatt} / \mathrm{cm}^{2}$, condição necessária para a aparição do efeito não linear [158]. Este fenômeno é conhecido como espalhamento Raman estimulado (SRS) [159-160]. Para verificar ou descartar a contribuição do efeito SRS na intensificação observada, foi utilizado uma microestrutura fabricada com o auxílio da implantação de $\mathrm{H}^{+}$que será apresentada posteriormente. A microestrutura consiste de uma área longitudinal de $10 \mu \mathrm{m} x$ $1000 \mu \mathrm{m}$ com estrutura de PS que se propaga $16 \mu \mathrm{m}$ em profundidade e $16 \mu \mathrm{m}$ lateralmente relativo à borda da janela utilizada para confinar a formação de PS (vide interior da Figura 6.22). A propagação lateral da estrutura de PS gera um filme fino de $1 \mu \mathrm{m}$ de espessura. $\mathrm{O}$ filme fino foi implantado com íons de $\mathrm{H}^{+}$e submetido ao processo RTA. Os espectros Raman da microestrutura foram obtidos em duas regiões de interesse: no primeiro caso o feixe foi focalizado na região com PS, no segundo caso o feixe foi focalizada na região do filme fino de $1 \mu \mathrm{m}$ espessura. Os espectros foram comparados com o do c-Si. Na Figura 6.22 são mostrados os espectros Raman observados na microestrutura. A fonte de excitação laser escolhida foi de $632,8 \mathrm{~nm}$ por estar próxima do máximo de emissão PL já que o deslocamento Raman $\Delta \omega$ do fônon óptico no c-Si é pequeno. Não foi observada uma intensificação Raman nesta microestrutura e, conseqüentemente, um possível efeito de intensificação Raman estimulado é descartado para explicar a intensificação observada nos filmes em estudo. 


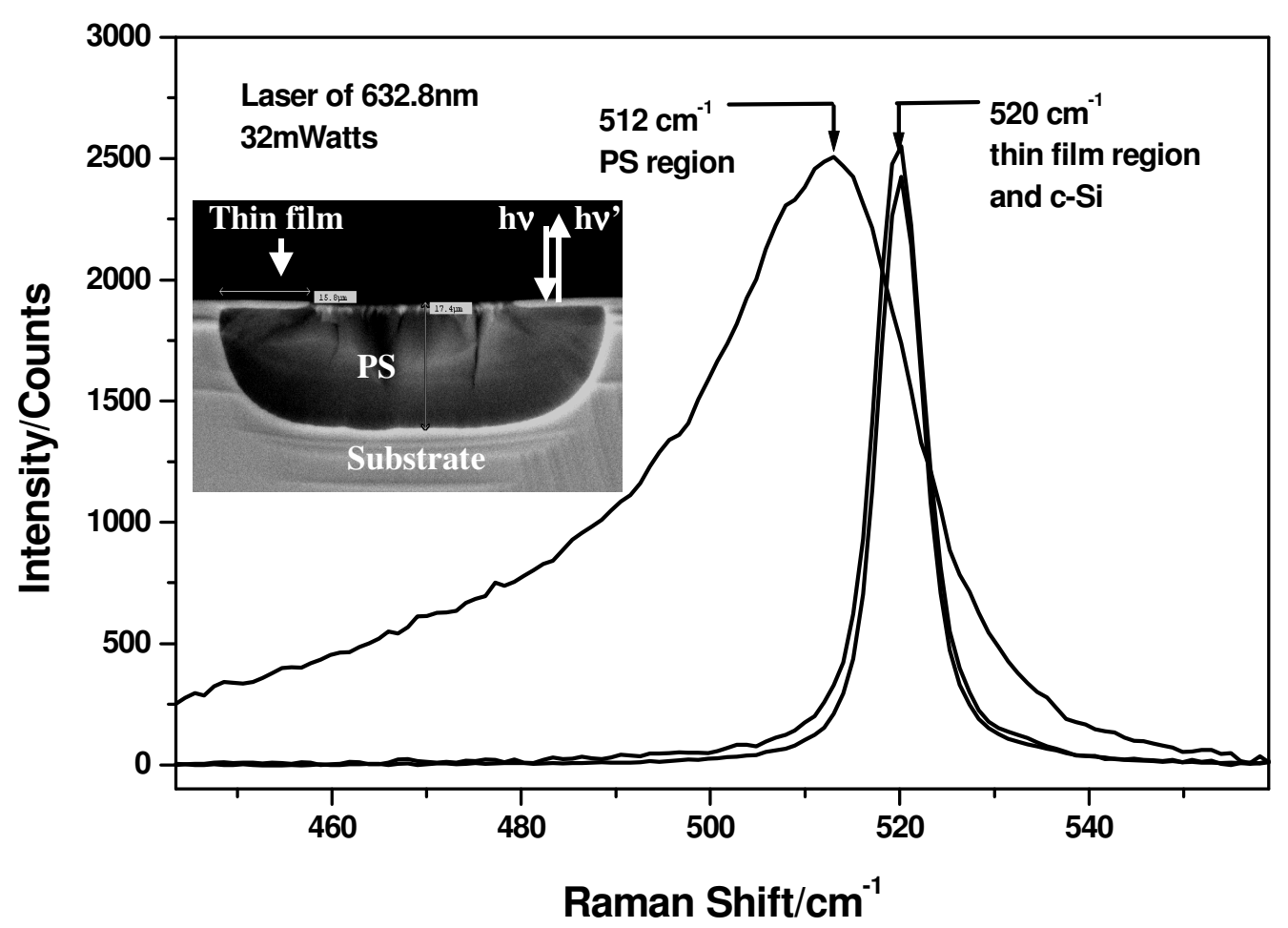

Figura 6.22 Espectros de espalhamento Raman numa microestrutura de PS. O interior da Figura mostra a seção transversal da microestrutura com o filme fino (thin film) de $1 \mu \mathrm{m}$ de espessura na parte superficial da estrutura de PS. $O$ feixe foi focalizado na região de filme fino.

Outro possível mecanismo pode ser o fenômeno de auto-focalização. A literatura reporta que alguns materiais e líquidos apresentam efeitos de auto-focalização quando a potência do laser é da ordem de Mwatts $/ \mathrm{cm}^{2}$ [161-162]. O fenômeno de auto-focalização se produz devido à indução de índice de refração positivo por conta do campo elétrico da radiação, acrescentando assim o índice de refração efetivo do meio. A parte central do feixe, que é a mais intensa, vê um índice de refração maior e assim propaga-se mais lentamente que nas bordas. Conseqüentemente a frente de onda é distorcida. O foco apresenta-se na posição $Z_{\mathrm{f}}(\mathrm{t})=\mathrm{K} /\left[\sqrt{\boldsymbol{P}(t)}-\sqrt{\boldsymbol{P}_{C r}}\right][163]$, onde $\mathrm{K}$ e $\mathrm{P}_{\mathrm{Cr}}$ são constantes que dependem das características do feixe de excitação e do material. À medida que a potência do laser cresce, $Z_{f}$ decresce. Quando $Z_{f}$ surge no meio, o foco intenso gera uma intensa radiação Raman. No presente trabalho este fenômeno não acontece porque na maior intensidade do laser 
não é observada uma sistemática intensificação do espalhamento Raman (Figura $6.20)$.

Um outro mecanismo de intensificação Raman pode ser o mecanismo de Raman intensificado por efeitos de superfície (plasma) conhecida como efeito SERS [164165]. Este tipo de intensificação é promovido pelos plasmas superficiais gerados em alguns metais com superfície rugosa onde uma elevada densidade de portadores livres fica disponível. As amostras em discussão foram implantadas com $\mathrm{H}^{+} \mathrm{e}$ submetidas a processos de RTA. Conseqüentemente, a densidade de portadores livres decresce fortemente e com isso a probabilidade de excitações coletivas deve decrescer também. No entanto, existem alguns isolantes e semicondutores que apresentam uma excitação coletiva. Os plasmas são gerados por excitação coletiva dos portadores na banda de valência [166]. Porém, no estágio atual, não podemos afirmar se este mecanismo contribui na intensificação Raman observada.

Por outro lado, a intensificação Raman depende da energia do laser de excitação (Figura 6.20). Elevada intensificação do espalhamento Raman corresponde ao laser de mais alta energia utilizada (457 nm). Para verificar se esta intensificação é devida a transições eletrônicas, as amostras E, S e R1 foram caracterizadas pela técnica de refletância especular óptica. Os espectros de refletância especular são mostrados na Figura 6.23. 


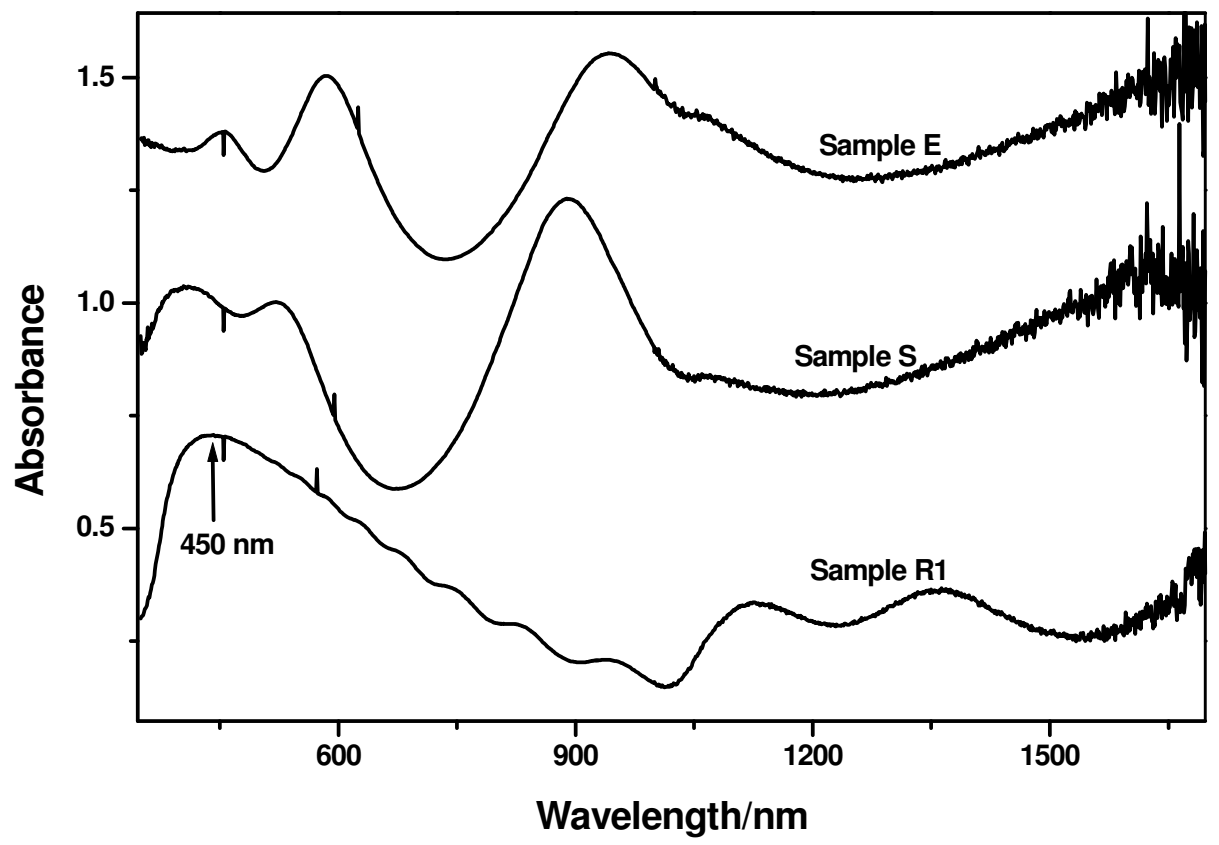

Figura 6.23 Espectros de refletância especular das amostras E, S e R1. A referência foi o c-Si com superfície polida.

Observa-se na Figura 6.23 que a amostra R1 apresenta uma banda de absorção melhor definida e intensa centrada em $450 \mathrm{~nm}$. A amostra $S$ apresentou uma banda de absorção menos intensa nessa região. No entanto, na amostra $E$, a banda de absorção nessa região apresenta-se bem menos definida e enfraquecida pelas figuras de interferência de filme fino. O resultado observado é diretamente correlacionado com a maior intensificação Raman na amostra $\mathrm{R} 1$ em relação às amostras $\mathrm{E}$ e $\mathrm{S}$ respectivamente. A banda de absorção discutida é significativamente larga o que explicaria a intensificação Raman observada ainda para radiação laser de $632,8 \mathrm{~nm}$. A partir dos resultados observados propomos o mecanismo de Raman ressonante como responsável pela intensificação observada. $O$ espalhamento Raman ressonante em sólidos é amplamente conhecido [167-169]. O diagrama básico destes processos é mostrado na Figura 6.24. A contribuição do tensor Raman nos processos de primeira ordem e processos de segunda ordem do tipo (a) apresenta dois termos de energia no denominador. O processo do tipo (b) apresenta três termos de energia no denominador. Portanto, quando todos os termos de 
energia do denominador eram iguais, eles ressonaram mais intensamente que aqueles do tipo (a). O processo tipo (c) é idêntico a dois processos consecutivos do primeiro tipo, porém os fótons de conexão podem ser virtuais. Aparecem quatro termos de energia no denominador. Assim, é possível uma ressonância mais intensa que em todos os casos anteriores. No entanto, este processo envolve seis vértices o que faz que o processo seja débil se comparado com os processos (a) e (b). No presente trabalho, as intensidades relativas das bandas de segunda ordem ( $\left.I_{\mathrm{sec}} / \mathrm{I}_{\mathrm{LO}}\right)$ mostraram-se iguais aos observados no c-Si, e conseqüentemente, podemos afirmar que a intensificação das bandas de segunda ordem responde ao mesmo mecanismo das da primeira ordem, isto é, no sentido de espalhamento Raman ressonante as bandas de espalhamento de segunda ordem são ressonantes segundo o mecanismo do tipo (a) anteriormente descrito.

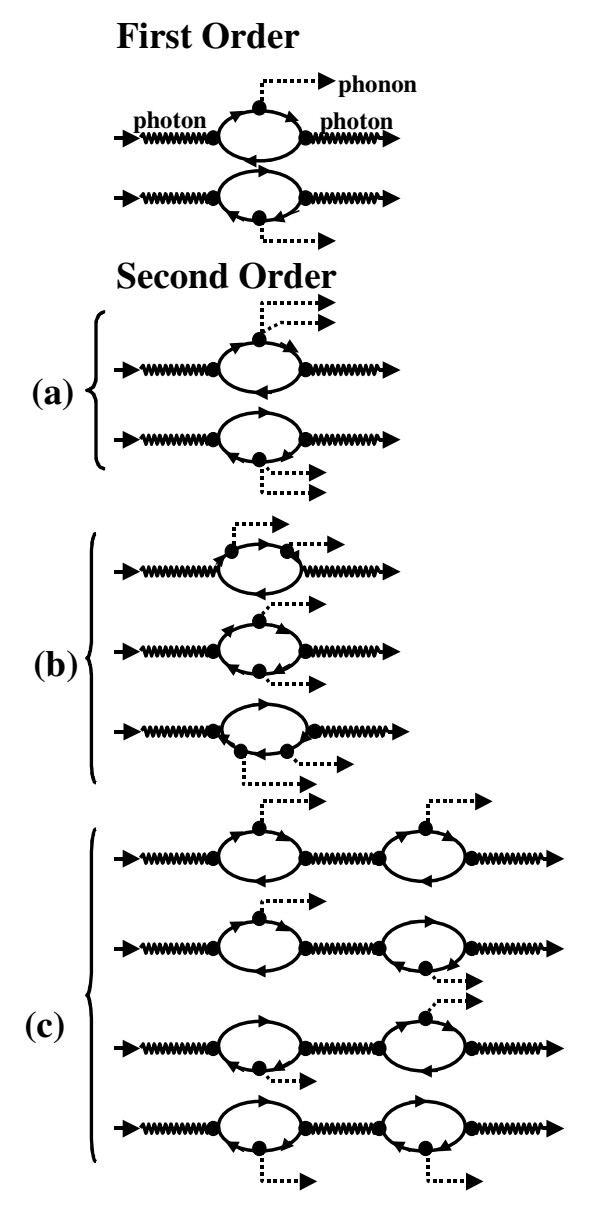

Figura 6.24 Diagramas esquemáticos dos processos de espalhamento Raman ressonante de primeira (first order) e de segunda ordem (second order). 


\section{CAPÍTULO VII}

\section{CONCLUSÕES E PERSPECTIVAS FUTURAS}

O método de auto-organização de esferas de poliestireno mostrou-se promissor na obtenção de estruturas organizadas de ouro para estudo da intensificação do espalhamento Raman de superfície e mostrou-se favorável para sua utilização na fabricação de cristais fotônicos metálicos. A melhor estrutura organizada foi obtida a partir de uma estrutura recozida a $400^{\circ} \mathrm{C}$ em ambiente de $\mathrm{N}_{2}$. Estas estruturas permitiram a obtenção de espectros Raman de moléculas de cristal violeta adsorvidas sobre elas. A intensificação do espalhamento Raman foi atribuída à intensificação do campo próximo na superfície metálica devido aos modos de plasma de superfície nas regiões nanométricas periódicas de interconexões de $\mathrm{Au}$. Estes resultados mostram que o cristal fotônico metálico pode ser um excelente substrato para a detecção de uma molécula devido à reprodutibilidade e à possibilidade do controle do tamanho da rede metálica regular como verificado neste trabalho. Adicionalmente, estas estruturas podem ser utilizadas no estudo de espalhamento Raman intensificado não linear.

A tecnologia do silício poroso é muito importante, pois pode modular as propriedades do silício, sendo as propriedades ópticas e físicas do silício poroso importantes para o desenvolvimento de dispositivos ópticos, elétricos e dispositivos sensores em geral. Podendo modular as propriedades estruturais do silício, pode-se variar a seção transversal de espalhamento Raman do silício, sendo esta uma forma alternativa de aumentar a eficiência do espalhamento Raman, isto é, a intensidade de emissão de Raman estimulado. Uma forma convencional de aumentar a secção de choque consiste em alinhar o cristal de silício numa direção adequada em relação à direção do feixe incidente. Com este procedimento é possível obter uma intensidade de espalhamento de até duas vezes em relação à configuração de mesmo espalhamento. A partir do método de implantação de hidrogênio foram obtidas nanoestruturas de silício poroso para intensificar o espalhamento Raman de silício, obtendo-se valores de intensificação de até 70 vezes em relação à intensificação Raman convencional do silício em sua configuração de máximo espalhamento. Então, foi demonstrada a modulação das propriedades ópticas dos 
filmes de PS através da implantação de íons $\mathrm{H}^{+}$. O filme de PS apresentou duas camadas bem definidas, sendo a camada superficial correlacionada com a profundidade de implantação dos íons $\mathrm{H}^{+}$, e a camada profunda correspondente á região não atingida pela implantação. A camada superficial mostrou as mesmas características estruturais do cristal de silício (c-Si) e a camada profunda apresentou uma estrutura típica de silício poroso com forte emissão PL. A camada superficial apresentou uma intensificação do espalhamento Raman. Esta intensificação é atribuída ao fenômeno de Raman ressonante. Este fenômeno de Raman ressonante pode ser utilizado para a obtenção de um dispositivo de emissão laser (laser de silício).

Adicionalmente, é importante considerar que a utilização do silício na obtenção das estruturas está relacionada à possibilidade de integração dos dispositivos em um único chip. Então, as estruturas de silício poroso foram também utilizadas para intensificação de campo próximo. Desta forma, é possível detectar um único átomo ou molécula adsorvida. A intensificação do campo próximo de superfície foi estudada através de uma molécula de prova (azul de metileno) previamente adsorvida na superfície das estruturas. O fenômeno de intensificação Raman observado nas estruturas obtidas não poderia ser explicado de acordo com os efeitos de espalhamento Raman intensificado por superfície (SERS) porque o substrato de silício é um material de baixa condutividade. Em superfícies condutoras o fenômeno está relacionado ao efeito de intensificação de superfície plasma-fônon (SERS). A intensificação Raman observada nas estruturas de silício poroso está relacionada ao decréscimo na banda fonônica óptica do filme macroporoso de silício. Então, propõese que há uma interação fônon-fônon responsável pela intensificação Raman. Este mecanismo proposto envolve dois diferentes processos fonônicos. Estes resultados reportados a respeito deste fenômeno são totalmente diferentes dos resultados reportados na literatura, já que aqueles reportados anteriormente envolvem somente substratos condutores.

Quanto às perspectivas futuras, o presente trabalho abre muitos leques $\mathrm{e}$ ramificações para a realização de trabalhos paralelos e trabalhos complementares. 
Os sistemas auto-organizados podem ser utilizados para a obtenção de nanoestruturas a serem utilizadas tanto como sensores ópticos como sistemas eletroquímicos. As próprias estruturas de Au ou mesmo sistemas auto-organizados de alumina porosa podem ser utilizadas como material sacrificial (máscara) para a obtenção de semicondutores organizados, em especial o silício, para possibilitar o uso das nanoestruturas em sistemas integrados na tecnologia do silício. A modulação das estruturas morfológicas, eletrônicas e ópticas do silício pode possibilitar a obtenção de laser de silício, combinando a característica óptica do efeito laser com as características eletrônicas e morfológicas do silício. Como os sistemas auto-organizados são importantes e podem gerar silício organizado para obtenção de intensificação Raman por campo próximo, há um grande interesse em estudar estes sistemas de forma minuciosa, sendo possível estudá-los propondo modelos a partir de morfologia matemática, redes neurais e modelos fractais. A proposição de ensaios de Raman estimulado em estruturas de silício poroso fabricadas a partir de substratos de silício implantados com $\mathrm{H}^{+}$é um importante trabalho futuro que poderá contribuir intensamente para o estudo dos efeitos de Raman estimulado no $\mathrm{Si}$, e consequentemente, na obtenção de dispositivos laser de silício. 


\section{REFERÊNCIAS BIBLIOGRÁFICAS}

[1] R. P. FEYNMAN. Classic Feynman: All the Adventures of a Curious Character, W. W. Norton \& Company: Portland (2005).

[2] R. FEYNMAN. "There's plenty of room at the bottom". Engineering and Science, 23, 22-36 (1959).

[3] E. BINZ; N. SCHEMPP. "INFORMATION TECHNOLOGY: the LIE GROUPS DEFINING the FILTER BANK OF THE COMPACt DISC". JOURNAL OF COMPUTATIONAL AND APPLIED MATHEMATICS. 144, 85-103 (2001).

[4] S. P. MURARKA. "Multilevel interconnections for ULSI and GSI era". Materials Science and Enginnering R. 19, 87-151 (1997).

[5] S. A. WILSON, et. al. "New materials for micro-scale sensors and actuators: An engineering review". Mat. Sci. and Eng. R. 56, 1-129 (2007).

[6] M. STEDMAN. "Scanning microsensors for nanotechnology". Sensors and Actuators A. 37, 11-15 (1993).

[7] F. THOMAS; J. R. DEGNA. "The implications of the fundamentals of shape selectivity for the development of catalysts for the petroleum and petrochemical industries". Journal of Catalysis. 216, 32-46 (2003).

[8] P. COUVREUR et al. "Nanotechnologies for drug delivery: Application to cancer and autoimmune diseases". Progress in Solid State Chemistry. 34, 231-235 (2006).

[9] J. RIU et. al. "Nanosensors in environmental analysis". Talanta. 69, 288-301 (2006).

[10] S. LIU et. al. Preparation and magnetic properties of $\mathrm{Fe}-\mathrm{Ag}$ granular alloy. Journal of Magnetism and Magnetic Materials. 233, 195-204 (2001).

[11] G. D. BERMAN. "Solid-state quantum computation - a new direction for nanotechnology". Superlattices and Microstructures. 27, 89-104 (2000).

[12] B. J. CROWFORD; R. D. BURKE. TEM and SEM Methods. Methods in Cell Biology. 74, 411-441 (2004).

[13] R. Wirth. "Focused Ion Beam (FIB) combined with SEM and TEM: Advanced analytical tools for studies of chemical composition, microstructure and crystal structure in geomaterials on a nanometre scale". Chem. Geol. 261 (3-4), 217-229 (2009). 
[14] G. BINNING, C. GERBER, E. STOLL; T. R. ALBRECHT; C. F. QUATE. "Atomic Resolution with Atomic Force Microscopy". Europh. Lett. 3, 1281-1286 (1987).

[15] I. LINDGREN. "Chemical shifts in X-ray and photo-electron spectroscopy: a historical review". J. of Elec. Spect. and Relat. Phen. 137-140, 59-71 (2004).

[16] E. V. EFREMOV; F. ARIESE; C. GOOIJER. "Achievements in resonance Raman spectroscopy: Review of a technique with a distinct analytical chemistry potential". Anal. Chim. Acta. 606 (2), 119-134 (2008).

[17] A. KUDELSKI. "Raman spectroscopy of surfaces”. Surf. Sci. 603 (10-12), 13281334 (2009).

[18] G. KAUPP; A. HERRMANN; J. SCHMEYERS; J. BOY. "SNOM: a new photophysical tool”. J. of Photochem. and Photobiol. A: Chemistry. 139 (2-3), 9396 (2001).

[19] O. SALA. Fundamentos de Espectroscopia Raman e no Infravermelho, Editora UNESP: São Paulo, 1995.

[20] R. J. H. CLARK; T. J. A. DINES. "Resonance Raman Spectroscopy, and Its Application to Inorganic Chemistry". New Analytical Methods (27). Angewandte Chemie International Edition in English. 25, 131-158 (1986).

[21] Z. Q. TIAN; B. REN; D. Y. WU. "Surface-Enhanced Raman Scattering: From Noble to Transition Metals and from Rough Surfaces to Ordered Nanostructures". J. Phys. Chem. B. 106, 9463-9482 (2002).

[22] K. KNEIPP; H. KNWIPP; I. ITZKAN; R. R. DASARI; M. S. FELD. Ultrasensitive Chemical Analysis by Raman Spectroscopy“. Chem. Rev. 99, 2957-2976 (1999).

[23] I. T. SHADI; B. Z. CHOWDHRY; M. J. SNOWDEN; R. WITHNALL. "Semiquantitative analysis of indigo by surface enhanced resonance Raman spectroscopy (SERRS) using silver colloids". Spectroch. Acta Part A: Molec. and Biomolec. Spectrosc. 59 (10), 2213-2220 (2003).

[24] A. HARTSTEIN; J. R. KIRTLEY; J. C. TSANG. Enhancement of the Infrared Absorption from Molecular Monolayers with Thin Metal Overlayers“. Phys. Rev. Lett. 45, 201-204 (1980).

[25] M. FLEISCHMANN; P. J. HENDRA; A. J. MCQUILLAN. "Raman spectra of pyridine adsorbed at a silver electrode“. Chem. Phys. Lett. 26, 163-166 (1974).

[26] D. L. JEANMARIE; R. P. VAN DUYNE. "Surface raman spectroelectrochemistry: Part I. Heterocyclic, aromatic, and aliphatic amines adsorbed on the anodized silver electrode“. J. Eletroanal. Chem. 84, 1-20 (1977). 
[27] K. KNEIPP et. al. "Single Molecule Detection Using Surface-Enhanced Raman Scattering (SERS)". Phys. Rev. Lett. 78, 1667-1670 (1997).

[28] B. PETTINGER; U. WENNING; H. WETZEL. "Surface plasmon enhanced Raman scattering frequency and angular resonance of Raman scattered light from pyridine on Au, Ag and Cu electrodes". Surface Sci. 101, 409-416 (1980).

[29] M. F. MROZEK; S. A. WASILESKI; M. J. WEAVER. "Periodic Trends in Electrode-Chemisorbate Bonding: Benzonitrile on Platinum-Group and Other Noble Metals As Probed by Surface-Enhanced Raman Spectroscopy Combined with Density Functional Theory". J. Am. Chem. Soc. 123, 12817-12825 (2001).

[30] R. K. CHANG; T. E. FURTAK. Surface Enhanced Raman Scattering. Plenum Press: New York, 1982.

[31] D. L. A. DE FARIA; M. L. A. TEMPERINI; O. SALA. "Vinte anos de efeito SERS". Química Nova. 22 (4), 541-552 (1999).

[32] A. OTTO et. al. Surface-enhanced Raman scattering. J. Phys. Condens. Matter. 4, 1143-1212 (1992).

[33] M. MOSKOVITS. "Surface-enhanced spectroscopy". Rev. Mod. Phys. 57, 783826 (1985).

[34] A. C. SANT'ANA et. al. "The adsorption of 2,2':6",2"-terpyridine, 4'-(5mercaptopentyl)-2,2':6',2"-terpyridinyl, and perchlorate on silver and copper surfaces monitored by SERS". Polyhedron. 22, 1673-1682 (2003).

[35] E. BURSTEIN et. al. "'Giant” Raman scattering by adsorbed molecules on metal surfaces". Solid State Comun. 29, 567-570 (1979).

[36] J. R. LOMBARDI et. al. "The effect of molecular structure on voltage induced shifts of charge transfer excitation in surface enhanced Raman scattering". Chem. Phys. Lett. 104, 240-247 (1984).

[37] J. C. RUBIM et. al. J. Phys. Chem. "Contribution of Resonance Raman Scattering to the Surface-Enhanced Raman Effect on Electrode Surfaces. A Description Using the Time Dependent Formalism“. 99, 15765-15774 (1995).

[38] F. W. KING; R. P. VAN DUYNE; G. C. J. SCHATZ. "Theory of Raman scattering by molecules adsorbed on electrode surfaces“. J. Chem. Phys. 69, 4472-4481 (1978).

[39] J. GERSTEN; A. J. NITZAN. "Electromagnetic theory of enhanced Raman scattering by molecules adsorbed on rough surfaces". J. Chem. Phys. 73, 30233037 (1980). 
[40] K. KNEIPP; H. KNEIPP; F. SEIFERT. "Near-infrared excitation profile study of surface-enhanced hyper-Raman scattering and surface-enhanced Raman scattering by means of tunable mode-locked Ti: sapphire laser excitation“. Chem. Phys. Lett. 233, 519-524 (1995).

[41] R. P. VAN DUYNE; J. C. HULTEEN; D. A. TREICHEL. "Atomic force microscopy and surface-enhanced Raman spectroscopy. I. Ag island films and Ag film over polymer nanosphere surfaces supported on glass“. J. Chem. Phys. 99, 2101-2115 (1993).

[42] F. J. GARCIA-VIDAL; J. B. PENDRY. "Collective Theory for Surface Enhanced Raman Scattering”. Phys. Rev. Lett. 77, 1163-1166 (1996).

[43] A. M. MICHAELS; M. NIRMAN; L. E. BRUS. "Surface Enhanced Raman Spectroscopy of Individual Rhodamine 6G Molecules on Large Ag Nanocrystals“. J. Am. Chem. Soc. 121, $9932-9939$ (1999).

[44] A. M. MICHAELS; J. JIANG; L. E. BRUS. "Ag Nanocrystal Junctions as the Site for Surface-Enhanced Raman Scattering of Single Rhodamine 6G Molecules". J. Phys. Chem. B. 104, 11965-11971 (2000).

[45] J. JIANG et. al. "Single Molecule Raman Spectroscopy at the Junctions of Large Ag Nanocrystals“. J. Phys. Chem. B. 107, 9964-9972 (2003).

[46] V. A. MARKEL et. al. "Small-particle composites. I. Linear optical properties". Phys. Rev. B. 53, 2425-2436 (1996).

[47] V. N. SHALAEV; E. Y. POLIAKOV; V. A. MARKEL. "Small-particle composites. II. Nonlinear optical properties". Phys. Rev. B. 53, 2437-2449 (1996).

[48] V. A. MARKEL et. al. "Near-field optical spectroscopy of individual surfaceplasmon modes in colloid clusters". Phys. Rev. B. 59, 10903-10909 (1999).

[49] V. P. DRACHEV et al. "Large local optical activity in fractal aggregates of nanoparticles". J. Opt. Soc. Am. B. 18, 1896-1903 (2001).

[50] H. XU; J. AIZPURUA; M. KÄLL. "Electromagnetic contributions to singlemolecule sensitivity in surface-enhanced Raman scattering". Phys. Rev. E. 62, 43184324 (2000).

[51] M. CARDONA; G. GÜBTHERODT. Light Scattering in Solids. Springer, Berlin, 1984.

[52] L. GUNNARSSON et. al. "Interparticle coupling effects in nanofabricated substrates for surface-enhanced Raman scattering”. Appl. Phys. Lett. 78, 802-804 (2001). 
[53] C. KITTEL. Introduction to Solid State Physics. John Wiley \& Sons, Inc.: New York, 1996.

[54] G. MIE. Ann. Phys. 25, 377 (1908).

[55] M. EL-SAYED; S. LINK. "Shape and size dependence of radiative, non-radiative and photothermal properties of gold nanocrystals“. Int. Rev. Phys. Chem. 19(3), 409-453 (2000).

[56] J. P. ABID. Laser Induced Synthesis and nonlinear Optical Properties of Metal Particles. Tese de doutorado, École Polytechnique Fédérale de Lausanne, Lausanne, França (2003).

[57] U. KREIBIG. Z. Phys. 234, 307 (1970).

[58] R. WANNEMACHER; M. HIETSCHOLD; A. PACK. "Failure of local Mie theory: optical spectra of colloidal aggregates“. Opt. Comm. 194, 277-287 (2001).

[59] D. FORNASIERO; F. J. GRIESER. "Analysis of the visible absorption and SERS excitation spectra of silver sols“. Chem. Phys. 87, 3213-3217 (1987).

[60] K. KNEIPP et. al. "Surface-enhanced Raman scattering and biophysics". J. Phys. Condens. Matter. 14, R597-R624 (2002).

[61] M. I. STOCKMAN; S. V. FALEEV; D. J. BERGMAN. "Localization versus Delocalization of Surface Plasmons in Nanosystems: Can One State Have Both Characteristics?" Phys. Rev. Lett. 87, 167401-1 - 167401-4 (2001).

[62] D. J. BERGMAN; M. I. STOCKMAN. "Surface Plasmon Amplification by Stimulated Emission of Radiation: Quantum Generation of Coherent Surface Plasmons in Nanosystems“. Phys. Rev. Lett. 90, 027402-1 - 027402-4 (2003).

[63] S. ZOU, N; JANEL, G. C. SCHATZ. "Silver nanoparticle array structures that produce remarkably narrow plasmon lineshapes“. J. Chem. Phys. 120, 10871-10875 (2004).

[64] E.C. Le Ru; P.G. ETCHEGOIN. "Sub-wavelength localization of hot-spots in SERS“. Chem. Phys. Lett. 396, 393-397 (2004).

[65] P. ETCHEGON et al. "Electromagnetic contribution to surface enhanced Raman scattering revisited“. J. Chem. Phys. 119, 5281-5289 (2003).

[66] A. M. MICHAELS; M. NIRMAN; L. E. BRUS. "Surface Enhanced Raman Spectroscopy of Individual Rhodamine 6G Molecules on Large Ag Nanocrystals“. J. Am. Chem. Soc. 121, $9932-9939$ (1999). 
[67] R. C. MAHER; L. F. COHEN; P. ETCHEGOIN. "Single molecule photo-bleaching observed by surface enhanced resonant Raman scattering (SERRS)". Chem. Phys. Lett. 352, 378-384 (2002).

[68] H. XU et. al. "Spectroscopy of Single Hemoglobin Molecules by Surface Enhanced Raman Scattering“. Phys. Rev. Lett. 83, 4357-4360 (1999).

[69] S. DUCOURTIEUX et. al. "Near-field optical studies of semicontinuous metal films". Phys. Rev. B. 64, 165403-1 - 165403-14 (2001).

[70] A. OTTO. "On the significance of Shalaev's Isquohot spotsrsquo in ensemble and single-molecule SERS by adsorbates on metallic films at the percolation threshold". J. Raman Spectrosc. 37, 937-947 (2006).

[71] R. PLASS; J.A. LAST; N.C. BARTELT; G.L. KELLOGG. "Nanostructures - Selfassembled domain patterns". Nature. 412, 875 (2001).

[72] P. NOZAR et. al. "The early stages of the self-assembly process of polystyrene beads for photonic applications". Synthetic Metals. 139, 667-670 (2003).

[73] R. K. SMITH; P. A. LEWIS; P. S. WEISS. "Patterning self-assembled monolayers". Progress in Surf. Sci. 75 (1-2), 1-68 (2004).

[74] A. STEIN; R. C. SCHRODEN. "Colloidal crystal templating of three-dimensionally ordered macroporous solids: materials for photonics and beyond". Current Opinion in Solid State and Materials Science. 5, 553-564 (2001).

[75] C. M. REGAN. Introduction to Self-Assembly Methods. Rensselear Polytechnic Institute. Materials Science Department, 2002.

[76] T. OHGl; H. Y. SHENG; H. NEJOH. "Au particle deposition onto self-assembled monolayers of thiol and dithiol molecules". Appl. Surf. Sci. 130-132, 919-924 (1998).

[77] k. A. MAURITZ. et al. "Self-assembled organic/inorganic hybrids as membrane materials". Electroch. Acta. 50 (2-3), 565-569 (2004).

[78] J. E. G. J. WIJNHOVEN; W. L. VOS. "Preparation of Photonic Crystals Made of Air Spheres in Titânia". Science. 281, $802-804$ (1998).

[79] M. EGEN et. al. "Heterostructures of Polymer Photonic Crystal Films". Chem. Mater. 15, 3786-3792 (2003).

[80] E. OZBAY. "Physics and applications of photonic crystals". Photon. and Nanostr. - Fundam. and Appli. 2 (2), 87-95 (2004).

[81] C. A. FUSTIN. "Parameters Influencing the Templated Growth of Colloidal Crystals on Chemically Patterned Surfaces". Langmuir. 20, 9114-9123 (2004). 
[82] Y. H. YE et. al. "Self-assembling three-dimensional colloidal photonic crystal structure with high crystalline quality". Applied Physics Letters. 78 (1), 52-54 (2001).

[83] Y. H. YE; S. BADILESCU; V. V. TRUONG. "Self-assembly of colloidal spheres on patterned substrates". Applied Physics Letters. 79 (6), 872-874 (2001).

[84] G. SUBRAMANIA et. al. "Synthesis of thin film photonic crystals". Synthetic Metals. 116, 445-448 (2001).

[85] B. GATES; Y. XIA. "Photonic band-gap properties of opaline lattices of spherical colloids doped with various concentrations of smaller colloids". Applied Physics Letters. 78 (21), 3178-3180 (2001).

[86] G. BARILLARO; A. NANNINI; F. PIERI. "Dimensional Constraints on High Aspect Ratio Silicon Microstructures Fabricated by HF Photoelectrochemical Etching". J. Eletrochemical Society. 149, C180-C185 (2002).

[87] W. J. SALCEDO. Silício poroso como material fotônico. Tese de Doutorado apresentada à Escola Politécnica da Universidade de São Paulo (1998).

[88] W. THEIB. "The dielectric function of porous silicon - how to obtain it and how to use it”. Thin Solid Films. 276, 7-12 (1996).

[89] C. PALSULE et al. "Electrical and optical characterization of crystalline silicon/porous silicon heterojunctions". Solar Ener. Mat. and Solar Cells. 46 (4), 261-269 (1997).

[90] H. FÖLL et al. "Formation and application of porous silicon". Materials Science and Engineering R. 39 (4), 93-141 (2002).

[91] J. M. RALSTON; R. K. CHANG. "Spontaneous-Raman-Scattering Efficiency and Stimulated Scattering in Silicon”. Phys. Rev. B. 2 (6), 1858-1862 (1970).

[92] G. G. MACFARLANE et al. "Fine Structure in the Absorption-Edge Spectrum of Si". Phys. Rev. 111, 1245-1958 (1958).

[93] Y. R. SHEN; N. BLOEMBERGEN. "Theory of Stimulated Brillouin and Raman Scattering". Phys. Rev. 137, A1787 - A1805 (1965).

[94] V. CHANDRASEKHARAN. "Scattering matrix for Raman effect in cubic crystals". Zeitschrift für Physik A Hadrons and Nuclei. 175 (1), 63-69 (1963).

[95] W. D. JOHNSTON; I. P. KAMINOW; J. G. BERGMAN. "Stimulated Raman Gain coefficients for $\mathrm{Li}_{6} \mathrm{NbO}_{3}, \mathrm{Ba}_{2} \mathrm{NaNb}_{5} \mathrm{O}_{15}$, and other materials". Appl. Phys. Lett. 13 (5), 190-193 (1968). 
[96] J. M. RALSTON; R. K. CHANG. "Optical limiting in semiconductors". Appl. Phys. Lett. 15 (6), 164-166 (1969).

[97] M. PANICCIA et al. A Hybrid Silicon Laser; Silicon photonics technology for future tera-scale computing. White Paper. Intel. 1-6 (2006).

[98] K. KNEIPP; H. KNEIPP; I. ITZKAN; R. R. DASARI; M. S. FELD. Chem. Phys. 274, 155 (1999).

[99] M. W. KLEIN; T. TRITSCHHLER; M. WEGENER. Phys. Rev. B. 72, 115113 (2005).

[100] E. J. LIANG; X. L. YE; W. KIEFER. "Surface-Enhanced Raman Spectroscopy of Crystal Violet in the Presence of Halide and Halate lons with Near-Infrared Wavelength Excitation". J. Phys. Chem. A. 101, $7330-7335$ (1997).

[101] K. INOUE; K. OHTAKA (eds.), Photonic Crystals (Springer-Verlag, Berlin/Heidelberg/New York, 2004).

[102] S. A. DARMANYAN; M. NEVIERE; A. V. ZAYATS. Phys. Rev. B. 70, 075103-1 (2004).

[103] J. DINTINGER et. al. Phys. Rev. B. 71, 035424-1 (2005).

[104] S. LINDEN et. al. Phys. Rev. B. 71, 245119-1 (2005).

[105] E. Y. POLIAKOV; V. A. MAKEL; V. M. SHALAEV. Phys. Rev. B. 57, 14901 (1998).

[106] R. F. AROCA et. al. "Surface-enhanced Raman scattering on colloidal nanostructures". Adv. Coll. and Interf. Sci. 116, 45-61 (2005).

[107] M. W. KLEIN; T. TRITSCHHLER; M. WEGENER. "Lineshape of harmonic generation by metallic nanoparticles and metallic photonic crystal slabs“. Phys. Rev. B. 72, 115113-1 - 115113-11 (2005).

[108] H. FOLL et al. "Formation and application of porous silicon". Mat. Sc. and Eng. R. 39, 93-141 (2002).

[109] W. J. SALCEDO; F. J. R. FERNANDEZ; J. C. RUBIM. "Enhancement of the Raman phonon spectra of porous silicon films by $\mathrm{H}^{+}$ion implantation". Vibrational Spectrosc. 36, 135-140 (2004).

[110] W. J. SALCEDO; F. J. R, FERNANDEZ; J. C. RUBIM. "Changes in the porous silicon structure induced by laser radiation". J. Raman Spectrosc. 32, 151-157 (2001).

[111] E. N. KESKINOVA; W. WERNKE; N. KIROV; P. P. KIRCHEVA. Bulg. J. Phys. 6 (3), 370 (1979). 
[112] S. H. A. NICOLAl. Estudo Espectroscópico do Azul de Metileno em Eletrodo de Prata. Tese de Doutorado. Instituto de Química. USP. 107 p (1998). [113] K. HUTCHINSON; R. E. HESTER; W. J. ALBERY; A. R. HILLMAN. "Raman spectroscopic studies of a thionine-modified electrode". J. Chem. Soc. Faraday Trans 1. 80, 2053-2071 (1984).

[114] B. KURE; M. D. MORRIS. "Raman spectra of phenothiazine and some pharmaceutical derivatives". Talanta. 23, 398-400 (1976).

[115] D. L. A. FARIA; P. S. SANTOS. "Pre-resonance Raman effect of solid-state phenothiazine". J. Raman Spectrosc. 25, 453-456 (1994).

[116] R. E. HESTER; K. P. J. WILLIAMS. "Free radical studies by resonance Raman spectroscopy: phenothiazine, 10-methylphenothiazine, and phenoxazine radical cations". J. Chem. Soc., Perkin Trans. 2, 852-859 (1981).

[117] N. NETO; F. AMBROSINO; S. CALIFANO. "Vibrational assignment of phenazine and phenazine-d8: Crystal spectra in polarized light and force constants calculations". Spectrochim. Acta. 20, 1503-1516 (1964).

[118] S. C. WAIT JR; J. C. MCNERNEY. "Vibrational spectra and assignments for quinoline and isoquinoline”. J. Molec. Spectrosc. 34, 56-77 (1970).

[119] J. H. S. GREEN. Spectrochim. Acta. 24A, 1627 (1968).

[120] T. I. COX; A. J. SIMONS; A. LONI; P. D. CALCOTT; L. T. CANHAM; M. J. UREN. "Modulation speed of an efficient porous silicon light emitting device". J. Appl. Phys. 86(5), 2764-2774 (1999).

[121] S. ZANGLIE; R. JANSSON; H. ARWIN. "Ellipsometric characterization of anisotropic porous silicon Fabry-Perot filters and investigation of temperature effects on capillary condensation efficiency". J. Appl. Phys. 86(2), 850-858 (1999).

[122] S. NAGATA; C. DOMOTO; T. NISHIMURA; K. IWAMÉ. "Single-mode optical waveguide fabricated by oxidization of selectively doped titanium porous silicon". Appl. Phys. Lett. 72(23), 2945-2947 (1998).

[123] S. L. MONICA; G. MAILOO; A. FERRARI; G. MASINI; S. LAZAROUT; P. JAGUIRO; S. KATSOUBA. "Progress in the field of integrated optoelectronics based on porous silicon". Thin Sol. Films. 297, 265-267 (1997). 
[124] W. LANG; F. KOZLOUSKi; P. ESTEINER; B. KNOLL; A. WEIDENHOFER; D. KOLLEWE; T. BACHMANN. "Technology and RBS analysis of porous silicon lightemitting diodes“. Thin Sol. Films. 297, 268-271 (1997).

[125] L. PAVESI, R. GUARDINI; P. BELLUTI. "Porous silicon n-p light emitting diode". Thin Sol. Films. 297, 272-276 (1997).

[126] W. THIEB; R. ARENS-FISCHER; S. HILBRICH; D. SHEYE; M. G. BERGER; M. KRUGER; M. THOINISSEN. Mat. Res. Soc. 452, 637 (1997)

[127] K. D. HIRSCHAMAN; L. TSYBESOV; S. P. DUTTAGUPTA; P. M. FAUCHET. Mat. Res. Soc. 452, 705 (1997).

[128] I. MIHALCESCU; G. LERONDEL; R. ROMESTAIN. "Porous silicon anisotropy investigated by guided light”. Thin Sol. Films. 297, 245-249 (1997).

[129] G. MAILLO; S. L. MONICA; A. FERRARI; G. MASINI; V. P. BONDARENKO; A. M. DOROFEEV; N. M. KAZUCHITS. "Light guiding in oxidised porous silicon optical waveguides". Thin Sol. Films. 297, 311-313 (1997).

[130] U. GRUNING; V. LEHMANN; S. OTOW; K. BUSCH. "Macroporous silicon with a complete two-dimensional photonic band gap centered at $5 \mu \mathrm{m}$ ". Appl. Phys. Lett. 68(6), 747-749 (1996).

[131] U. ROSSOW; U. FROTSCHER; D. E. ASPNES; W. RICHTER. Mat. Res. Soc. 405, 209 (1996).

[132] U. ROSSOW; U. FROTSCHER; M. THOINISSEN; M. G. BERGER; S. FROHNHOFF; H. MUNDER; W. RICHTER. „Influence of the formation conditions on the microstructure of porous silicon layers studied by spectroscopic ellipsometry". Thin Sol. Films. 255, 5-8 (1995).

[133] M. FRIED; T. LAHNER; O. POLGAR; P. PETRISE; É. VÁZSONYI; I. BÁRONY; J. P. PIELAND; J. L. STEHLE. „Characterization of different porous silicon structures by spectroscopic ellipsometry“. Thin Sol. Films. 276, 223-227 (1996).

[134] W. THEIB. "The dielectric function of porous silicon - how to obtain it and how to use it”. Thin Sol. Films. 276, 7-12 (1996). 
[135] L. PAVESI; C. MAZZOLENI; A. TREOLICUCCI; V. PELLEGINI. "Controlled photon emission in porous silicon microcavities". Appl. Phys. Lett. 67(22), 32803282 (1995).

[136] C. MAZZOLENI; L. PAVESI. "Application to optical components of dielectric porous silicon multilayers". Appl. Phys. Lett. 67(20), 2983-2985 (1995).

[137] M. THONISSEN; M.G. BERGER; S. BILLOT; R. ARENS-FISCHER; M. KRUGER; H. LUTH; W. THEIB; S. HILLBRICH; P. GROSSE; G. LERONDEL; U. FROTSCHER. "Analysis of the depth homogeneity of $p$-PS by reflectance measurements". Thin sol. Films. 297, 92-96 (1997).

[138] M. CRUZ; M. R. BELTRAN; C. WANG; J. TAGUEÑA. Mat. Res. Soc. 452, 69 (1997)

[139] D. BUTTARD; G. DOLINO; D. BELLET; T. BAUMBACH. Mat. Res. Soc. 452, 437 (1997).

[140] R. L. SMITH; S. D. COLLINS. "Porous silicon formation mechanisms". J. Appl. Phys. 71(8), R1 (1992).

[141] H. UNNO; K. IMAI; S. MURAMOTO. "Dissolution Reaction Effect on PorousSilicon Density". J. Electrochem. Soc. 134(3), 645-648 (1987).

[142] V. BeRTAGnA; C. PloungonVen; F. ROUELle; M. CHEMLA. "P- and NType Silicon Electrochemical Properties in Dilute Hydrofluoric Acid Solutions". J. Electrochem. Soc. 143(11), 3532-3538 (1996).

[143] M. THONISSEN; M. G. BERGER; R. ARENS-FISCHER; D. GLUCK, M. KRUGER; H. LUTH. „Analysis of the depth homogeneity of p-PS by reflectance measurements“. Thin Sol. Films. 276(1-2), 21-24 (1996).

[144] J. RAPPICH; H. J. LEWERENZ. "Photo- and potential-controlled nanoporous silicon formation on n-Si(111): an in-situ FTIR investigation“. Thin Sol. Films. 276(12), 25-28 (1996).

[145] T. DITTRICH; I. SIEBER; S. RAUSCHER; J. RAPPICH. "Preparation of thin nanoporous silicon layers on n- and p-Si“. Thin Sol. Films. 276, 200-203 (1996) 
[146] A. ABOULIATIM; P. JOUBRT; P. GUYADER. "Effect of light intensity on photoluminescence properties of n-type porous silicon". Thin Sol. Films. 276, 208211 (1996).

[147] S. HILBRICH; W. THEIß; R. ARENS-FISCHER; O. GLUCK, M. G. BERGER. "The influence of the doping level on the optical properties of porous silicon". Thin sol. Films. 276, 231-234 (1996).

[148] G. POLISSKI; A. V. ANDRIANOV; D. KOVALEV; F. KOCH. "Polarization memory induced by polarized light-assisted anodization of n-type Si". Thin Sol. Films. 276, 235-237 (1996).

[149] M. G. BERGER; R. ARENS-FISCHER; M. THONISSEN; M. KRUGER; S. BILLAT; H. LUTH; S. HILBRICH; W. THEIß; P. GROSSI. "Dielectric filters made of PS: advanced performance by oxidation and new layer structures". Thin Sol. Films. 297, 237-240 (1997).

[150] L.T. CANHAM. Mat. Res. Soc. Symp. Proc. 452, 29 (1997)

[151] M. STAVOLA. 5 ${ }^{\text {th }}$ Braz. School. Semiconductor. Phys., Ed. J. R. Leite, A. Fazzio, A. S. Chavez, 221 (1991).

[152] S. GUHA; P. Steiner; F. Kozlowski; W. Lang. "Excitation wavelength dependence of Raman and photoluminescence spectra of porous Si membranes". Thin Solid Films. 276, 73-75 (1996).

[153] I. H. CAMPBELL; P. M. FAUCHET. "The effects of microcrystal size and shape on the one phonon Raman spectra of crystalline semiconductors". Sol. Stat. Commun. 58, 739-741 (1986).

[154] H. RICHTER; Z. P. WANG; L. LEY. "The one phonon Raman spectrum in microcrystalline silicon". Sol. Stat. Commun. 39, 625-629 (1981).

[155] F. BECHSTEDT; R. ENDERLEIN. "Theory of resonance Raman scattering in disordered solids“. Phys. Stat. Sol. (B) 83, 239-247 (1977).

[156] H. SCHRODER; E. OBERMEIRAND; A. STECKENBORN. "Micropyramidal hillocks on $\mathrm{KOH}$ etched $\{100\}$ silicon surfaces: formation, prevention and removal". J. Micromech Microeng. 9(2), 139-145 (1999). 
[157] M. ELWENSPOEK. "Stationary hillocks on etching silicon". J. Micromech Microeng. 9(2), 180-185 (1999).

[158] N. BLOEMBERGEN. "The Stimulated Raman Effect". Am. J. Phys. 35, 9891023 (1967).

[159] J. A. ARMStRONG; N. BLOEMBERGEN; J. DUCUING; P. S. PERSHAN. "Interactions between Light Waves in a Nonlinear Dielectric". Phys. Rev. 127(6), 1918-1939 (1962).

[160] Y. R. SHEN; N. BLOEMBERGEN. "Theory of Stimulated Brillouin and Raman Scattering". Phys. Rev. 137, A1786-A1805 (1965).

[161] G. HAUCHECORNE; G. MAYER. "Effets de l'anisotropie moléculaire sur la propagation d'une lumière intense". Comp. Acad. Sci. 261, 4014-4017 (1965).

[162] Y. R. SHEN; Y. J. SHAHAM. "Beam Deterioration and Stimulated Raman Effect”. Phys. Rev. Lett. 15, 1008-1010 (1965).

[163] P. L. KELLY. "Self-Focusing of Optical Beams". Phys. Rev. Lett. 15, 10051008 (1965).

[164] J. C. RUBIM. O efeito Raman intensificado por superfície - SERS (surface enhanced Raman scattering) e algumas aplicações em química. Tese de LivreDocência, IQUSP, 97 p (1993).

[165] T. E. Furtak. Surface Enhanced Raman Scattering; Ed. By R. K. Chang, (Plenum, New York 1982).

[166] W. Hayes, R. Loudon. Scattering of Light by Crystal. John Wiley \&Sons, New York (1978).

[167] J. B. REUNICCI; R. N. TYTE; M. CARDONA. "Resonant Raman scattering in silicon". Phys. Rev. B. 11(10), 3885-3895 (1975).

[168] B. A. WEINSTEIN; M. CARDONA. "Resonant First- and Second-Order Raman Scattering in GaP”. Phys. Rev. B. 8(6), 2795-2809 (1973).

[169] M. A. RENUCCI; J. B. RENUCCI; R. ZEYHER; M. CARDONA. "Second-order Raman scattering in germanium in the vicinity of the E1, E1+ $\Delta 1$ edges". Phys. Rev. 10(10), 4309-4323 (1974). 
ANEXO A: Publicações durante o Programa de Doutorado

\section{A.1 Trabalhos Completos em Periódicos}

1. RAIMUNDO, Daniel Scodeler; CALÍOPE, Priscila Braga; HUANCA, Danilo Roque; SALCEDO, Walter Jaimes. ANODIC POROUS ALUMINA STRUCTURAL CHARACTERISTICS STUDY BASED ON SEM IMAGE PROCESSING AND ANALYSIS. Microelectronics Journal, 40, 844 (2009).

2. HUANCA, Danilo Roque; RAIMUNDO, Daniel Scodeler; SALCEDO, Walter Jaimes. BACKSIDE CONTACT EFFECT ON THE MORPHOLOGICAL AND OPTICAL FEATURES OF POROUS SILICON PHOTONIC CRYSTAL. Microelectronics Journal, 40, 744 (2009).

3. RAIMUNDO, Daniel Scodeler; STELET, Adriana Barboza; HUANCA, Danilo Roque; SALCEDO, Walter Jaimes. ELECTRICAL TRANSPORT MECHANISMS IN MONO-LAYER PHTHALOCYANINE DEVICE. ECS Transactions, 14, 1, 597 (2008).

4. ACOSTA, Aldo Aparicio; RAIMUNDO, Daniel Scodeler; HUANCA, Danilo Roque; SALCEDO, Walter Jaimes. NANOCOMPOSITE OF POROUS SILICON AND METHYLENE BKUE MOLECULES FOR OPTICAL GAS SENSOR APPLICATION. ECS Transactions, 14, 1, 57 (2008).

5. RAIMUNDO, Daniel Scodeler, CECHELERO, Gustavo Sampaio e Silva; ACOSTA, Aldo Aparício; FERNANDEZ, Francisco Javier Ramirez; SALCEDO, Walter Jaimes. MACROPOROUS SILICON STRUCTURE FUNCTIONALIZED BY METHYLENE BLUE TO pH MEASUREMENTS APPLICATION. ECS Transactions, 9, 1, 579-586 (2007).

6. RAIMUNDO, Daniel Scodeler; FERNANDEZ, Francisco Javier Ramirez; SALCEDO, Walter Jaimes. FORMATION OF ANODICALLY SELF-ASSEMBLED OXIDIZED ALUMINUM FOR PHOTONIC CRYSTAL FABRICATION. ECS Transactions, 4, 1, 495 (2007). 
7. RAIMUNDO, Daniel Scodeler; SANT'ANA, Antônio Carlos; FERNANDEZ, Francisco Javier Ramirez; SALCEDO, Walter Jaimes. REGULAR ORDERED GOLD METALLIC ARRAY AND RAMAN SCATTERING INTENSIFICATION. Physica Status Solidi (A), 4, 973-978 (2007).

8. RAIMUNDO, Daniel Scodeler; STELET, Adriana Barbosa; FERNANDEZ, Francisco Javier Ramirez; SALCEDO, Walter Jaimes. SELF-ASSEMBLED SYSTEMS OBTAINED BY CHEMICAL AND ELECTROCHEMICAL TECHNIQUES FOR PHOTONIC CRYSTAL FABRICATION. Microelectronics Journal, 36, 207211 (2005).

\section{A.2 Trabalhos Completos em Anais}

1. STELET, Adriana Barboza; RAIMUNDO, Daniel Scodeler; RAMIREZFERNANDEZ, Francisco Javier; SALCEDO, Walter Jaimes. PHTHALOCYANINE THIN FILM ON POROUS SILICON STRUCTURE APPLIED FOR GAS SENSOR DEVICE. In: V CONGRESSO IBEROAMERICANO DE SENSORES (IV IBERSENSOR), 2006, Montevideo - Uruguay. Ibersensor 2006 Memorias. Montevideo - Uruguai, 2006, pp. 1/4-4/4.

2. RAIMUNDO, Daniel Scodeler; RAMIREZ-FERNANDEZ, Francisco Javier; SALCEDO, Walter Jaimes. THE CONTROLLING OF RELATIVE HUMIDITY (RH) IN THE SELF-ASSEMBLED POLYSTYRENE MICRO-SPHERES STRUCTURES FORMATION. In: V CONGRESSO IBEROAMERICANO DE SENSORES (IV IBERSENSOR), 2006, Montevideo - Uruguay. Ibersensor 2006 Memorias. Montevideo - Uruguai, 2006, pp. 1/5-5/5.

3. RAIMUNDO, Daniel Scodeler; FERNANDEZ, Francisco Javier Ramirez; SALCEDO, Walter Jaimes. FORMATION OF ANODICALLY SELF-ASSEMBLED OXIDIZED ALUMINUM FOR PHOTONIC CRYSTAL FABRICATION. In: Microelectronics Technology and Devices (SBMicro), 2006, Ouro Preto, MG, Brazil. ECS tRANSACTIONS. THE ELECTROCHEMICAL SOCIETY. Pennington NJ USA; The Electrochemical Society, 2006. Proceedings. v. 4, pp 495-501. 